\title{
Mariana Figueiroa Careta
}

Estudo prospectivo para avaliar a evolução radiológica de 12 pacientes portadores de esclerodermia da face e perfil demográfico, manifestações clínicas e alterações laboratoriais de 34 casos

Tese apresentada à Faculdade de Medicina da Universidade de São Paulo para obtenção do título de Doutor em Ciências

Programa de Dermatologia

Orientador: Dr. Ricardo Romiti

Coorientadora: Dra. Claudia da Costa Leite

São Paulo

2013 
Dados Internacionais de Catalogação na Publicação (CIP)

Preparada pela Biblioteca da

Faculdade de Medicina da Universidade de São Paulo

Creprodução autorizada pelo autor

Careta, Mariana Figueiroa

Estudo prospectivo para avaliar a evolução radiológica de 12 pacientes portadores de esclerodermia da face e perfil demográfico, manifestações clínicas e alterações laboratoriais de 34 casos / Mariana Figueiroa Careta. -- São Paulo, 2013.

Tese(doutorado)--Faculdade de Medicina da Universidade de São Paulo. Programa de Dermatologia.

Orientador: Ricardo Romiti.

Coorientadora: Claudia da Costa Leite

Descritores: 1.Esclerodermia localizada 2.Esclerodermia localizada/epidemiologia 3.Face 4.Estudos prospectivos 5.Seguimento 6.Sinais e sintomas 7.Imagem por ressonância magnética 8 .Neuroimagem 9.Manifestações neurológicas

10.Encefalopatias/diagnóstico 11.Manifestações oculares 12. Investigação laboratorial 13.Doenças do sistema imune 14.Doenças do colágeno 


\section{Dedicatória}

Ao meu esposo, Gustavo.

Aos meus pais, Nino e Cleusa.

Aos meus irmãos, Marco e Marina.

Aos meus afilhados, Carlos Eduardo e Juliana 


\section{Agradecimentos}

Aos funcionários do Ambulatório de Dermatologia do HCFMUSP - Márcia, Sandra, Alexandre Vargas e Yara - pela colaboração no agendamento e localização dos pacientes.

À funcionária Mara, do setor da ressonância magnética do Instituto de Radiologia, pelo auxílio no agendamento dos pacientes.

À funcionária do Departamento de Dermatologia do HCFMUSP - Eli Maria de Freitas e Márcia Fernandes- pela atenção e ajuda durante o curso da pós-graduação.

À Rosimeire Figueiroa Zorzeto, pela revisão e presença constante.

À Dra. Mirian Tsunemi, pela realização da análise estatística deste estudo.

À Prof. Dra. Mirian N. Soto, por tornar possível a execução deste estudo.

À Prof. Dra. Neusa Y. S. Valente, pelo apoio e atenção.

Ao Prof. Dr. Luis Torezan, pela amizade, estímulo e apoio.

Ao Prof. Dr. José Albino, pela avaliação neurológica dos pacientes.

Ao Prof. Dr. Fernando Cresta, pela avaliação oftalmológica dos pacientes.

Aos Prof. Drs. Maria da Graça Morais Martin, Patrícia Érica Christofoletti Daldon e Vitor Reis, membros do exame de qualificação, pelas sugestões e correções neste trabalho.

Ao Prof. Dr. Claudia da Costa Leite, exemplo e fonte de inspiração profissional, por sua co-orientação neste estudo.

Ao Prof. Dr. Ricardo Romiti, meu orientador, grande idealizador e incentivador na execução desta tese.

Ao CNPq (Conselho Nacional de Desenvolvimento Científico e Tecnológico) pela inclusão nas cotas do programa de pós-graduação.

Aos demais colegas e funcionários do Departamento de Dermatologia que, direta ou indiretamente, contribuíram para a elaboração deste trabalho. 
Sumário 


\section{LISTA DE ABREVIATURAS}

\section{LISTA DE FIGURAS}

\section{LISTA DE TABELAS}

\section{RESUMO}

\section{SUMMARY}

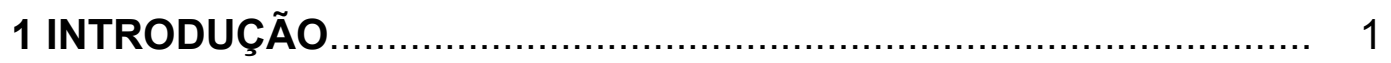

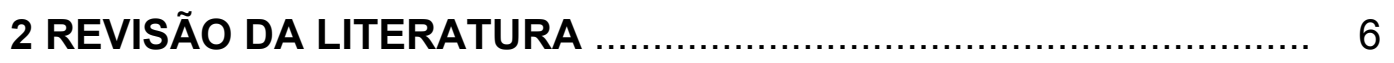

2.1 Classificações........................................................................... 7

2.2 Esclerodermia localizada - subtipos ……………..................... 9

2.2.1 Morfeia em placa................................................................ 9

2.2.2 Morfeia bolhosa................................................................. 10

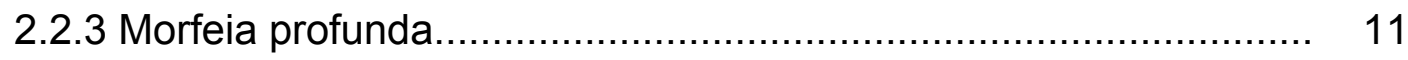

2.2.4 Morfeia generalizada............................................................ 12

2.2.5 Fasceíte eosinofílica............................................................. 13

2.2.6 Morfeia panesclerótica da infância................................................ 14

2.2.7 Esclerodermia linear............................................................ 14

2.2.8 Esclerodermia linear em golpe de sabre ................................. 17

2.2.9 Síndrome de Parry-Romberg....................................... 19

2.3 Esclerose sistêmica.................................................. 22

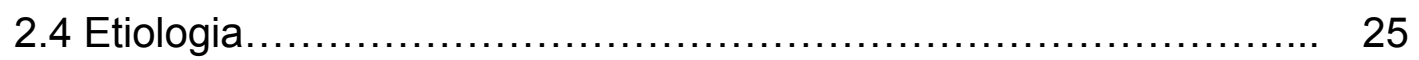

2.5 Manifestações extracutâneas........................................ 28

2.5.1 Envolvimento neurológico...................................... 32

2.5.2 Alterações oculares................................................. 36

2.6 Alterações laboratoriais.............................................. 39

2.7 Alterações radiológicas................................................. 41

2.8 Alterações anatomopatológicas cutâneas.............................. 49

2.9 Alterações neuropatológicas........................................ 52

2.10 Terapêutica........................................................ 55

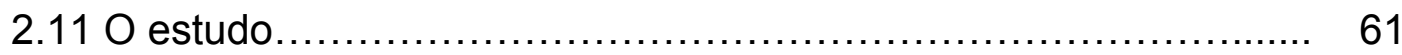

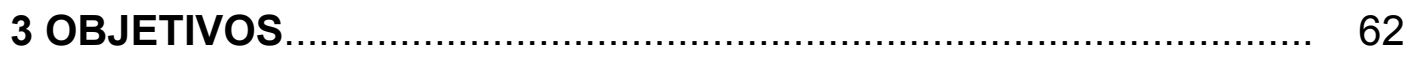

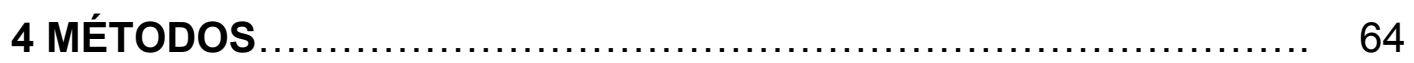

4.1 Seleção de pacientes.................................................. 65

4.2 Protocolo de investigação.......................................................... 66 


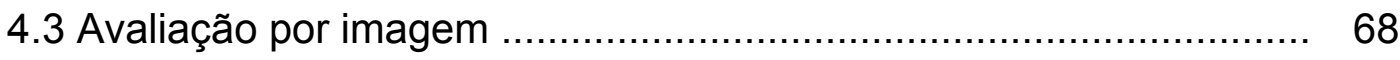

4.4 Avaliação clínico neurológica................................................. 68

4.5 Avaliação oftalmológica................................................ 70

4.6 Avaliação laboratorial................................................. 71

4.7 Outros achados............................................................ 72

4.8 Análise estatística.................................................................. 72

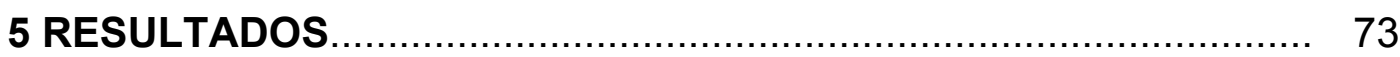

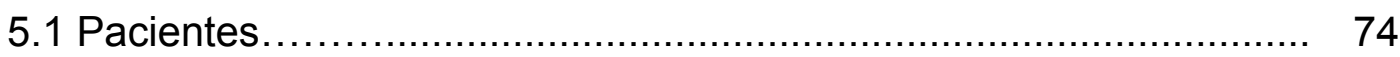

5.2 Avaliação por imagem.......................................................... 78

5.3 Avaliação clínica neurológica ...................................................... 83

5.4 Avaliação oftalmológica............................................... 85

5.5 Avaliação laboratorial............................................ 88

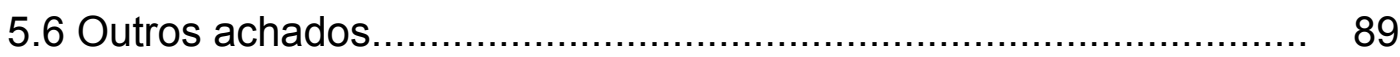

5.7 Seguimento radiológico.............................................. 89

6 DISCUSSÃO

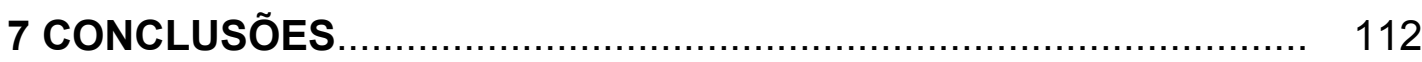

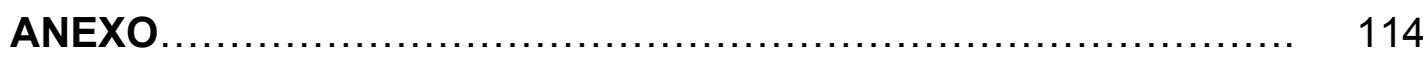

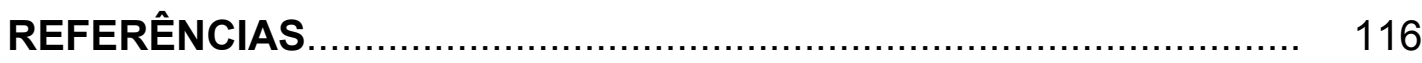


Listas 


\section{LISTA DE ABREVIATURAS}

\begin{tabular}{|c|c|}
\hline ACA & Anticorpo anti centrômero \\
\hline DRGE & Doença do refluxo gastroesofágico \\
\hline EDA & Endoscopia digestiva alta \\
\hline EED & Exame fluoroscópico radiográfico do esôfago, estômago e duodeno \\
\hline EEG & Eletroencefalograma \\
\hline EL & Esclerodermia localizada \\
\hline ELF & Esclerodemia localizada na face \\
\hline ELGS & Esclerodermia linear em golpe de sabre \\
\hline ES & Esclerose sistêmica \\
\hline FAN & Fator antinucleo \\
\hline FR & Fator reumatoide \\
\hline HFP & Hemiatrofia facial progressiva \\
\hline LES & Lupus eritematoso sistêmico \\
\hline MMF & Micofenolato mofetil \\
\hline PFP & Prova de função pulmonar \\
\hline RGE & Refluxo gastroesofágico \\
\hline RM & Ressonância magnética \\
\hline $\mathbf{R X}$ & Raio X \\
\hline ScL-70 & Anticorpo anti topoisomerase 1 \\
\hline SNC & Sistema nervoso central \\
\hline SPR & Síndrome de Parry-Romberg \\
\hline TC & Tomografia computadorizada \\
\hline USG & Ultrassom \\
\hline VHS & Velocidade de hemossedimentação sérica \\
\hline
\end{tabular}




\section{LISTA DE FIGURAS}

Figura 1. Lesão de morfeia em placa no tronco............................................... 10

Figura 2. Paciente com morfeia profunda no membro inferior direito............... 11

Figura 3 A. Paciente com lesão na fronte de esclerodermia linear (trilinear).... 15

Figura 3 B. Esquema das linhas de Blaschko...................................

Figura 4. Paciente com ELGS.................................................. 18

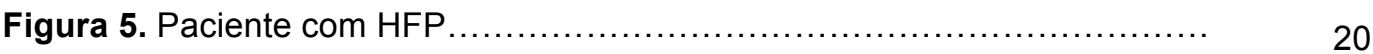

Figura 6. Histologia da esclerodermia na fase tardia........................................ 50

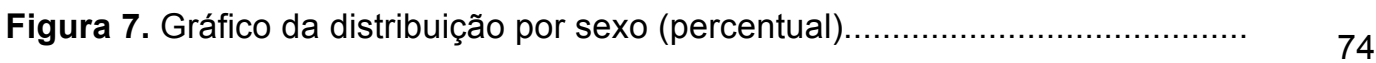

Figura 8. Gráfico da Classificação Clínica dos pacientes segundo Clínica Mayo

modificada.

Figura 9 A. Imagem axial pesada em T2 demonstra afilamento ósseo e do tecido celular subcutâneo na região frontal paramediano à direita (SETA). Note ainda foco de hipersinal à esquerda (cabeça de seta)

Figura 9 B. Foto clínica da paciente com lesão escleroatrófica, pigmentada, deprimida paramediana à direita (PACIENTE 6).

Figura $10 \mathrm{~A}$. Foto clínica da paciente com lesão escleroatrófica, linear, levemente deprimida na fronte paramediana direita (PACIENTE 30).

Figura $10 \mathrm{~B}$. Imagem axial pesada em T2 em corte inferior à $\mathrm{D}$ demonstra a assimetria dos ventrículos laterais, sendo ligeiramente maior o esquerdo.

Figura $10 \mathrm{C}$. Imagem axial pesada em FLAIR demonstra lesões periventriculares com hipersinal (SETAS).

Figura $10 \mathrm{D}$. Imagem axial FLAIR realizada 3 anos após não demonstra alterações significativas

Figura $11 \mathrm{~A}$. Foto clínica do paciente com lesão escleroatrófica, pigmentada, deprimida na fronte paramediana direita, mento e submandibular (PACIENTE 24).

Figura 11 B e C. Imagem axial pesada em FLAIR (B) e imagem axial pesada em T2 (C) demonstram duas lesões focais com marcado hipossinal (SETA), que podem corresponder a calcificação ou hemossiderina e são melhores identificadas em T2.

Figura 12 A e B. Imagens axiais pesadas em T2 (A) e T1 (B) mostram lesão em ínsula e núcleo lentiforme direito associada a alargamento da fissura Sylviana adjacente, com aspecto sequelar de provável origem isquêmica (PACIENTE 15)..

Figura $13 \mathrm{~A}$. Foto clínica da paciente com discreta lesão atrófica, levemente pigmentada, mediana na fronte (PACIENTE 25).

Figura $13 \mathrm{~B}$. $\mathrm{Na}$ imagem axial pesada em T2 note o afilamento do tecido subcutâneo frontal direito (SETA).

Figura $13 \mathrm{C}$ e D. Imagens axiais pesadas em gradiente eco $\left(\mathrm{T} 2^{*}\right)$ com intervalo de 3 anos ( $C$ e $D)$ demonstram persistência da pequena lesão frontal direita (SETA) que apresenta hipossinal. 


\section{LISTA DE TABELAS}

Tabela 1. Classificação de morfeia ou esclerodermia localizada - estabelecida na Conferência do Consenso de Pádua (Itália) 2004. 9

Tabela 2. Descrição das formas de esclerodermia localizada. 17

Tabela 3. Comparação de HFP e ELGS. 22

Tabela 4. Achados clínicos e radiológicos - adaptada de Kister et al 48

Tabela 5. Achados na HFP e ELGS. 54

Tabela 6. Algoritmo terapêutico da esclerodermia localizada 61

Tabela 7. Cálculo das estatísticas para as variáveis quantitativas separadamente dos resultados da evolução clínica. 78

Tabela 8. Correlação entre os achados neurológicos, oftalmológicos e da RM. 87

Tabela 9. Dados demográficos dos pacientes com seguimento de RM após 3 anos. 92

Tabela 10. Achados neurológicos dos pacientes com seguimento de RM após 3 anos 93 


\section{ANEXO}

Anexo Aprovação pelo Comitê de Ética e Pesquisa... 
Resumo 
Careta MF. Estudo prospectivo para avaliar a evolução radiológica de 12 pacientes portadores de esclerodermia localizada da face e perfil demográfico, manifestações clínicas e alterações laboratoriais de 34 casos [tese]. São Paulo: Universidade de São Paulo, Faculdade de Medicina; 2013.

Introdução: A esclerodermia é rara doença do tecido conectivo que se manifesta através da esclerose cutânea e variável acometimento sistêmico. Duas categorias de esclerodermia são conhecidas: esclerose sistêmica, caracterizada por esclerose cutânea e acometimento visceral e a esclerodermia localizada ou morfeia que classicamente apresenta evolução benigna e autolimitada, confinada a pele e/ou tecidos subjacentes. Estudos recentes demonstram que a forma localizada possa eventualmente apresentar acometimento de órgãos internos e morbidade variável. Objetivo: Neste estudo objetivamos determinar as características demográficas, a prevalência de manifestações sistêmicas e alterações laboratoriais, bem como a associação com doenças autoimunes, em pacientes com esclerodermia da face. Métodos: Pacientes com esclerodermia localizada, incluindo os casos de esclerodermia em golpe de sabre, síndrome de Parry-Romberg e morfeia em placas com acometimento facial, foram avaliados e submetidos à investigação neurológica, incluindo exame clínico neurológico e ressonância magnética de crânio, e avaliação oftalmológica. Após 3 anos, o subgrupo de pacientes disponível para seguimento foi ressubmetido à ressonância magnética. Resultados: Foram estudados 34 pacientes com esclerodermia localizada da face. Deste total, $64,7 \%$ apresentavam uma ou mais manifestações extracutâneas, sendo cefaleia a queixa mais frequente, encontrada em $61,8 \%$ dos pacientes. Dos 23 pacientes submetidos à avaliação neurológica, $56,5 \%$ apresentaram alterações neurológicas possivelmente associadas à esclerodermia. Alterações à ressonância magnética foram observadas em $50 \%$ dos casos. $O$ achado mais frequente foi a presença de lesões parenquimatosas com alteração de sinal em $50 \%$ dos pacientes. Dos pacientes que apresentavam alteração neurológica, $80 \%$ também apresentavam alguma alteração à ressonância magnética. Doze pacientes foram ressubmetidos a novo exame após 3 anos. Em todos os pacientes os achados de imagem se mantiveram inalterados. Durante esse intervalo de 3 anos, $25 \%$ dos pacientes apresentaram sinais de atividade da esclerodermia. Quanto à avaliação oftalmológica, $67,9 \%$ dos pacientes avaliados apresentaram alteração, sendo os achados mais frequentes a ocorrência de alterações orbiculares da esclerodermia $(20,6 \%)$ e xeroftalmia $(10,7 \%)$. Conclusão: Pacientes com esclerodermia localizada da face apresentam alta prevalência de alterações neurológicas e oftalmológicas. Baseado nestes achados, sugerimos que todos os casos de esclerodermia localizada da face devam ser detalhadamente examinados quanto à presença de alterações sistêmicas.

Descritores: 1.Esclerodermia localizada 2.Esclerodermia localizada/epidemiologia 3.Face 4.Estudos prospectivos 5.Seguimento 6.Sinais e sintomas 7.Imagem por ressonância magnética 8.Neuroimagem 9.Manifestações neurológicas 10.Encefalopatias/diagnóstico 11.Manifestações oculares 12.Investigação laboratorial 13.Doenças do sistema imune 14.Doenças do colágeno 
Summary 
Careta MF. Prospective study to evaluate the radiological evolution of 12 patients with localized scleroderma of the face and the demographic, clinical and laboratory findings of 34 cases [thesis]. "São Paulo: Universidade de São Paulo, Faculdade de Medicina"; 2013.

Introduction: Scleroderma is a rare connective tissue disease that manifests as skin sclerosis and variable systemic involvement. Two categories of scleroderma are known: systemic sclerosis, characterized by cutaneous sclerosis and visceral involvement and localized scleroderma or morphea which classically presents benign evolution and selflimited, confined to the skin and / or underlying tissue. Recent studies show that the localized form may possibly course with involvement of internal organs and variable morbidity. Objective: This study aimed to determine the demographic characteristics, the prevalence of systemic manifestations and laboratory findings, as well as the association with autoimmune diseases, in patients with scleroderma of the face. Methods: Patients with localized scleroderma, including cases of scleroderma en coup de sabre, Parry-Romberg syndrome and morphea plaque with facial involvement were evaluated and underwent neurological examination, including neurologic examination and magnetic resonance imaging, and ophthalmology evaluation. After 3 years, the subgroup of patients available for follow-up was subjected again to MRI. Results: We studied 34 patients with localized scleroderma of the face. Of this total, $64,7 \%$ had one or more extracutaneous manifestation, headache being the most frequent complaint found in $61,8 \%$ of patients. Of the 23 patients undergoing neurological evaluation, $56,5 \%$ had neurological changes possibly associated with scleroderma. MRI changes were observed in $50 \%$ of cases. The most frequent was the presence of parenchymal lesions with signal alteration in $50 \%$ of patients. Of the patients who had neurological deficits, $80 \%$ also had a change to MRI. Twelve patients were subjected again to another MRI scan after 3 years. In all patients, imaging findings were unchanged. During this interval of 3 years, $25 \%$ of patients showed signs of activity of scleroderma. As for ophthalmologic evaluation, $67,9 \%$ of patients showed abnormalities, with the most frequent findings being the occurrence of orbicular changes of scleroderma $(20.6 \%)$ and xerophthalmia (10.7\%). Conclusion: Patients with localized scleroderma face have a high prevalence of neurological and ophthalmological changes. Based on these findings, we suggest that all cases of localized scleroderma of the face should be thoroughly examined for the presence of systemic changes.

Descriptors: 1. Scleroderma, localized 2. Scleroderma, localized/epidemiology 3.Face 4.Prospective studies 5.Follow-up studies 6 .Signs and symptoms 7 .Magnetic resonance imaging 8 .Neuroimaging 9.Neurologic manifestations 10.Brain diseases/diagnosis 11.Eye manifestations 12. Immune system diseases 13 .Laboratory research 14 . Collagen diseases 
1 Introdução 
A esclerodermia localizada ou morfeia é uma doença crônica do tecido conectivo de etiologia desconhecida (Fitzpatrick et al., 1987). Existem diversos tipos de morfeia, cada uma com diferentes manifestações clínicas e variáveis graus de acometimento do tecido conectivo. A morfeia é caracterizada pelo espessamento cutâneo com aumento do depósito de colágeno resultando em lesões endurecidas (Matsuuara et al., 1997). As duas categorias principais são conhecidas: a esclerose sistêmica (ES), caracterizada por esclerose cutânea e variável acometimento visceral (principalmente de esôfago, pulmão e sistema vascular); e a esclerodermia localizada (EL) que na maioria dos casos é benigna, autolimitada, confinada à pele e/ou tecido celular subcutâneo. Esta última categoria inclui a esclerodermia linear, morfeia em placa, profunda, bolhosa e generalizada. (Cassidy JT; Petty, 2001; Nelson, 2001; Uziel et al., 1995). Cada um desses subtipos pode envolver a face com intensidade variável. A EL é o subtipo mais frequente de esclerodermia na infância. Na EL as categorias não são mutuamente exclusivas, pois diferentes subtipos podem ocorrer associados num mesmo paciente.

A EL é doença rara com incidência em torno de 0,3 a 3 casos por 100.000 habitantes/ano (Peterson et al., 1997). É mais frequente nas mulheres caucasianas com uma relação de 2 a 4 mulheres para cada homem, sendo a prevalência semelhante nas crianças e adultos (Peterson et al., 1997; Marzano et al., 2003; Zulian et al., 2006; Leitenberger et al., 2009). O pico de incidência ocorre na $5^{\circ}$ década nos adultos, enquanto $90 \%$ das crianças são diagnosticadas entre 2 a 14 anos de idade (Fett; Werth VP, 2011; Leitenberger et al., 2009; Christen-Zaech et al, 2008; Zulian et al., 2006). 
A esclerodermia linear é caracterizada por uma ou mais faixas lineares com endurecimento cutâneo que pode se estender à derme, subcutâneo, músculo e osso subjacente. Acomete as extremidades, face e couro cabeludo (ou duas ou três áreas simultaneamente), sendo este subtipo de EL mais frequente em crianças e adolescentes. Pode estar associada à morfeia em placas ( Laxer; Feldman, 1997; Menni et al., 1997). Quando o segmento cefálico é afetado o quadro é designado como "golpe de sabre", geralmente localizado na fronte paramediana (Nadeau, 2002; Liu et al., 1994; Blaszczyk et al., 1998; Emery, 1998).

Os relatos da literatura sugerem que a EL não é exclusivamente uma doença cutânea (Dehen et al., 1994). Especialmente em adultos com a forma localizada da doença, existe evidência de envolvimento de órgãos internos, associação com outras doenças do tecido conectivo e excepcionais formas transicionais para ES (Birdi et al., 1993; Mayorquin et al., 1994).

As alterações oculares e neurológicas podem eventualmente ocorrer associadas à esclerodermia localizada da face (ELF) (Uziel et al., 1995; Grosso et al., 2003; Liu et al., 1994).

Outros achados incluem assimetria da língua, fenômeno de Raynaud, doença pulmonar restritiva, refluxo gastroesofágico (RGE), dentição alterada e cáries. As anormalidades clínicas silenciosas também podem ocorrer (Chung et al., 1995; Itin; Schiller, 1999; Ramboer et al., 1997). O envolvimento orbitário tem sido descrito, porém é raro (Fitzpatrick et al., 1987).

Estudos recentes têm demonstrado a prevalência de manifestações reumatológicas, neurológicas e oftalmológicas em $20 \%$ dos pacientes com EL (Zulian et al., 2006; Marzano et al., 2003). 
À histologia, todas as formas de EL e ES apresentam as mesmas alterações e consistem em área localizada de depósito de colágeno denso na derme, que pode se estender para o tecido conectivo profundo, incluindo fáscia e músculo. $\mathrm{Na}$ esclerodermia linear em golpe de sabre (ELGS) pode ocorrer involução progressiva do osso craniofacial, culminado com atrofia da hemiface correspondente, através de mecanismo não completamente identificado (Krafchik, 1992). Esta expressão extrema de ELGS parece ser idêntica aos casos descritos por Parry and Romberg em 1825, designados de hemiatrofia facial progressiva idiopática (HFP) ou síndrome de Parry-Romberg (SPR). Essa forma de esclerodermia é rara, com associações infrequentes de manifestações neurológicas, principalmente convulsões do tipo parcial complexo (Krafchik, 1992; David et al., 1991; Higashi et al., 2000). A etiologia dos sintomas do sistema nervoso central (SNC) não é bem estabelecida.

As manifestações neurológicas associadas a EL foram previamente descritas em relatos de casos e séries de casos. A prevalência real das anormalidades de neuroimagem não foi determinada. O exame de imagem neurológica na maioria dos casos é apenas realizado em pacientes sintomáticos e manifestações subclínicas muitas vezes não são diagnosticadas.

Neste estudo avaliamos os dados demográficos e a prevalência de alterações extracutâneas, especialmente neurológicas e oftalmológicas, existentes nos pacientes com ELF, sintomáticos ou não, por meio de avaliação clínica neurológica, oftalmológica e exame de ressonância magnética (RM) de crânio. Avaliação laboratorial com dosagem de fator antinúcleo (FAN), anticorpo topoisomerase-1 (Scl70) e fator reumatoide (FR) também foram realizados.

Devido à incerteza do comportamento neurológico desta doença, os pacientes foram submetidos à repetição do exame de RM do crânio, três anos após 
a realização do primeiro exame, para avaliação do comportamento da imagem cerebral e sua correlação clínica com a atividade da doença. 
2 Revisão da Literatura 


\subsection{Classificações}

Em 1995, Peterson et al. estabeleceram uma classificação para a EL (Peterson et al., 1995). Esta classificação é abragente e amplamente utilizada nos diferentes protocolos de pesquisa, como se segue:

1. Morfeia em placa
a. Morfeia em placa
b. Morfeia gutata
c. Atrofodermia de Pasini e Pierini
d. Morfeia queloideana (nodular)
e. Líquen escleroso e atrófico;

2. Morfeia generalizada;

3. Morfeia bolhosa;

4. Morfeia linear
a. Morfeia linear (esclerodermia linear)
b. Em golpe de sabre
c. Hemiatrofia facial progressiva;

5. Morfeia profunda
a. Morfeia profunda
b. Morfeia subcutânea
c. Fasceíte eosinofílica
d. Morfeia panesclerótica da infância.

No presente estudo, optamos por utilizar esta classificação, conhecida como Classificaçao da Clínica Mayo (Peterson et al., 1995) na sua forma simplificada, por ser mais objetiva e utilizada na literatura. Utilizamos, assim, a Classificação da 
Clínica Mayo modificada, destacando os subtipos de esclerodermia linear que acometem a face, como ELGS e HFP. Nesta forma são apresentados em cinco grupos de EL, como segue:

1. Morfeia em placa,

2. Morfeia generalizada,

3. Morfeia bolhosa,

4. Esclerodermia linear (incluindo os subtipos que acometem a cabeça e face, ELGS e SPR),

5. Morfeia profunda.

Outra classificação foi definida por Tuffanelli, em 1998, dividindo a EL em 3 grupos principais (Tuffanelli, 1998):

1. Esclerodermia localizada

1a - Morfeia: em placas, gutata, profunda, nodular e atrofodermia Bulhosa de Passini e Pierini.

1b - Esclerodermia linear: golpe de sabre, com atrofia facial (síndrome de Parry-Romberg), acral, associada à artrite, miosite e defeitos de crescimento ou ósseos.

1c - Morfeia generalizada: panesclerótica, edematosa, com líquen escleroso.

2. Esclerodermia localizada com componente de síndrome overlap

$2 a$ - Doença mista do tecido conectivo

$2 b$ - Doença indiferenciada do tecido conectivo

$2 c-$ Esclerodermatomiosite

3. Esclerodermia localizada com componente de fasceíte eosiniofílica (síndrome de Schulman). 
Em 2004 na Conferência do Consenso de Pádua, na Itália, um grupo da Sociedade Europeia de Reumatologia Pediátrica estabeleceu uma nova proposta de classificação para EL, onde incluíram a morfeia mista, que acomete $15 \%$ das crianças com morfeia (Laxer; Zulian F, 2006).

Tabela 1. Classificação de morfeia ou esclerodermia localizada - estabelecida na Conferência do Consenso de Pádua (Itália) 2004.

1. Morfeia circunscrita

a. superficial

b. profunda

2. Esclerodermia linear

a. tronco/ extremidades

b. cabeça;

3. Morfeia generalizada;

4. Morfeia panesclerótica;

5. Morfeia mista.

\subsection{Esclerodermia localizada - subtipos}

\subsubsection{Morfeia em placa}

A forma mais frequente de EL em adultos é a morfeia em placa, circunscrita, tipicamente confinada à derme (Peterson et al., 1995; Nelson, 1996; Zulian et al., 2005; Marzano et al., 2003). Manifesta áreas delimitadas de pele endurecida e brilhante, ovais ou arredondadas, acometendo um ou mais territórios anatômicos, com maior frequência no tronco e extremidades proximal. Nas fases iniciais é 
possível observar halo violáceo característico ao redor da placa (“anel lilás”), que corresponde a fase inflamatória da morfeia. Quando as lesões manifestam placas levemente deprimidas de tonalidade marrom acinzentada e sem esclerose evidente o quadro se denomina atrofodermia de Pasini e Pierini (Tuffanelli, 1998; Chung et al., 2006). Muitos autores acreditavam que essas lesões sem endurecimento da pele constituem uma variante de morfeia, vista como uma forma abortiva desta (Tuffanelli, 1998; Kencka et al., 1995) ou uma variante na qual a esclerose está limitada à derme papilar (Jablonska; Blasczyk, 2004). Atualmente são descritas como formas distintas, relatando a coexistência de lesões do tipo atrofodermia de Pasini e Pierini com morfeia em placa em 20\% dos casos (Kencka et al., 1995).

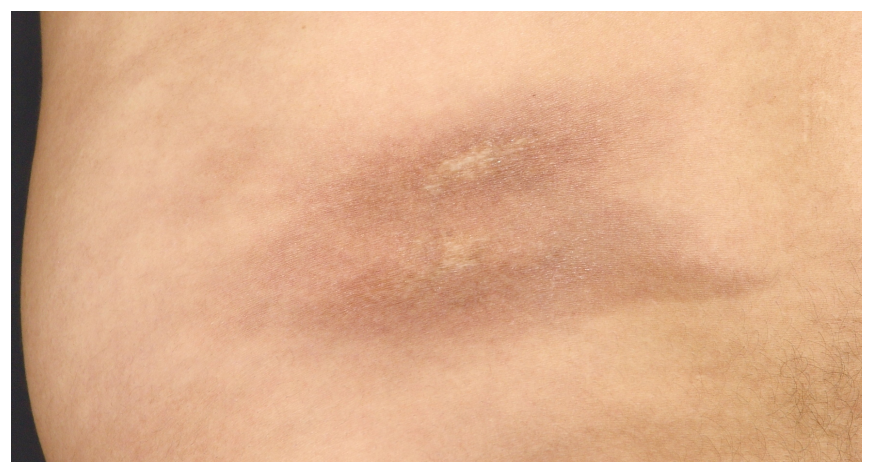

Figura 1. Lesão de morfeia em placa no tronco

\subsubsection{Morfeia bolhosa}

Uma forma não usual é o aparecimento de bolhas ou erosões sobre as placas de morfeia, denominada morfeia bolhosa. É descrita a transição histopatológica de líquen escleroso e atrófico (LEA) em morfeia bolhosa (Trattner et al., 1994). A coexistência não tão frequente, mas bem documentada, é de lesões de morfeia em placa e LEA em um mesmo paciente (Sawamura et al., 1998; Shono et al., 1991; Farrel et al., 2000). 


\subsubsection{Morfeia profunda}

O subtipo classificado como morfeia profunda (Kobayashi et al., 1991; Kirsner et al., 1993; Azad et al., 2004) geralmente se manifesta como lesão única no tronco superior, próximo à coluna vertebral. A pele suprajacente pode ter aspecto normal, atrófica ou estar endurecida, quase sempre estará deprimida ou aderida ao plano profundo. Geralmente é assintomática e não está associada ao acometimento visceral (Blaszczyk et al., 2000; Malandrini et al., 1997). A morfeia profunda não é precedida por evidência clínica de inflamação, descoloração da pele ou esclerose. Alguns autores concluem que a HFP pode ser considerada uma variedade da esclerodermia linear profunda (Blaszczyk et al., 2000; Blaszczyk et al., 1999). São descritos alguns casos de morfeia profunda isolada ou lesões similares relacionadas à aplicação de vacinas (Torrelo et al., 2006) ou injeção intramuscular de vitamina K (Morrel; Betloch, 1995).

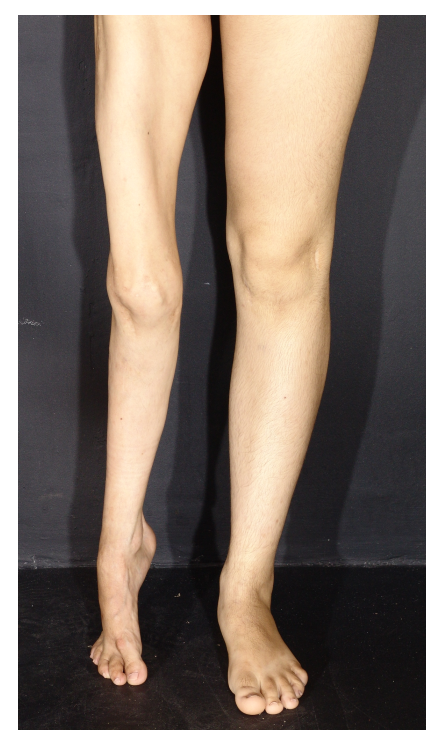

Figura 2. Paciente com morfeia profunda no membro inferior direito 


\subsubsection{Morfeia generalizada}

Quando as placas de morfeia afetam mais de 2 territórios anatômicos é denominada morfeia generalizada. Mais frequente em mulheres, já foi aventado exercício físico como fator desencadeante. São placas levemente inflamadas, pigmentadas, mal definidas, frequentes no tronco e extremidades, espessadas, aderida a planos profundos, fascia e músculo. O início da esclerose é gradual e relativamente rápido durante um período de alguns meses. Os sinais de inflamação aguda, como edema e eritema, podem estar ausentes. É possível, embora infrequente, a coexistência de lesões de LEA e formação de bolhas na superfície das placas (Daoud et al., 1994).

A revisão detalhada da literatura permite comprovar que quadros descritos com clínica similar descrita acima aparecem referenciados de maneira indistinta como morfeia generalizada e morfeia profunda (Su; Person, 1999; Park; Lee, 2000; Bielsa et al., 1985). Ambos os termos são utilizados para descrição da mesma situação clínica em que o processo escleroso afeta fundamentalmente a derme profunda e o tecido adiposo, mas também a fáscia e o músculo superficial de uma maneira extensa. $O$ termo morfeia generalizada faz referência à extensão que a fibrose pode alcançar, enquanto o termo morfeia profunda pretende descrever os achados histológicos de acometimento do músculo superficial, fascia, tecido adiposo e derme profunda de uma forma localizada clinicamente.

A morfeia generalizada se distingue da ES. Os pacientes podem desenvolver esclerose dos dedos, mas não costumam apresentar ulcerações, reabsorção de falange, alteração de capilares da prega ungueal ou fenômeno de Raynaud. A face geralmente é poupada. Por outro lado, são frequentes contraturas em flexão das articulações e manifestações músculo articulares (Bielsa et al., 1985). De uma forma 
ocasional foi documentado anomalias pulmonares, esofágicas, renais ou cardíacas (Marzano et al., 2003; Leitenberger et al., 2009; Bielsa et al., 1985; Dehen et al., 1994; Christen-Zaech et al., 2008).

\subsubsection{Fasceíte eosinofílica}

Fasceíte eosinofílica é considerada uma síndrome esclerodermiforme (Connolly, 2008). A sua inclusão no grupo das morfeias é de grande discussão na literatura. É caracterizada por endurecimento da pele das quatro extremidades, bilateral e simétrica. A maioria inicia com quadro edematoso e eritema leve ou difuso nas extremidades, que pode durar pouco ou passar despercebido, seguido por endurecimento e irregularidade da pele das extremidades superiores e face interna dos músculos. Isso ocorre como consequência de bandas de esclerose que atravessam perpendicularmente o panículo adiposo, unindo focalmente a derme profunda com a fáscia. Em um estágio final, a pele fica lisa, endurecida e aderida a planos profundos. As lesões típicas de morfeia em placa são observadas no tronco em cerca de $30 \%$ dos pacientes com fasceíte eosinofílica (Miller, 1992; Castanet et al., 1994, Heidary et al., 2009). Geralmente essas lesões não são sincrônicas com a fasceíte, podendo aparecer antes ou depois da inflamação da fascia.

Muitos achados da fasceíte eosinofílica são compartilhados com morfeia

profunda ou generalizada. É provável que todos esses termos façam referência a mesma situação clínica. Porém, a existência de formas isoladas de cada uma destas situações clínicas, provavelmente, mantêm conservado a distinta terminologia. 


\subsubsection{Morfeia panesclerótica da infância}

A morfeia panesclerótica da infância, variante rara da morfeia profunda, tende a ser agressiva e mutilante. Apesar de mais frequente na infância, já foi descrito o início na vida adulta. A manifestação é semelhante à morfeia generalizada, mas com acometimento mais extenso de todas as camadas da pele, subcutâneo, músculo, tendão e osso. É característico o surgimento de placas de esclerose na superfície de extensão dos membros e tronco, que de forma progressiva afeta a totalidade da pele, incluindo face, pescoço e couro cabeludo. Respeita a ponta dos dedos das mãos e pés, não apresentando fenômeno de Raynaud (Maragh et al., 2005). Ocorrem contraturas articulares, deformidades, ulcerações muito dolorosas e calcificações. Ocasionalmente, surge carcinoma espinocelular sobre as placas escleróticas de longa evolução (Parodi et al., 2001; Wollina et al., 2002).

\subsubsection{Esclerodermia linear}

A esclerodermia linear é frequentemente observada na infância e adolescência, sendo a variante mais frequente neste grupo, afetando 40 a $70 \%$ das crianças estudadas (Zulian et al., 2006; Leitenberger et al., 2009; Christen-Zaech et al., 2008). Cerca de $67 \%$ dos pacientes com esclerodermia linear são diagnosticados antes dos 18 anos (Peterson et al., 1997). Geralmente é uma lesão única, unilateral, de distribuição linear, que com frequência acomete as extremidades, face ou couro cabeludo. Muitas vezes as lesões seguem as linhas de Blaschko. 

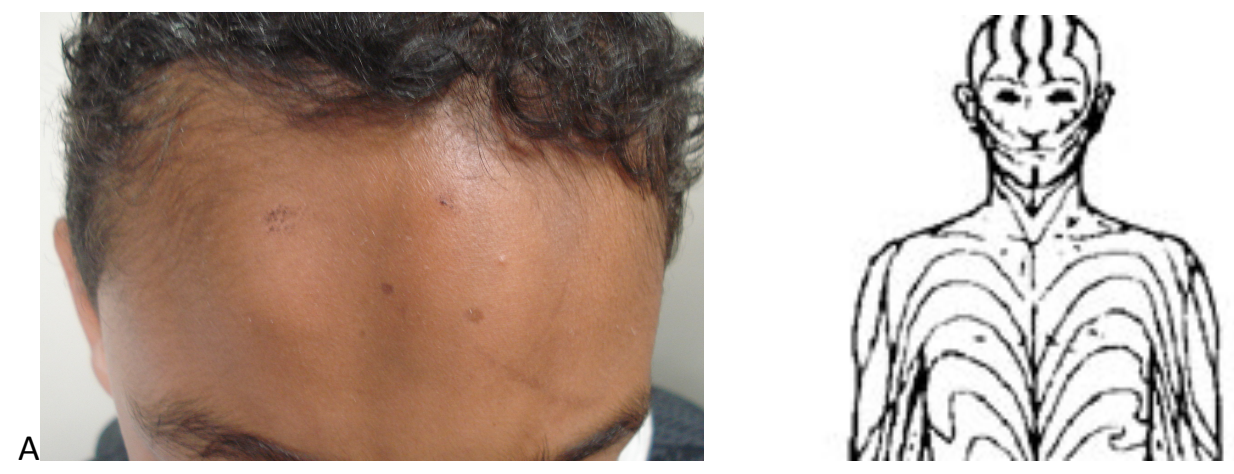

Figura 3. A) Paciente com lesão na fronte de esclerodermia linear (trilinear); B) Esquema das linhas de Blaschko

A esclerodermia linear pode acometer músculos e ossos subjacentes causando distúrbio de crescimento e anquilose (Hatzis et al., 1992; Tuffanelli, 1998). Afeta mais frequentemente crianças que adultos. Com acometimento semelhante entre os sexos. Cerca de $50 \%$ dos pacientes com esclerodermia linear tem esclerodermia em placas associada (Falanga et al., 1987). As formas "mistas" (ELF associada a morfeia em placa ou esclerodermia linear em outras áreas, mais frequente no tronco) são uma variante peculiar das crianças e raramente vistas em adultos (Marzano et al., 2003). A duração da doença é duas vezes mais longa na EL da infância do que quando iniciada na fase adulta, sendo as recidivas e atividade crônica da doença reportadas com maior frequência (Marzano et al., 2003).

A ELF não é frequente. Jablonska et al. estudaram pacientes do Instituto Nacional da Cidade do México por 20 anos e encontraram 30 pacientes com diagnóstico de ELGS e 9 com HFP (Jablonska; Blaszyk, 2005).

Quando localizada no couro cabeludo origina uma placa de alopecia de disposição linear, muitas vezes atrófica e ligeiramente deprimida, com pele lisa, brilhante, endurecida e às vezes pigmentada. Geralmente é unilateral, acometendo a região parietal e com tendência para deformar o osso, originando lesões deprimidas, descrita como ELGS. Pode se estender à região malar, nasal e lábio superior. 
Quando o transtorno afeta completamente a metade da face caracteriza a HFP ou SPR (Orozco-Covarrubias et al., 2002; Blaszczyk et al., 2003; Tollefson; Witman, 2007). O processo causa atrofia de todo o tecido adiposo e músculo, com deformidade óssea, aparentemente sem alteração da pele. Geralmente inicia com a idade média de 11 anos, tendo o curso da doença com evolução em poucos anos, seguido de estabilização, predominando o acometimento na mulher 2-3:1.

As complicações neurológicas, oftalmológicas e de neuroimagem são idênticas na ELGS e na SPR. (Grosso et al., 2003; Yano et al., 2000; Korkmaz et al., 2005; Kreuter et al., 2005).

As variantes consideradas de maior gravidade são a morfeia panesclerótica ou generalizada, ELF e os subtipos com evidência de alta morbidade (envolvimento do SNC, encurtamento do membro, contratura da articulação). A gravidade moderada foi definida como morfeia profunda circunscrita ou esclerodermia linear no tronco ou na extremidade sem evidência de alta morbidade. Pacientes com baixa gravidade são aqueles com morfeia circunscrita superficial (em placas) (Li et al., 2010). 
Tabela 2. Descrição das formas de esclerodermia localizada

\begin{tabular}{|c|c|c|c|c|}
\hline Classificação & Subtipos & $\begin{array}{l}\text { Característica das } \\
\text { lesões }\end{array}$ & Envolvimento tecidual & Localização principal \\
\hline Morfeia em placa & $\begin{array}{l}\text { Superficial } \\
\text { Profunda }\end{array}$ & Lesões ovais & $\begin{array}{l}\text { Limitada a epiderme e } \\
\text { derme } \\
\text { Induração profunda } \\
\text { Derme e SC } \\
\text { Variável fáscia e } \\
\text { músculo }\end{array}$ & Tronco \\
\hline Morfeia linear & $\begin{array}{l}\text { Cabeça (ELGS) } \\
\text { SPR }\end{array}$ & Induração linear & $\begin{array}{l}\text { Derme e SC (pode } \\
\text { acometer músculo e } \\
\text { osso) } \\
\text { Derme frontoparietal } \\
\text { (músculo, osso e SNC) } \\
\text { Derme, SC, músculo, } \\
\text { cartilagem e osso }\end{array}$ & $\begin{array}{l}\text { Tronco e MM } \\
\text { Face e couro cabeludo } \\
\text { Face unilateral }\end{array}$ \\
\hline Morfeia generalizada & & $\begin{array}{l}4 \mathrm{ou}+\text { placas } \\
\text { induradas }>3 \mathrm{~cm}\end{array}$ & $\begin{array}{l}\text { Limitada a derme e } \\
\text { raro no SC }\end{array}$ & $\begin{array}{l}\text { Difusa (sem face ou } \\
\text { mãos) }\end{array}$ \\
\hline $\begin{array}{l}\text { Morfeia } \\
\text { panesclerótica }\end{array}$ & & Circuferencial & $\begin{array}{l}\text { Epiderme, derme, SC, } \\
\text { músculo e osso }\end{array}$ & Membros \\
\hline Morfeia mista & & & $\begin{array}{l}\text { Combinação de } 2 \text { ou + } \\
\text { subtipos }\end{array}$ & \\
\hline
\end{tabular}

MM: membro; SC: subcutâneo; SNC: Sistema Nervoso Central

\subsubsection{Esclerodermia linear em golpe de sabre (ELGS)}

ELGS é uma rara e intrigante variante de EL, descrita inicialmente por Addison em 1854 (Addison, 1892). Possui curso lentamente progressivo e geralmente restrito à hemiface. As lesões de ELGS geralmente se iniciam com contração e rigidez da área afetada, formando um sulco deprimido na região frontoparietal que se estende para o couro cabeludo, produzindo uma zona de alopecia linear. A depressão pode se estender para região nasal, superior do lábio e 
algumas vezes gengiva. A língua ipsilateral pode ser atrófica e o espaço e direção dos dentes podem ser afetados. A mandíbula pode ser acometida e os ossos do crânio. Quando há deforminade da mandíbula, pode cursar com consequente má oclusão dental, implantação inadequeda dos dentes, atrofia das raízes e atraso na aparição dos dentes (Tollefson; Witman, 2007).

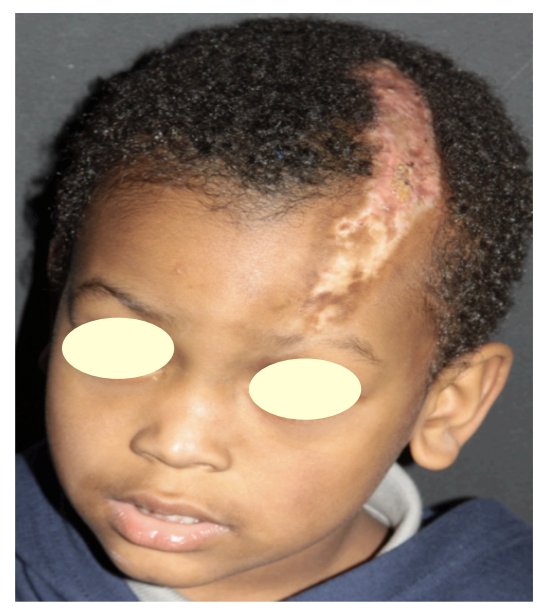

Figura 4. Paciente com ELGS

Acomete principalmente crianças com predomínio em pacientes do sexo feminino, com relação de 3:1 e maior incidência na menarca. A idade média de início é ao redor dos 13 anos de idade (Fett; Werth, 2011) e a fase de atividade das lesões cutâneas geralmente dura de 2 a 5 anos (Tuffanelli, 1998; Chiang et al., 2009). Muito pouco é sabido sobre a patogênese. Consequentemente uma terapia efetiva não foi achada.

A ELGS é raramente associada a sintomas neurológicos e oftalmológicos (Chung et al., 1995; Luer et al., 1990). Entretanto, a população pediátrica apresenta mais alterações extracutâneas, principalmente ortopédicas, oculares, e neurológicas, quando comparado com a população adulta (Zulian et al. 2006).

Algumas vezes, encontram-se placas de morfeia no corpo ou esclerodermia linear nas extremidades ou no tronco (Menni et al., 1997). 
A ELGS é usualmente unilateral, mas raros casos bilaterais foram reportados (Ostertag et al., 1994; Rai et al., 2000; Gambichler et al., 2001).

\subsubsection{Síndrome de Parry-Romberg}

A hemiatrofia facial progressiva (HFP), também conhecida como síndrome de Parry-Romberg (SPR), foi descrita por Parry em 1825 e Romberg em 1846. Caracteriza rara doença de etiologia desconhecida que usualmente se desenvolve entre a primeira e segunda década de vida (Parry, 1825; Romberg, 1846). É caracterizada por lenta progressão, autolimitada e geralmente progride por 2 a 20 anos até se tornar estacionária. Cursa com atrofia unilateral da pele, subcutâneo, músculo e estruturas ósseas subjacentes, muitas vezes afetando dermatomos de um ou múltiplos ramos do nervo trigêmeo. A atrofia pode ser precedida por enduração cutânea e descoloração da área afetada, como despigmentação ou hiperpigmentação e alopecia cicatricial podem ser observadas nas áreas afetadas do couro cabeludo. Na maioria dos casos inflamação cutânea, enduração e adesão estão ausentes ou são mínimas (Jappe et al., 1996; Jablonska; Blaszczyk, 1998; Lehmann, 1992). Geralmente é mais frequente o acometimento abaixo da região dos olhos. 


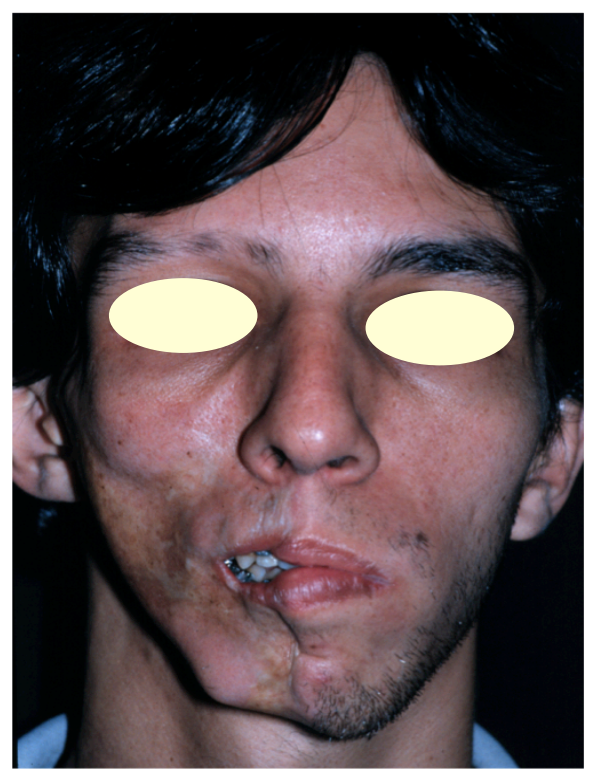

Figura 5. Paciente com HFP

A HFP é uma das apresentações que pode ser clinicamente muito similar a ELGS, podendo coexistir em cerca de $20-37 \%$ dos pacientes (DeFelipe et al., 2001; Woolfenden et al., 1998), tornando difícil a distinção entre ambas. Esta porcentagem de coexistência é muito maior do que da ELGS com outras variantes de EL (Tollefson; Witman, 2007; Jablonska et al., 1998). Porém, a HFP não demonstra esclerose cutânea em nenhum dos estágios (Parry, 1825; Romberg, 1846). Alguns autores descrevem pacientes com ELGS convertendo em HFP com o tempo (Cory et al., 1997; Taylor et al., 1997; Goldenstein et al., 1990; Lehmann, 1992; Blaszczyk et al., 1996). A época do diagnóstico é significante quando o diagnóstico é ELGS ou SPR. Muitos autores consideram a ELGS e SPR espectro da mesma doença (Vierra; Cunningham, 1999; Gamblicher T et al., 2001). Wartenberg descreveu a ELGS como uma forma abortiva de SPR (Wartenberg et al., 1945), no entanto, Wolf e Ehrenclou acreditavam que SPR não é uma doença distinta, mas uma síndrome, que pode coexistir com esclerodermia linear ou ocorrer como uma sequela de várias condições (Wolf; Ehrenclou, 1927). Não existe um critério histopatológico para diferenciar ambas as formas (Gambichler et al., 2001). 
Tanto a ELGS quanto a HFP podem acometer somente o tecido subcutâneo, mais frequentemente na face, ou afetar primariamente a pele e depois os demais tecidos profundos (Sommer et al., 2006).

Os casos pronunciados de HFP parecem estar associados com acometimento importante do SNC, que é observado nos pacientes com doença de início precoce ou história prévia de trauma precedendo a lesão (Blaszczyk; Jablonska, 1999; Blaszczyk et al., 2003).

Nos pacientes com HFP, cerca de $30-40 \%$ apresentam alterações típicas de morfeia ou esclerodermia linear fora da face (Blaszczyk et al., 2003; Gamblicher et al., 2001; Jablonska; Blaszczyk M, 1998; Orozco-Covarrubias et al., 2002).

A frequência de complicações neurológicas é em torno de $20 \%$ (Zulian et al. 2006; Blaszczyk et al., 2003; Tollefson; Witman, 2007) e oftalmológicas de $15 \%$ (Zannin et al., 2007). 
Tabela 3. Comparação de HFP e ELGS

\begin{tabular}{|c|c|c|}
\hline Achados & HFP & $\begin{array}{l}\text { Esclerodermia em golpe de } \\
\text { sabre }\end{array}$ \\
\hline Face & $\begin{array}{l}\text { Atrofia Unilateral } \\
\text { Mínima ou ausente enduração ou } \\
\text { inflamação prévia } \\
\text { Atrofia cutânea (cabelo normal e } \\
\text { esclerose ausente) } \\
\text { Associado com displasia do osso } \\
\text { subjacente, língua, gengiva e palato } \\
\text { unilateral }\end{array}$ & $\begin{array}{l}\text { Banda esclerótica frontoparietal } \\
\text { unilateral } \\
\text { Geralmente precedida por } \\
\text { enduração da pele } \\
\text { Geralmente não se extende } \\
\text { abaixo da sobrancelha } \\
\text { Esclerose cutânea importante, } \\
\text { deprimida, hiperpigmentada, } \\
\text { brilhante, acometendo couro } \\
\text { cabeludo } \\
\text { Frequentemente causa } \\
\text { deformidade e contraturas } \\
\text { Amolecimento das lesões ocorre } \\
\text { ao longo do tempo }\end{array}$ \\
\hline
\end{tabular}

\subsection{Esclerose sistêmica (ES)}

A ES é uma doença do tecido conectivo, multissistêmica e progressiva, de etiologia desconhecida, caracterizada por depósito de colágeno nos vasos da pele e órgãos internos. Acomete principalmente o trato gastrointestinal, pulmão, coração e rins (Perason, 1991; Blann et al., 1993; Uziel et al., 1995).

Os pacientes podem desenvolver esclerose dos dedos, apresentar ulcerações, reabsorção de falange, alteração de capilares da prega ungueal e/ou 
fenômeno de Raynaud. Na face ocorre adelgaçamento dos lábios, desaparecimento das rugas de expressão e pregas radiais ao redor da boca (Bielsa et al., 1985).

A designação síndrome CREST é usada para descrever um subtipo de pacientes com ES limitada (enduração limitada ás extremidades distais e face) que apresentam: calcinose, fenômeno de Raynaud, envolvimento esofágico, esclerodactilia e telangectasia (Poormoghim et al., 2000).

Historicamente, a principal diferença entre ES e EL é o envolvimento de órgãos internos, na primeira, com grau variável de acometimento. A EL seria confinada a pele e apresentaria curso relativamente benigno.

Por outro lado, durante as últimas décadas, publicações de relatos de casos com possível transição de EL para ES (Birdi et al., 1993; Mayorquin et al., 1994) e séries de casos de pacientes com esclerodermia linear e envolvimento de órgãos internos (Dehen et al., 1994) sinaliza para o amplo espectro de manifestações extracutâneas da EL. Atualmente, a extensão do envolvimento sistêmico não parece oferecer critério isolado para a diferenciação entre EL e ES.

$\mathrm{Na}$ ES, cerca de $10 \%$ dos casos desenvolve sinais de falência cerebrovascular aguda ou crônica, muitas delas transitórias (Pizova, 2004). As causas prováveis propostas foram: defeito do mecanismo imunorregulatório com presença de autoimunidade; vasoespasmo (disfunção autonômica); isquemia por vasculite ou vasculopatia da vasa nervorum e causa metabólica, cursando com desmielinização. Alteração do metabolismo do colágeno com proliferação de fibroblastos não costuma causar alterações no SNC devido à escassez de tecido conectivo no cérebro (Pathak; Gabar, 1991). É reportada a incidência de lesão nervosa periférica que varia de $10 \%$ à $86,7 \%$. Sendo sensitiva simétrica $(16,7 \%)$, sensitivo motor (21,1 a $60 \%)$, polineuropatia ou radiculopatia, lesão de nervo craniano $(76,7 \%)$, incluindo neuropatia sensorial do trigêmeo (4 a 32\%) (Campello, 
1997; Olney, 1998), múltiplas neuropatias (raros casos) e síndrome do túnel do carpo (46,7\%) (Hietaharju et al., 1993; Rosenbaum, 2001).

Em um estudo realizado por Spirin et al. foram avaliados 179 pacientes com doença difusa do tecido conectivo, 40 pacientes apresentavam ES e 139 lúpus eritematoso sistêmico (LES). Doenças que podem estar associadas à polineuropatias e síndromes do túnel do carpo. Foram encontrados $89,7 \%$ dos pacientes apresentando lesão do nervo periférico, sendo a lesão motora observada em $76 \%$ dos pacientes, com leve ou moderada paresia (Spirin et al., 2007).

A relação entre EL e ES foi comparada com a relação entre o lúpus discoide e LES. Porém nestes últimos a progressão entre eles é mais frequente, sendo extremamente raro nos primeiros (Vierra; Cunningham, 1999; Krafchik, 1992; Birdi et al., 1993; Dehen et al., 1994; Tuffanelli, 1998; Jablonska et al., 1992; Blaszczyk et al., 1996).

Um estudo comparou 14 pacientes com ES e os respectivos controles realizando RM do crânio, sendo hipersinal na substância branca o achado mais frequente no primeiro grupo (Sardanelli et al., 2005). Os autores concluem que o número e tamanho do hipersinal sugere anormalidade no território dos pequenos vasos e perfurantes, confirmando a hipótese de microangiopatia como já aventada por outros autores (Cutolo, Nobili et al., 2000; Cutolo, Sulli et al., 2000).

Heron et al. estudaram 37 pacientes com ES e 74 controles. Dos pacientes com ES, 16 pacientes (43\%) sofriam de convulsões, 12 apresentavam calcificação intracerebral e dos controles somente 7 pacientes. A duração média do fenômeno de Raynaud era maior nos pacientes com calcificação intracerebral. A maioria dos pacientes apresentava calcificações nos núcleos basais (Heron et al., 1999), sendo esses achados semelhantes aos relatados na EL. 


\subsection{Etiologia}

A patogênese da ELGS, HFP, EL e ES parecem ser similares. Há referências ao desencadeamento por infecção viral ou bacteriana, como pela B. Burgorferi (Sahin; Baris, 2004; Blaszczyk et al., 1996; Emery, 1998). Outros estudos negam esta associação (Esgleyes-Ribot et al., 1991; Sommer et al., 2006).

Os fatores genéticos foram implicados (Blaszczyk, et al., 1996). Porém, não parece consistente, tendo sido relatado apenas $4,7 \%$ de concordância entre gêmeos (Feghali-Bostwick et al., 2003) e, em estudo de familiares, foi revelado $1,6 \%$ de frequência entre parentes de $1^{\circ}$ grau (Katsumoto et al., 2011; Arnett et al., 2001).

As anormalidades vasculares também foram atribuídas na patogênese da esclerodermia (Woolfenden et al., 1998). Algumas pesquisas acreditam que as calcificações cerebrais associadas à esclerodermia da face representam hemangiomas calcificados (Asher; Berg, 1982). A presença de neurovasculite foi identificada em diferentes estudos. (Stone et al., 2001; Menni et al., 1997; Blaszczyk; Jablonska, 1999; Appenzeller et al., 2004; Holland et al., 2006; Holl-Wieden et al., 2006). O dano e disfunção endotelial, assim como sugerido na ES (Campbell; Le, 1975), leva a um aumento da atividade do fibroblasto e isquemia por estreitamento luminal, com consequente modificação da produção de colágeno (Blaszczyk et al., 1996; Eubanks et al., 1996). Esse mecanismo pode ter um papel importante na ELF, explicando as lesões cerebrais isquêmicas encontradas em alguns pacientes (Menni et al., 1997). As estruturas mesenquimais cervicocefálica como derme, subcutâneo, músculo e esqueleto são derivados das células da crista neural, podendo explicar a associação da HFP e alterações vasculares (Schievink et al., 2003). Outra hipótese para início do dano microvascular é o trauma, tendo sido reportado na população pediátrica (Yamanaka; Gibbs, 1999; Salpietro et al., 2004). 
O trauma é reportado como ativador ou iniciador da HFP (Blaszczyk; Jablonska, 1999; Fry et al., 1992; Yamanaka; Gibbs, 1999; Komocsi et al., 2000; Pupillo et al., 1996). Alguns estudos, no entanto, não encontram relação entre o trauma como desencadeante ou preditor de severidade na HFP (Sommer et al., 2006). Não podendo ser excluída a existência de bias, pelo questionamento sobre fatores desencadeantes aos pacientes.

Como a ELGS e HFP podem envolver os tecidos faciais e parênquima cerebral ipsilateral, que tem em comum a mesma célula progenitora, existe a hipótese de disgenesia cortical, uma malformação afetando um lado do tubo neural rostral (Dupont et al., 1997; Terstegge et al., 1994; Nussgens; Roggenkamper, 1992). Alguns caracterizam como uma síndrome neurocutânea (Taylor et al., 1997; Goldenstein et al., 1990), sendo as manifestações cutâneas induzidas por malformações cerebrais primárias (Menni et al., 1997). A explicação para coexistência de HFP e acometimento cerebral ipsilateral, pode sugerir uma origem embriológica da doença, envolvendo tanto das células neurais, quanto das outras áreas da face, como osso, derme, gordura, musculatura. A alteração de um lado da face pode determinar as síndromes unilaterais, como HFP e esclerodermia (Cohen, 2001). Um clone de células vulneráveis desenvolveriam as lesões seguindo a linha de Blaschko. Aventa-se a possibilidade de mosaicismo genético como fator determinante da distribuição linear do processo de esclerose (Weibel; Harper, 2008). Essa teoria explicaria como podem ocorrer múltiplas lesões frontoparietais (Soma; Fujimoto, 1998).

Devido à descrição de lesões cutâneas com acometimento correspondente a área dos ramos do nervo trigêmeo, foi sugerida a desregulação das fibras simpáticas como possível etiologia por Romberg (Lehmann, 1992). Em 1997, Cory et al., aventou que a hiperexcitação simpática poderia originar o processo ou estar 
associado à esclerose cutânea (Cory et al., 1997; Catala, 1998). Alguns autores reproduziram HFP em estudos com coelhos após ablação ganglionar cervical superior (Resende et al., 1991). Existem relatos de HFP após simpatectomia (Scope et al., 2004). Podendo, ainda, estar envolvidos nesse processo alguns dos fatores previamente relatados como o trauma facial, hiper ou hipoatividade do sistema nervoso simpático, anormalidade do trigêmeo, infecção bacteriana ou viral, incluindo a B. Burdorferi (DeFelipe et al., 2001; Derex et al., 1995).

Já foi ilustrada a evidência patológica de inflamação intracerebral em relatos de casos com biópsia cerebral (Pupillo et al., 1996; Tersteege et al., 1994; Stone et al., 2001; Grosso et al., 2003; Luer et al., 1990).

Algumas alterações que sugerem processo autoimune são descritas como: elevação de anticorpo antinuclear (Bonilla et al., 1995); associação com doenças como LES, artrite reumatoide (AR) e ES (Stone, 2003; Kanzato et al., 1999); associação com mielite transversa (Littman, 1989) e a presença de bandas oligoclonais no líquor, com convulsões e RM com lesões cerebrais. A produção intratecal de imunoglobulinas foi documentada em alguns casos na literatura (Stone et al., 2001; Unterberger et al., 2003; Luer et al., 1990). A resolução e melhora com a terapia imunossupressora, também suportam essa teoria (Goldberg-Stern et al., 1997; Stone et al., 2001; Unterberger et al., 2003). Todos esses achados podem indicar possível relevância da autoimunidade na patogênese desta doença (Kanzato et al., 1999; Gambichler et al., 2001; DeFelipe et al., 2001; Garcia de la Torre et al., 1995; Paprocka et al., 2006).

Luer et al. sugeriram que as lesões da ELGS envolvendo o cérebro são de natureza inflamatória. Lesões de hipersinal em T2, predominando ipsilateral, cortical e subcortical na RM foram descritas em uma mulher de 32 anos que tinha também uveíte, fenômeno de Raynaud, e síntese de lgG intratecal (Luer et al., 1990). Este 
caso demonstrou remissão espontânea de algumas lesões. A evidência de substrato inflamatório deve-se a estudos sorológicos, que demonstraram alta freqüência de anticorpos antinucleares positivos e fator reumatoide (FR) (Garcia de la Torre et al., 1995). A prevalência destes exames demonstrou ser significantemente maior em pacientes com envolvimento extracutâneo que pacientes com envolvimento cutâneo exclusivo (Zulian et al., 2005). O fato das alterações neurológicas serem não correspondentes, exclusivamente, ao local da lesão cutânea, suporta esta hipótese, evidenciando um processo autoimune sistêmico, mais do que uma disgenesia de estruturas cerebrais e faciais serem responsável por esta associação.

Após extensa revisão da literatura, o que parece estar mais evidentemente associado com a etiopagenia nos pacientes com ELF é o processo inflamatório de provável substrato autoimune e origem embriológica da doença, como o mosaicismo genético. Os dados disponíveis sugerem um complexo mecanismo de patogênese da esclerodermia, no qual vasos, sistema imune e matriz extracelular estão afetados e podem contribuir para o desenvolvimento da doença.

\subsection{Manifestações extracutâneas}

O envolvimento extracutâneo na EL é considerado extremamente incomum por muitos autores (Vierra; Cunningham,1999; Krafchik, 1992; Birdi et al., 1993; Dehen et al., 1994; Tuffanelli, 1998; Jablonska et al., 1992; Blaszczyk et al., 1996).

O desenvolvimento da doença cutânea geralmente precede o início das manifestações extracutâneas. O início dos achados sistêmicos geralmente ocorre após alguns meses, mas há relatos de doença neurológica muitos anos após (Stone et al., 2001; Menni et al., 1997). Sintomas e sinais sistêmicos podem não cursar em paralelo com a atividade da doença cutânea (Menni et al., 1997). 
São descritos os seguintes envolvimentos extracutâneos: artrite, outras limitações articulares, envolvimento ocular, neurológico, perda de cabelo no sítio específico acometido, fenômeno de Raunayd, envolvimento da fáscia ou músculo (documentado por biópsia ou imagem), RGE, anormalidade na prova de função pulmonar (PFP), esofagite documentada na endoscopia digestiva alta (EDA), anormalidades específicas na tomografia computadorizada (TC) ou nos raios- $X$ (RX) de tórax, dispneia ou tosse, vasculite, arritmia, envolvimento profundo do tecido mamário e outros (Li et al., 2012).

A alteração da dentição (Marzano et al., 2003; Itin; Schiller, 1999; Sandhu; Handa, 2004; Rai et al., 2000), podendo levar à má oclusão são achados descritos na ELGS e SPR (Marzano et al., 2003), e atrofia da língua também (Marzano et al., 2003; Itin; Schiller, 1999; Rai et al., 2000).

Mais de $20 \%$ dos pacientes com EL desenvolve manifestações extracutâneas, incluindo artrite, convulsões e uveíte (Zulian et al., 2005; ChristenZaech et al., 2008). As complicações neurológicas constituem a associação de manifestações sistêmica mais comum na ELGS (Liu et al, 1994; Appenzeller et al., 2004).

Artralgia foi descrita em $44 \%$ de 191 pacientes com morfeia em placa e $40 \%$ de 44 pacientes com morfeia generalizada (Christianson et al., 1956). Várias doenças dermatológicas incluindo líquen plano, vitiligo e alopecia areata foram associadas com morfeia (Zulian et al., 2006).

Devido ao possível início precoce da EL e persistência por anos, a morbidade da EL pode ser substancial. Crianças com EL apresentam risco maior de distúrbio do crescimento, incluindo diferença de comprimento entres os membros, contraturas articulares e atrofia facial. Revisando o registro prospectivo de mais de 100 pacientes com EL na infância foi encontrado $38 \%$ com atrofia muscular, 
encurtamento do membro, hemiatrofia facial e/ou contraturas articulares e $25 \%$ com limitação da capacidade funcional (Wu et al., 2011). Em um estudo de seguimento longo com pacientes com EL com inicio na infância, 25\% reportaram leve a moderada desabilidade após 20 anos (Peterson et al., 1993). Outro estudo com adultos que iniciaram a doença na infância, mais de $50 \%$ reportaram sequela permanente, incluindo limitação para movimentação, atrofia de tecido profundo e diferença de tamanho das extremidades (Saxton-Daniels; Jacobe, 2010).

Portanto, complicações ortopédicas, como de tecido subcutâneo ou atrofia muscular, interferindo na mobilidade articular ou ocasionando contraturas articulares severas, são frequentes na esclerodermia linear envolvendo os membros, principalmente nas crianças. São raramente vistas nos grupo de adultos com EL. Sendo mais frequentes em algumas variantes como a morfeia generalizada (4 de 9 casos) e morfeia profunda (2 de 4 casos estudados) segundo Marzano et al. (Marzano et al., 2003).

Em geral, quanto mais extenso e profundo o processo esclerodermiforme, maior a probabilidade de apresentar uma anomalia visceral associada. Ocorrendo principalmente na esclerodermia linear, morfeia generalizada e profunda (Marsol, 2012).

O fenômeno de Raynaud usualmente é associado com capiloroscopia ungueal alterada, sugerindo doença do tecido conectivo. Em um estudo de Marzano et al., em 113 pacientes adultos com EL, fenômeno de Raynaud foi encontrado em 7\% deles, sendo que $87,5 \%$ apresentavam fator antinúcleo (FAN) positivo e 50\% anticorpo anticentrômero (ACA). Nas 126 crianças estudadas, a prevalência foi de 2\% (Marzano et al., 2003). 
O fenômeno de Raynaud é considerado fator de risco para desenvolvimento de doença sistêmica (Marzano et al., 2003), sendo mandatório o seguimento cauteloso desses pacientes.

Zulian et al. estudaram a prevalência de manifestações extracutâneas em 750 crianças com EL. Cerca de 22,4\% apresentavam manifestações extracutâneas, dentre elas, articular $(47,2 \%)$, vascular $(2,4 \%)$, gastrintestinal $(6,2 \%)$, neurológica $(4,4 \%)$, respiratória $(2,6 \%)$, ocular $(2,1 \%)$, cardíaca $(1 \%)$ e renal $(1 \%)$. Outras condições autoimunes estavam presentes em $7,3 \%$ dos pacientes, não havendo diferença entre o grupo com manifestação extracutânea e o com manifestação somente cutânea. Dentre elas: vitiligo, diabetes mellitus (DM) insulino dependente, tireoidite de Hashimoto, doença de Graves e colite ulcerativa, que também foram reportadas em outros relatos (Zulian et al., 2006; Lee et al., 2002; Dervis et al., 2004; Finkelstein et al., 1995) .

A incidência de doenças autoimunes e prevalência de autoanticorpos estão aumentadas em pacientes com esclerodermia linear comparado com grupo controle saudável (Zulian et al.,2005).

Nesse estudo coorte de Zulian et al., o fenômeno de Raynaud foi reportado em 16 pacientes. O acometimento pulmonar encontrado essencialmente foi à doença pulmonar restritiva. RGE foi a única alteração gastrintestinal encontrada em 12 pacientes. Em 4\% dos pacientes foram identificado múltiplas manifestações extracutâneas, mas ES desenvolveu em apenas 1 paciente. Em 92\% dos pacientes as manifestações extracutâneas seguiam ao surgimento de lesões cutâneas. Em 13,5\% dos pacientes ocorreram eventos associados com o início da doença, como: trauma, infecção ou exposição à droga. O subtipo de esclerodermia linear foi o mais frequente encontrado, em torno de $60 \%$ dos pacientes. As associações mais frequentes foram: articular/neurológica, ocular/neurológica e fenômeno de Raynaud / 
articular. Os autores recomendaram especial atenção na avaliação de acometimento das articulações, olhos e SNC nos pacientes com EL (Zulian et al., 2005).

O achado de mais de um acometimento extracutâneo não parece representar um risco para desenvolvimento de ES. A prevalência de evolução de esclerodermia linear para ES é em torno de 0,9 a 1,3\% (Dehen et al.,1994; De P et al., 2000). Porém, a doença nos pacientes com envolvimento extracutâneo parece ser mais agressiva do que naqueles com envolvimento apenas cutâneo, baseado na presença de inflamação sistêmica e maior frequência de necessidade de terapia imunossupressora. Nestes pacientes o envolvimento dos órgãos é mais leve do que em pacientes com ES e não oferece risco a vida. Desta forma, acredita-se que EL e ES representam diferentes espectros da mesma doença.

Foi reportado que os pacientes com morfeia apresentam um maior risco de doenças autoimunes nos seus familiares (Zulian et al., 2006; Leitenberger et al., 2009).

Em questionário aplicado pela internet por Stone $\mathrm{J}$ et al., em 205 pacientes com HFP, $80 \%$ eram mulheres, $11 \%$ relataram epilepsia, $52 \%$ enxaqueca ou dor facial, $46 \%$ problemas visuais e $46 \%$ depressão ou ansiedade. Foi descrito coexistência com outras doenças autoimunes como vitiligo (17\%), doença tireoidiana $10 \%$, ES $(5 \%)$, doença inflamatória intestinal $(5 \%)$, artrite reumatoide $(4 \%)$, espondilite anquilosante (2\%), LES e esclerose múltipla (Stone, 2003).

\subsubsection{Envolvimento neurológico}

O acometimento neurológico na EL tem sido discutido desde o século 19, refletindo uma possível relação patogênica (Blaszczyk et al., 1996; Blaszczyk; Jablonska, 1999; Sommer et al., 2006; Orozco-Covarrubias et al, 2002; Wolf; Verity, 
1974; Asher; Berg, 1982; Fry et al., 1992; Uziel et al., 1995; Blaszczyk et al., 2003; Stone, 2003).

O acometimento neurológico consistentemente associado à esclerodermia tem sido reportado em cerca de $10 \%$ dos pacientes, sendo epilepsia o mais comum (Marzano et al., 2003; Flores-Alvarado et al., 2003; Obermoser et al., 2003; Blaszczyk et al., 2003; Higashi et al., 2000; David et al., 1991; LuHer et al., 1990; DeFelipe et al., 2001; Derex et al., 1995; Pichiecchio et al., 2002; Schievink et al., 1995; Chung et al., 1995; Fry et al., 1992; Woolfenden et al., 1998; Stone, 2003). Em um estudo que revisou 54 casos com manifestação neurológica descritos na literatura, $73 \%$ apresentavam convulsões, sendo 33\% descritos como refratários a medicação (Kister et al., 2008). Convulsão parcial complexa é o subtipo mais frequente ou focal contralateral, seguido por convulsão tônico clônica, crise de ausência, assim como estado epiléptico (Holland et al., 2006; Falanga et al., 1987; Flores-Alvarado et al., 2003). As lesões corticais têm sido responsabilizadas pelas convulsões em alguns pacientes com ELGS (Appenzeller et al., 2004).

As convulsões podem inclusive ocorrer precedendo o achado de lesões faciais (David et al., 1991; Orozco-Covarrubias et al., 2002; Liu et al., 1994). Em $16 \%$ dos casos os sintomas neurológicos precedem as manifestações cutâneas (Kister et al., 2008).

A epilepsia pode não estar associada às lesões cerebrais detectáveis ou pode preceder o aparecimento destas (Goldberg-Stern et al., 1997; Yano et al., 2000; Menni et al., 1997; Aynaci et al., 2001).

Ambas as doenças, ELGS e SPR, têm sido reportadas associadas com convulsões focais contralaterais e sinal de liberação piramidal, atrofia progressiva das estruturas cerebral unilateral (geralmente unilateral a lesão cutânea) 
(Gambichler et al., 2001) e calcificação intracraniana ipsilateral (Paprocka et al., 2006; Liu et al., 1994).

O acometimento neurológico também pode compreender: cefaleia (Kister et al., 2008; David et al., 1991), que é referida em 35\% dos pacientes com ELGS, sendo geralmente associado à outra queixa neurológica (Kister et al., 2008). Enxaqueca e enxaqueca que mimetiza hemiplegia são as formas mais prevalentes (Kister et al., 2008; David et al., 1991).

Casos com déficit neurológico focal (Kister et al., 2008; Marzano et al., 2003; Stone et al., 2001; Terstegge et al., 1994); hemiparesia; fraqueza muscular (Stone et al., 2001; Unterberger et al., 2003; Menni et al., 1997; Paprocka et al., 2006; Liu et al., 1994); malformação vascular, aneurisma intracraniano (Shievink et al., 2003); alterações de neuroimagem isoladas até vasculite do SNC e neuropatia periférica são descritos na literatura.

A encefalite de Rasmussen (EH) foi descrito como achado na HFP, doença caracterizada por convulsões intratáveis, hemiparesia progressiva e alterações patológicas de encefalite crônica, podendo o mesmo processo autoimune justificar a associação entre a EH e HFP (Shah et al., 2003). A deterioração mental e alteração do comportamento tem sido descritos em 15\% dos pacientes (Grosso et al., 2003; Shah et al., 2003; Paprocka et al., 2006; Carreno et al., 2007; Gambichler et al., 2001); higroma subdural (Sandhu; Handa S, 2004); paralisia facial periférica; paralisia do nervo oculomotor (Gambichler et al., 2001); neuralgia do trigêmeo (Marzano et al., 2003); espasmo mastigatório (Unterbeger et al., 2003); parestesia. A depressão e psicose foram reportadas em mais de $46 \%$ dos pacientes com HFP (Stone, 2003).

No estudo realizado por Zulian et al. as alterações neurológicas encontradas foram: convulsões $(n=10)$, vasculite do SNC $(n=2)$, neuropatia periférica $(n=3)$, 
malformação vascular $(n=2)$, cefaleia $(n=7)$ e anormalidade de imagem. Em 4 pacientes as alterações neurológicas não estavam correlacionadas com o sítio da lesão cutânea e em 12 casos eram ipsilaterais ao acometimento cutâneo. O envolvimento neurológico foi significantemente maior em pacientes com esclerodermia da face (ELGS e HFP). No total, em um quarto dos pacientes as alterações neurológicas, articulares e oculares não estavam correlacionadas com o sítio da lesão cutânea (Zulian et al., 2005).

Assim, as lesões intracerebrais não são sempre adjacentes ao sítio de lesão cutânea. Existe relato de um caso com lesão de esclerodermia linear no membro inferior esquerdo, sem lesões faciais, desenvolvendo após 5 anos epilepsia e deterioração mental, com envolvimento apenas do hemisfério cerebral ipsilateral ao membro. A esse caso se atribui um processo autoimune, ocasionando obliteração vascular e consequente atrofia cerebral (Grosso et al., 2003).

Foi relatado também inflamação ou edema no lobo frontal ocasionando aumento da pressão intracraniana, sendo subsequentemente atribuído como causa dos sintomas de cefaleia e tontura ( $\mathrm{Ng}$ et al., 1996).

Aparentemente não há correlação com a severidade das alterações cerebrais e o quadro clínico (Nadeau, 2002; Liu et al.,1994). São descritos alguns pacientes assintomáticos clinicamente do ponto de vista neurológico, a despeito das anormalidades cerebrais detectadas (Goldberg-Stern et al., 1997; Liu et al., 1994). Geralmente são encontradas anormalidades cerebrais ipsilaterais à lesão cutânea nos pacientes assintomáticos (Unterberger et al., 2003; Appenzeller et al., 2004; Holland et al., 2006). 


\subsubsection{Alterações oculares}

O acometimento ocular não é comum nas crianças com EL, estando presente em cerca de $3,2 \%$. Nos adultos, o envolvimento ocular na EL ocorre em cerca de $10 \%$ e em um terço do pacientes com SPR. Na ELGS, que também afeta o segmento cefálico, ocorre envolvimento do olho e estruturas anexas com prevalência de 14\%. Esta manifestação, geralmente, é de início precoce (Zannin et al., 2007).

As alterações reportadas na literatura foram acometimento das estruturas anexiais (Zannin et al., 2007), segmento anterior e posterior do olho (SuttorpSchulten; Koorn, 1990) e SNC (Blaszczyk et al., 2003; Obermoser et al., 2003; HollWieden et al., 2006). O acometimento da musculatura extrínseca dos olhos é muito raro, mas já foi bem descrito tanto pela tomografia computadorizada (TC), quanto pela RM (Ramboer et al., 1997; Suttorp-Schulten; Koornneef, 1990) e pode ser suspeito na presença de dor a movimentação ocular, diplopia e estrabismo.

A inflamação do segmento anterior e uveíte anterior são geralmente ocasionais, assintomáticas e unilaterais (Zannin et al., 2007). As manifestações oculares incluem ainda: ptose (Peterson et al., 1997; Obermoser et al., 2003; Hawk; English, 2001; Gambichler et al., 2001; Goldberg-Stern et al., 1997; SuttorpSchulten; Koornneef, 1990); pseudoparalisia oculomotora; miopatia dos músculos externos dos olhos com desordem da mobilidade e atrofia da musculatura (SuttorpSchulten; Koornneef, 1990); uveíte (Obermoser et al., 2003; Marzano et al., 2003; Luer et al., 1990); episclerite, iridociclite; heterocromia da íris (Suttorp-Schulten; Koornneef, 1990; Rai et al., 2000); anisocoria; enoftalmo (Ramboer et al., 1997); exoftalmo (Marzano et al., 2003); xeroftalmia, glaucoma; papiledema; dor retrobulbar (Obermoser et al., 2003) e perda dos cílios e sobrancelhas (David et al., 1991). 
O acometimento ocular é atribuído a diversas condições. Zannin et al. fizeram um estudo multicêntrico avaliando o envolvimento ocular na EL em crianças (Zannin et al., 2007). A alteração ocular foi divida por grupos:

1. Acometimento por fibrose das pálpebras, sobrancelhas e cílios ou glândulas lacrimais com olho seco. Esta complicação é a mais frequente encontrada $(41,7 \%)$. Esta anormalidade pode evoluir com a inabilidade de piscar os olhos e algumas vezes com ectóprio, com risco de ceratopatia. Neste grupo, geralmente a lesão é evidente e diagnóstico é precoce e apropriado.

2. Acometimento da câmara anterior do olho é a segunda alteração mais frequente, presente em $29,2 \%$ dos pacientes com exame ocular alterado. Sendo a uveíte anterior o achado mais relevante. Assim como a artrite idiopática juvenil, essa condição representa uma manifestação de processo autoimune sistêmico. A uveíte anterior é assintomática e pode não estar relacionada com sítio do envolvimento cutâneo, devendo, portanto, ser realizado um exame oftalmológico periódico nesses pacientes para evitar complicações como glaucoma. A episclerite é tida como provável expressão de lesão fibrótica inflamatória subconjuntival, similar às lesões cutâneas. Geralmente são refratárias a corticoterapia, provavelmente devido à prevalência do componente fibrótico.

3. Anormalidades relacionadas ao SNC. Nos pacientes com pupila dilatada e anormalidades oculares complexas, estudo por imagem do SNC deve ser realizado. De outra forma, se a manifestação neurológica ou a alteração de imagem do SNC estiver presente, uma avaliação oftalmológica completa deve ser providenciada. Ainda não 
foram achados mecanismos fisiopatológicos entre o envolvimento do SNC e ocular.

4. Variedade de condições, tais como: estrabismo por paralisia, pseudopapiledema e erros de refração.

O acometimento da órbita tem sido descrito, mas é raro (Fitzpatrick et al., 1987; Suttorp-Schulten; Koornneef, 1990). A reabsorção do osso da órbita também foi descrito (Peterson et al., 1995).

A enoftalmia pode ser explicada pela atrofia da gordura orbital, que é apenas parcialmente substituída por fibrose na ELF (Kirkali et al., 1991).

Entre os exames de imagem, o mais indicado para distinguir entre atrofia da gordura na órbita, edema e fibrose são a RM (Ramboer K et al., 1997).

Zannin et al. encontraram uma prevalência de $50 \%$ de concomitante envolvimento dos órgãos internos nos pacientes com manifestação ocular (Zannin et al., 2007). A associação mais frequente é com anormalidades do SNC, devido à próxima relação entre esses dois órgãos (Blaszczyk et al., 2003). Porém, lesões oculares não ocorrem somente na esclerodermia com envolvimento facial, sustentando o conceito que EL é uma doença sistêmica.

No estudo de Zulian et al. as manifestações oculares foram encontradas quase exclusivamente nos pacientes com ELF e HFP, como: episclerite $(n=3)$, uveíte $(n=4)$, xeroftalmia $(n=2)$, glaucoma $(n=2)$ e papiledema $(n=1)$. Em 4 pacientes as alterações não estavam correlacionadas com o sítio da lesão cutânea, em 12 eram ipsilaterais (Zulian et al., 2005).

Achado frequente, a presença de ceratite punctata indica alteração do filme lacrimal, presente nos olhos secos (Zannin et al., 2007). 
Também foi reportado aneurisma da artéria da retina em pacientes com HFP (Gass et al., 1991).

\subsection{Alterações laboratoriais}

Enquanto na ES determinadas alterações séricas são consideradas marcadores da doença, como a presença de Scl-70, na EL as alterações laboratoriais são variáveis e sua relação com a doença de base é questionável.

O anticorpo da topoisomerase 1, denominado Scl-70, é considerado marcador sorológico de ES (Marzano et al., 2003).

O ACA, anticorpo anti-centrômero, é considerado marcador da síndrome CREST (calcinose, fenômeno de Raynaud, dismotilidade esofágica, esclerodactilia, telangectasias) (Marzano et al., 2003).

A velocidade de hemossedimentação (VHS) é um exame encontrado aumentado em caso de atividade da doença. $O$ aumento de eosinófilos foi observado também nos casos de atividade da doença ou recidiva (Marzano et al., 2003).

Acredita-se que o FAN esteja positivo nos pacientes com formas mistas. Quando presente na ELF indicaria formas mais prolongadas e de curso complicado, não estando correlacionado com atividade da doença (Marzano et al., 2003). O FAN com padrão homogêneo e salpicado está positivo em 37 a 50\% dos pacientes com esclerodermia linear (Peterson et al., 1997; Blaszczyk et al., 1996; Tuffanelli, 1998).

Os marcadores sistêmicos, como FAN, ACA e Scl-70 não são sempre sinal de doença sistêmica (Jablonska et al., 1992; Marzano et al., 2003). Os 
autoanticorpos como anticentrômero, Ro/La, RNP e Scl-70 podem preceder o desenvolvimento de doença sistêmica, sendo que pacientes com essas alterações devem ser seguidos por muitos anos (Blaszczyk et al., 1996).

$\mathrm{O}$ achado de fator reumatoide (FR) é fator de risco para acometimento articular nos pacientes com EL, sugerindo o FR como marcador clínico maior, devendo-se monitorar cuidadosamente os pacientes com FR positivo (Zulian et al., 2005).

Nos pacientes com esclerodermia generalizada é frequente o encontro de eosinofilia periférica que, às vezes, pode ser muito importante; aumento de gamaglobulina ou alterações imunológicas como o achado de FAN, anti DNA de cadeia simples, diminuição de complemento ou presença de anticorpo antifosfolipídeo (Bielsa et al., 1985; Falanga et al., 1987). Os anticorpos anti-histona e a elevação sérica de pró-colágeno tipo III foram demonstrados como indicadores de gravidade na EL, mas não é infrequente detectar essas anomalias em formas extensas e profundas de morfeia (Sato et al.,1994; Parodi et al., 1995; Kikuchi et al., 1994).

Marzano et al., estudaram 239 pacientes com EL, sendo 113 adultos e 126 crianças. Foi encontrado FAN positivo em $45 \%$ e $26 \%$, respectivamente, não encontrando correlação com a atividade clínica. Os anticorpos séricos estavam positivos em $20 \%$ e $7 \%$ dos casos, respectivamente. O VHS aumentado em $10 \%$ e $2 \%$ respectivamente, indicando atividade da doença. A eosinofilia em $6 \%$ e $7 \%$, respectivamente, sendo mais comum na morfeia generalizada e profunda, indicando atividade da doença ou recidiva. $\mathrm{O}$ anticorpo Scl-70 foi encontrado em 1 adulto e 3 crianças, não evoluindo para doença sistêmica após 5 e 7 anos de seguimento, respectivamente (Marzano et al., 2003). 
Num grupo de pacientes com EL, naqueles com acometimento extracutâneo a prevalência de FAN e FR foi significantemente maior do que nos pacientes com envolvimento cutâneo exclusivo. Trinta por cento dos pacientes com artrite apresentavam FR positivo, enquanto apenas 13,8\% sem artrite tinham o mesmo exame positivo, diferença estatisticamente significativa. No entanto, anticorpo anti topoisomerase 1 (Scl-70) e ACA, marcadores de ES, não estavam aumentados significantemente. Assim, mensuração de FAN, FR, Scl-70, ACA e anticardiolipina (ACL) foram sugeridas para este subgrupo de pacientes (Zulian et al., 2005).

\subsection{Alterações radiológicas}

Grosso et al. já sugeriram que as anormalidades cerebrais deveriam ser consideradas nos pacientes com EL que acometem face ou couro cabeludo, sendo que os estudos de neuroimagem indentificaram lesões cerebrais em pacientes assintomáticos (Grosso et al., 2003).

A TC e RM foram sugeridas para investigação de pacientes com ELGS, particularmente para detecção de alterações intracranianas inaparentes (Stone et al., 2001; Maurer et al., 1999; Gambichler et al., 2001). A TC de alta resolução seria o exame de escolha para detecção da progressão das anormalidades da calota craniana e identificação de calcificações parenquimatosas. A RM de crânio é o exame mais sensível para identificação das lesões cerebrais subjacentes (Appenzeller, Montenegro et al., 2004).

Alguns artigos descrevem lesões ipsilaterais ou contralaterais na substância branca na TC ou RM do crânio (Chung et al., 1995; David et al., 1991). 
A lesão cerebral mais frequente nos pacientes com ELGS é a calcificação intraparenquimatosa, que pode envolver os núcleos basais, tálamo e núcleo denteado (Unterberger et al., 2003; Appenzeller et al., 2004; Holland et al., 2006; Liu et al., 1994; Nadeau, 2002; Blanco et al., 1999; Obermoser et al., 2003). As calcificações são encontradas em $37 \%$ das RM dos pacientes com esclerodermia craniofacial (Kister et al., 2008). Caracteristicamente foram descritas calcificações cerebrais ipsilaterais à lesão cutânea (Uziel et al., 1995; Grosso et al., 2003; Fry et al., 1992; Dupont et al., 1997; Goldberg-Stern et al., 1997; Cory et al., 1997; Taylor et al., 1997; Liu et al., 1994), mas também contralaterais (Stone et al., 2001; Fry et al., 1992; Moseley et al., 2010). Associação com calcificações cerebrais e achados neurológicos clínicos têm sido reportados na HFP (Fry et al., 1992). Na ELGS também foram descritas calcificações cerebrais e epilepsia (Diley; Perry HO, 1968; David et al., 1991; Luer et al., 1990; Fry et al., 1992; Liu et al., 1994). Essas observações levam a hipótese por alguns autores que as manifestações cutâneas são induzidas primariamente por anormalidade cerebral incluindo calcificação intracerebral (Menni et al., 1997). Como referido anteriormente, alguns pesquisadores postulam que as calcificações cerebrais possam representar hemangiomas calcificados (Asher; Berg, 1982).

Entretanto, a calcificação intracraniana é muita rara em crianças com ELGS. Em uma série de 13 casos, não foi identificado nenhum caso de calcificação intracraniana (Orozco-Covarrubias et al., 2002). Em outro estudo com ELGS, apesar da observação de convulsões, também não foram reportadas calcificações (David et al., 1991).

Liu et al. descreveram calcificação intracraniana em 2 casos de ELGS em uma série de 23 pacientes com EL (Liu et al., 1994). Não foi reportada associação 
de calcificação intracerebral com os principais fatores de risco cardiovasculares, exceto com a idade.

Yano et al. demonstraram que as calcificações na HFP são adquiridas e podem estar estabelecidas com 2 anos após o início da doença, provavelmente refletindo a evolução dinâmica inicial (Yano et al., 2000).

A maioria dos relatos descrevem as convulsões como achados secundário, associado a lesões intracranianas, que seguem as alterações cutâneas (Duppont et al., 1997; Goldeberg-Stern et al., 1997; Taylor et al., Goldstein et al., 1990; DeFelipe et al., 2001). Mas também existe relato de paciente com convulsão parcial complexa ou simples de surgimento prévio as lesões cutâneas e anormalidades cerebrais (Yano et al., 2000).

Outros achados na RM incluem hipersinal ipsilateral na substância branca em T2, na região cortical e subcortical (Luer et al., 1990), mas também com localização no corpo caloso, núcleo cinzento profundo e pedúnculo cerebral (Grosso et al., 2003; Liu et al., 1994; David et al., 1991; Pupilo et al., 1996; Lehman, 1992; Higashi et al., 2000; Sakai et al., 2008; Unterberger et al., 2003; Appenzeller et al., 2004; Holland et al., 2006; Holl-Wieden et al., 2006; Fry et al., 1992; Dupont et al., 1997; Goldberg-Stern et al., 1997; Cory et al., 1997; Taylor et al., 1997). Foi reportada convulsão associada ao hipersinal na substância branca no exame de RM (Chung et al., 1995; Fry et al., 1992; Liu et al., 1994; Terstegge et al., 1994). O realce das lesões de substância branca pelo gadolíneo foi reportado em $32 \%$ dos pacientes com ELF que fizeram RM (Kister et al., 2008). O realce do contraste pode persistir ou aumentar, em um curso de 3 anos ou mais apesar do tratamento com imunossupressor (Cory et al., 1997; Grosso et al., 2003; Stone et al., 2001).

As alterações ipsilaterais consistem na anormalidade da interface entre a substância branca e cinzenta, que foram previamente interpretadas como lesões 
representativas de possível processo de alteração na migração neuronal ou desmielinização (Liu et al., 1994; Grosso et al., 2003). Os achados como afilamento cortical abaixo da lesão cutânea, geralmente respeitando a linha média; anormalidades do giro (acentuação do sulco) e borramento da interface entre substância branca e cinzenta são sinais de atrofia cerebral (Lehamnn, 1992; Higashi et al., 2000; Dupont et al., 1997; Tersteege et al., 1994; Shah et al., 2003; Appenzeller et al., 2004; Carreno et al., 2007; Paprocka et al., 2006). É sugerido também que o borramento entre a substância branca e cinzenta possa consistir em distúrbio no desenvolvimento cortical (Grosso et al., 2003; Chung et al., 1995).

As lesões cerebrais são descritas como ipsilaterais à lesão cutânea em $78 \%$ a 100\% dos casos (Kister et al., 2008; Moko et al., 2003; Terstegge et al., 1994).

As alterações neurovasculares relatadas na HFP são: malformação arteriovenosa (Lehmann, 1992; Pensler et al., 1990), fístula arteriovenosa (Schievink et al., 1995) e aneurisma com dissecção ou não (Schievink et al., 1996). A angiografia cerebral ou angioressonância foram realizadas em 20 pacientes da literatura, demonstrando sinais indicativos de vasculite em 8 deles (40\%) (Carrreno et al., 2007; Goldberg-Stern et al., 1997; Grosso et al., 2003; Holl-Wieden et al., 2006; Miedziak et al., 1998;Woolfenden et al., 1998; Korkmaz et al., 2005).

Poucos artigos reportaram acentuação das lesões em T1, que foi atribuído ao achado de vasculopatia cerebral, demonstrado na angiografia e neuropatologia (Unterberger et al., 2003; Appenzeller et al., 2004; Holland et al., 2006; Holl-Wieden et al., 2006). As áreas de microssangramento são encontradas ao redor de locais de injúria da parede vascular, que apresentam aumento da permeabilidade vascular. Esses achados, que correspondem a vasculopatia cerebral, foram reportados em colagenoses que acometem os vasos, como LES, artrite reumatoide ou mais raramente na ES (Fieschi et al., 1998). 
Na ELGS também foram reportados vasos ectasiados anômalos (Chung et al., 1995) e também o achado de redução do calibre da artéria cerebral média e carótida interna associada à atrofia do hemisfério cerebral correspondente (Grosso et al., 2003).

Na HFP, o acometimento cerebral foi caracterizado por aumento da incidência de hemiatrofia cerebral, com anormalidades da vasculatura intracraniana inespecífica (Woolfenden et al., 1998) e realce da meninge (Terstegge et al., 1994). Quatro pacientes com SPR foram descritos com distúrbio no desenvolvimento cortical consistindo de espessamento cortical e apagamento do giro, que foi considerado congênito (Dupont et al., 1997). O achado de deformidade cortical também foi relatado (Appenzeller et al., 2004).

As lesões infratentoriais e hemiatrofia cerebelar são vistas nos pacientes com alteração neurológica clínica mais evidente (Asher; Berg, 1982; Ledeman, 1984; Sathornsumetee et al., 2005).

Os achados neurorradiológicos da ELGS e HFP geralmente são comuns (Duont et al., 1997; Liu et al., 1994; Fry et al., 1992; Chung et al., 1995). Não existe achado típico na RM ou no exame anatomopatológico.

A RM é um exame útil para avaliar a causa dos sintomas no SNC. As calcificações aparecem como áreas de baixa intensidade em T1 e T2 e marcado hipossinal na sequência T2 gradiente eco ou também chamada de T2* (Otaduy et al., 2011). Imagem em T1 demonstra hipossinal e em T2 hipersinal em lesões inflamatórias (Gordon et al., 1999).

O exame de RM demonstrou ter maior sensibilidade na detecção precoce de anormalidades do SNC (sintomáticas ou assintomáticas) comparado ao eletroencefalograma (EEG) (Blaszczyk et al., 2003; Sardanelli et al., 2005). Portanto, optamos pela realização deste exame em nossos pacientes. 
Anormalidades dos exames de RM geralmente estão correlacionadas com a progressão clínica da ELGS (Ramboer et al., 1997). Especula-se que as alterações cutâneas são induzidas por malformações cerebrais primárias, sugerindo que a ELGS possa representar síndrome neurocutânea de displasia vascular, similar a síndrome de Sturge-Weber, mais do que uma forma de doença vascular do colágeno localizada (Chung et al., 1995). A hemiatrofia facial já foi reportada em associação com a síndrome de Sturge-Weber (Koch, 1972). Achados radiológicos semelhantes também são encontrados na síndrome de Sturge-Weber, na qual angioma da leptomeninge causa calcificação e atrofia do hemisfério subjacente (Govori et al., 2009).

Terstegge et al. reportaram a perda de definição dos sulcos cerebrais na presença de dilatação ventricular (Terstegge et al., 1994). Atrofia do hemisfério ipsilateral e alargamentos dos sulcos foram reportados também (Sathornsumetee et al., 2005).

Kister et al. reviu na literatura os casos descritos até o momento de 54 pacientes com EL e sintomas ou sinais neurológicos não atribuídos à outra doença neurológica, que foram submetidos à RM ou TC do crânio; sendo excluídos os pacientes com esclerodermia da face com anormalidades neurorradiológicas, mas sem manifestações neurológicas. Esses achados estão demonstrados na tabela abaixo (Appenzeller et al., 2004; Asher; Berg, 1982; Aktekin et al., 2005; Carreno et al., 2007; Chang et al., 2004; Chapman et al., 1999; Chung et al., 1995; Cory et al., 1997; David et al., 1991; DeFelipe et al., 2001; Dupont et al., 1997; Duyff; Vos, 1998; Flores-Alavarado et al., 2003; Fry et al., 1992; Gambichler et al., 2001; GoldbergerStern et al., 1997; Grosso et al., 2003; Higashi et al., 2000; Holl-Wieden et al., 2006; Holland et al., 2006; Kasapcopur et al., 2003; Ledeman, 1984; Liu et al., 1994; Luer et al., 1990; Miedziak et al., 1998; Menni et al., 1997; Moko et al., 2003; Obemoser 
et al., 2003; Paprocka et al., 2006; Piette et al., 1985; Pichiecchio et al., 2002; Pupillo et al., 1996; Ramboer et al., 1997; Sagild; Alving, 1985; Sathornsumetee et al., 2005; Shah et al., 2003; Stone et al., 2001; Tersteege et al., 1994; Unterberger et al., 2003; Yano et al., 2000; Woolfenden et al., 1998; Lederman, 1984; Kister et al., 2008). 
Tabela 4. Achados clínicos e radiológicos de 54 pacientes com EL e manifestações neurológicas (adaptada de Kister I et al., 2008)

\begin{tabular}{|c|c|}
\hline & 54 pacientes \\
\hline Feminino: masculino & $1: 3$ \\
\hline Idade media de início & $9,5(+/-7,9)$ anos, $1-34$ anos \\
\hline Idade - início das manifestações do SNC & $13,8(+/-10)$ anos, $2-43$ anos \\
\hline Tempo médio entre manifestação cutânea e do SNC & $4,3(+/-7,3)$ anos \\
\hline Pacientes com MC do SNC antes da lesão cutânea & $16 \%$ \\
\hline Pacientes com MC do SNC com 1 ano de morfeia & $29 \%$ \\
\hline ELGS & $71 \%$ \\
\hline HFP & $64 \%$ \\
\hline ELGS e HFP associado & $35 \%$ \\
\hline Lesões lado direito & $42 \%$ \\
\hline Lesões bilaterais & $10 \%$ \\
\hline Lesões craniofaciais e não craniofaciais & $18 \%$ \\
\hline Uveítes, neurite óptica/ atrofia óptica & $22 \%$ \\
\hline MC não neurológicas e oftalmológicas & $9 \%$ \\
\hline Convulsões & $73 \%$ \\
\hline Convulsões intratáveis & $-/ 33$ \\
\hline Cefaleia & $27 / 29$ \\
\hline Deficit neurológico focal & $11 / 34$ \\
\hline MC Neuropsiquiátrica & $2 / 14$ \\
\hline FAN & $26 \%$ \\
\hline Outros anticorpos & $17 \%$ \\
\hline Leucocitose & $7 / 11$ \\
\hline Bandas oligoclonais (aumento de $\lg G$ no LCR) & $7 / 11$ \\
\hline RM (49/54 pacientes) - normal & $11 \%$ \\
\hline Pequena lesão isolada & $31 \%$ \\
\hline Lesões múltiplas ou difusas & $63 \%$ \\
\hline Lesão cerebral ipsilateral a lesão cutânea & $88 \%$ \\
\hline Calcificações na TC ou RM & $37 \%$ \\
\hline Realce pelo contraste na TC ou RM & $8 / 16$ \\
\hline Sem lesões em T2, com outras anormalidades & $6 \%$ \\
\hline Repetição da TC/RM com novas lesões & $15 / 29$ \\
\hline Angio ressonância ou angiografia convencional alterada & $6 / 19$ \\
\hline EEG alterado & $24 / 29$ \\
\hline Biópsia cerebral com lesão inflamatória & $7 / 10$ \\
\hline $\begin{array}{l}\text { Efeito positivo de drogas anti-inflamatórias nas MC do } \\
\text { SNC }\end{array}$ & $11 / 15$ \\
\hline
\end{tabular}

MC: manifestações clínicas 
Temos na literatura poucas descrições de pacientes com esclerodermia craniofacial, apresentando anormalidades neurorradiológicas, assintomáticos do ponto de vista clínico neurológico. A maioria dos casos descritos com estudo de imagem inclui pacientes neurologicamente sintomáticos (Appenzeller et al., 2004; Blaszczyk et al., 2004).

\subsection{Alterações anatomopatológicas cutâneas}

A histologia da esclerodermia depende de dois fatores: o estágio da doença (inicial inflamatório e posteriormente com esclerose) e a profundidade do comprometimento. Na maioria das situações as alterações morfológicas são melhor vistas na transição entre a derme e o subcutâneo. Desta forma, a amostra de pele deve conter o tecido subcutâneo.

Nas lesões iniciais, que apresentam ainda componente eritematoso, ou seja, na fase inflamatória, a histologia não é característica de esclerodermia, sendo o diagnóstico definitivo de esclerodermia difícil de ser firmado. Nesta fase é observada presença de colágeno mais denso, homogeneizado, um pouco mais eosinofílico, principalmente ao redor de anexos e vasos. O infiltrado inflamatório linfohistiocitário com fibroblastos é perianexial e perivascular com o desaparecimento ou diminuição do coxim gorduroso perianexial. Os cordões de colágeno neoformado já podem ser observados invadindo o tecido adiposo como pseudópodes podendo estar acompanhados de infiltrado inflamatório linfohistiocitário com fibroblastos. Os vasos, tanto da derme quanto da hipoderme, podem mostrar um endotélio tumefeito com diminuição do lúmen (Fitzpatrick et al., 1987). 
Nas lesões mais tardias, a esclerodermia está instalada e não há evidência clínica de inflamação, caracteriza-se por fibrose intensa na derme, que vai substituindo o panículo adiposo, sendo o diagnóstico histológico definitivo possível. Nesta fase, o colágeno dérmico é esclerótico, isto é, eosinofílico, homogeneizado e denso, e o infiltrado inflamatório estão ausentes, ou restritos, de maneira discreta, ao redor de anexos que já se mostram atróficos. A tendência dos anexos, com a evolução da doença, é ser substituído por fibrose. Nessa fase, o conjuntivo já invade o tecido adiposo, substituindo-o em grande extensão. Os vasos da hipoderme mostram-se com a parede espessada e o lúmen significativamente diminuído. A substituição do tecido adiposo por colágeno esclerótico é melhor avaliada, quando se compara com um fragmento de pele normal contralateral. A destruição do tecido adiposo é evidenciada clinicamente pela depressão da superfície cutânea (Matsuura et al., 1997).

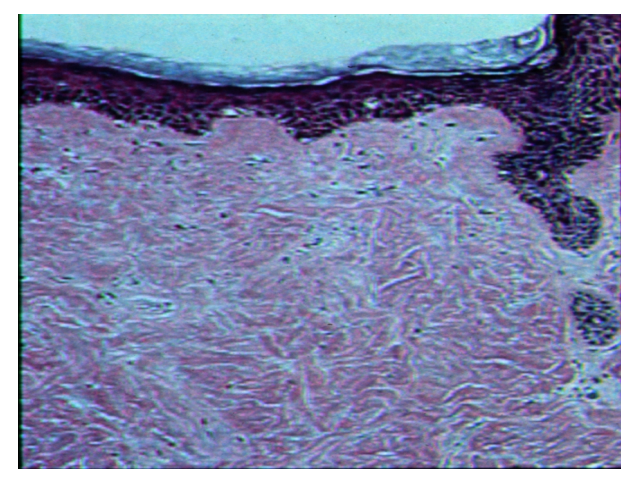

Figura 6. Histologia da esclerodermia na fase tardia

Em resumo, as lesões de esclerodermia são caracterizadas por estágio inflamatório inicial seguido por um estágio de fibrose, resultando na substituição de estruturas normais da derme e hipoderme por colágeno anormal (Fett; Werth, 2011). 
Em ambas as fases histológicas a epiderme pode estar atrófica ou retificada com ortoqueratose. À medida que o material de colágeno acumula, diminuiu o número de apêndices da pele (folículo piloso, glândulas sebáceas e sudoríparas).

O achado de inflamação e fibrose progressiva, oclusão da microvasculatura e aumento de macromoléculas no tecido conectivo (colágeno, glicosaminoglicana, tenascina e fibronectina) na amostra cutânea indicam atividade da doença.

$\mathrm{Na}$ morfeia em placa, o processo fibroso está limitado à derme, preferencialmente derme reticular. Já a esclerodermia linear, a fibrose afeta a derme, o tecido adiposo, músculo e frequentemente o osso. Na morfeia profunda, a fibrose também afeta a derme profunda, o tecido adiposo e o músculo, diferenciando-se da forma linear, por serem lesões mais difusas e não seguirem um padrão linear (Marsol, 2012). O envolvimento da fáscia é obrigatório na morfeia profunda, caracterizado pela substituição do tecido diferenciado por bandas de colágeno. A biópsia cutânea da morfeia profunda demonstra infiltrado inflamatório no endomísio e perimísio, densa esclerose do colágeno, marcada inflamação subcutânea com linfócitos e plasmócitos, sendo observado ocasionalmente formação de osso na derme profunda (Ahn et al., 1996; Julian; Bowera, 2003).

$\mathrm{Na}$ morfeia bolhosa ocorre uma alteração histológica semelhante ao LEA (Trattner et al., 1994). É atribuída esta alteração a uma obstrução linfática (Daoud et al., 1994) por esclerose ou associação com doença autoimune (Rencic et al., 2002). 


\subsection{Alterações neuropatológicas}

Achados neuropatológicos na ELGS foram reportados em poucos pacientes, na maioria deles inconsistentes, como infiltrado inflamatório perivascular (Pupilo et al., 1996; Tersteege et al., 1994) e disgenesia vascular não inflamatória (Chung et al., 1995). Os achados conflitantes são provavelmente resultantes de diferentes estágios clínicos do processo patogênico (Tersteege et al., 1994).

Chung et al. reportaram um paciente com EL e convulsões intratáveis. $\mathrm{Na}$ fase T1 da RM foi encontrada uma possível calcificação no lobo frontal esquerdo abaixo da área de lesão cutânea, envolvendo o córtex e a substância branca. Essa área foi ressecada para tratamento, encontrando-se bandas escleróticas na leptomeninge, calcificação intraparenquimatosa e ectasia dos vasos com gliose adjacente, sem evidência de inflamação, sugerindo ser uma síndrome neurocutânea. Concluíram, então, que neste caso a esclerodermia focal estava relacionada à disgenesia vascular cerebral e não encontraram evidência histopatológica sugestiva de processo inflamatório. Os autores sugeriram que esse achado representaria uma síndrome neurocutânea, de forma semelhante ao que é visto na síndrome de Sturge-Weber (Chung et al., 1995).

Outros reportaram processo inflamatório crônico com infiltrado perivascular, perda neuronal, e gliose, geralmente circunscritos (Stone et al., 2001; Obermoser et al., 2003).

Outro relato descreve um paciente com HFP com alterações semelhante a encefalite de Rasmussen, caracterizada por convulsões intratáveis, hemiparesia progressiva e alterações patológicas de encefalite crônica (Shah et al., 2003).

DeFelipe et al. reportaram um caso de SPR com epilepsia do lobo temporal intratável, e a histopatologia desta área revelou um grupo de células ectópicas, 
perda neuronal e gliose. Na microscopia eletrônica havia um aumento do número de sinapses na região do giro denteado (DeFelipe et al., 2001).

Relatos na literatura de exame histopatológico cerebral realizado para tratamento de convulsões intratáveis demonstraram alteração da arquitetura e da rede vascular do córtex cerebral e forte deposição de proteína ácida glial fibrilar (GFAP) na zona subpial, sugestivo de gliose. Na substância branca foi encontrado heterotopia de células ganglionares. Na rede vascular, havia hipertrofia e aumento das ramificações, sem sinais inflamatórios (Paprocka et al., 2006). Outros achados de vasos anormais e ectasiados foram encontrados em biópsias e estudos angiográficos, suportando a teoria de vasculopatia ou vasculite ocasionando as alterações cerebrais (Holland et al., 2006; Holl-Wieden et al., 2006; Sakai et al., 2008; Pichiecchio et al., 2002; Lederman, 1984). Foram, ainda, documentados 3 casos de biópsia com vasculite cerebral (Holland et al., 2006; Obermoser et al., 2003; Stone et al., 2001). 
Tabela 5. Achados na HFP e ELGS

\begin{tabular}{lll}
\hline Achados & Hemiatrofia Facial Progressiva & Esclerodermia em golpe de sabre
\end{tabular}

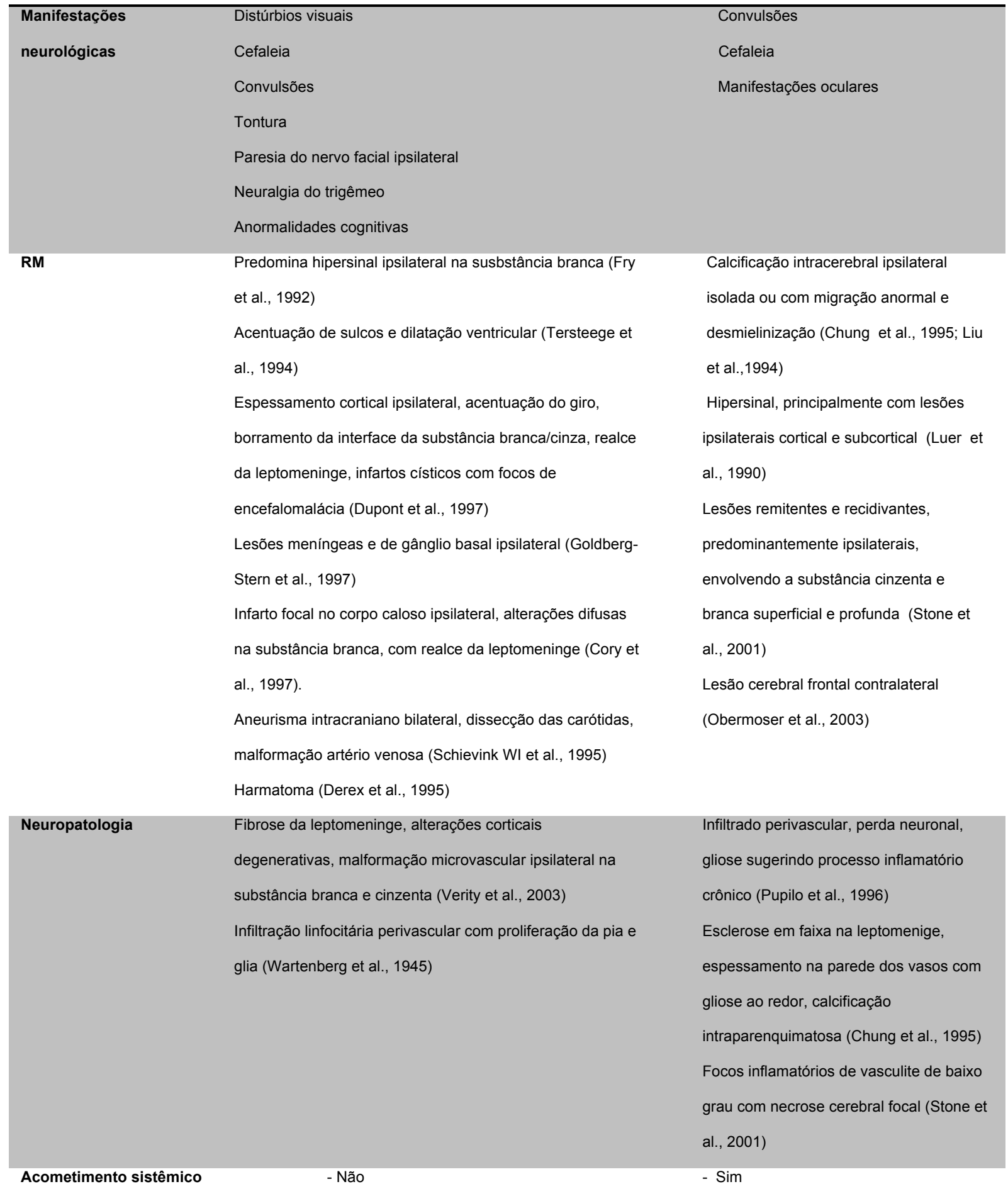




\subsection{Terapêutica}

O manejo da EL ainda é insatisfatório e raros são os estudos terapêuticos controlados e randomizados (Gambichler et al., 2001). Diferentes modalidades terapêuticas foram aventadas, incluindo o uso de medicações tópicas, agentes farmacológicos imunossupressores, fisioterapia e fototerapia (Hunzelmann et al., 1998).

O tratamento deve ser iniciado de forma precoce, antes que ocorram complicações da EL de grande morbidade que trazem limitação da movimentação e deformidades. Para iniciar ou indicar a terapêutica devemos considerar a atividade ou não da doença.

São considerados critérios de atividade da doença:

- Novas lesões nos últimos 3 meses, documentado pelo médico;

- Extensão, nos últimos 3 meses, de lesão pré existente, documentado pelo médico;

- Eritema moderado ou intenso, ou borda eritematosa;

- Lesão ou borda violácea;

- Documentação de atividade ou progressão para tecidos profundos, pelo médico, fotográfica, por RM ou por ultrassonografia (USG).

- Enduração acentuada da borda;

- Piora da perda de cabelo no couro cabeludo, sobrancelha ou cílios, documentado pelo médico;

- Aumento de CK na ausência de outra alteração;

- Biópsia cutânea demonstrando doença ativa.

Por outro lado, são parâmetros que indicam dano clínico:

- Atrofia da derme; 
- Atrofia do tecido subcutâneo;

- Hiperpigmentação;

- Hipopigmentação;

- Centro da lesão com aumento da espessura da pele.

Vários métodos de avaliação clínica foram publicados, como "score" de despigmentação, induração, eritema, telangectasias, "score" de pele modificado de Rodnan (MRSS) e índice cutâneo de severidade da EL (LoSSI) (Dytoc et al., 2004; Clements et al., 1995; Arkachaisri; Pino, 2008). Todos estes índices avaliam atividade e dano conjuntamente, baseados em parâmetros clínicos limitados. A falta de validação para critérios de resposta ao tratamento limita a habilidade dos clínicos de realizarem julgamentos sobre a eficácia dos tratamentos.

Não existe consenso sobre o tratamento da EL e uma variedade de estratégias terapêuticas têm sido propostas. As maiorias dos estudos são de série de casos, com poucos estudos comparativos ou placebo controlados (Chung et al., 2006; Fett et al. part II, 2011; Vilela et al., 2010). De acordo com estudo realizado por Li et al., nos Estados Unidos e Canadá, em 2012, reumatologistas pediátricos tratam morfeia em placa circunscrita superficial com MTX ou corticoesteroide sistêmico; já dermatologistas, comumente, prescrevem agentes tópicos e fototerapia (Weibel et al., 2006; Fett et al. part II, 2011; Li et al., 2010; Zulian et al., 2011; Uziel et al., 2000; Zwischenberger; Jacobe, 2011).

Algumas opções terapêuticas são propostas para EL: d-penicilamina, vitamina D tópica ou oral, fotoquimioterapia com psoralênico e UVA, fenitoína, corticoesteroides, metotrexato, ciclosporina e interferon (Cunningham et al., 1998; Hulshof et al., 2000; Elst et al., 1999; Higashi et al., 2000). 
A respeito do tratamento tópico, que deve ser limitado a formas mais superficiais e limitadas de morfeia, como a morfeia em placas, estão disponíveis várias opções.

$\mathrm{Na}$ fase inicial, mais inflamatória, recomenda-se o uso de corticoesteroides tópicos de alta potência. Porém, não há nenhum estudo que tenha demonstrado a eficácia real desta terapêutica (Fett; Werth, 2011).

Existe um estudo piloto, controlado, com tacrolimus tópico, que incluiu 10 pacientes com morfeia em placa, demonstrando eficácia (Kroft et al., 2009). O uso de imiquimod tópico 3 vezes por semana foi demonstrado eficaz em reduzir o eritema e o endurecimento das placas de morfeia em um estudo com 12 pacientes e um relato de 2 casos (Dytoc et al., 2005; Campione et al., 2009). A associação de calcipotriol à betametasona tópica foi demonstrada eficaz em um estudo prospectivo de 6 pacientes com morfeia em placas (Dytoc et al., 2007).

Em um estudo não controlado, foi observado que a esclerodermia na infância pode ser tratada com calcipotriol tópico e baixa dose de fototerapia UVA com sucesso (Kreuter et al., 2001).

$\mathrm{Li}$ et al. estabeleceram o consenso de plano para tratamento (CTPs) na EL moderada a severa para os primeiros 12 meses de atividade. Baseado em evidências científicas, especifica o uso somente de MTX ou com corticoterapia administrada EV ou oral, sendo o micofenolato mofetil (MMF) como opção nos pacientes intolerantes ao MTX ou que falharam em responder a ele (Martini G et al., 2000). Este consenso baseou-se em índices de atividade, dano e eficácia de tratamento. Foi guiado pelos membros do CARRA (Aliança de Pesquisa Reumatológica e de Artrite na Infância) (Li et al., 2012).

Assim o MTX pode ser usado isoladamente ou em associação com corticoterapia via oral ou injetável (Seyger et al., 1998; Kreuter et al., 2005; Uziel et 
al., 2000; Weibel et al., 2006; Fitch et al., 2006; Cox et al., 2008; Kroft et al., 2009). A dose preconizada é de $1 \mathrm{mg} / \mathrm{kg} / \mathrm{semana}$, via $\mathrm{SC}$, com dose máxima de 25mg/semana, suplementando ácido fólico $0,4-1 \mathrm{mg} / \mathrm{dia}$ ou $5 \mathrm{mg}$ semanalmente ( $\mathrm{Li}$ et al., 2010).

A maioria dos estudos descreve uma melhora de $80 \%$ com este esquema terapêutico (Seyger et al., 1998; Kreuter et al., 2005). Os resultados foram semelhantes nos pacientes tratados com MTX e corticosteroide comparado ao uso de MTX isoladamente. O uso de corticosteroide isolado é eficaz, porém o risco de recaída é maior (Joly et al., 1994).

A taxa de recorrência varia de $28-44 \%$ em $16-20$ meses depois da suspensão do MTX e nos adultos com início da doença na infância em torno de 59\% (Weibel et al., 2006; Mirsky et al., 2012; Saxton-Daniels; Jacobe, 2010). A doença ativa continuamente foi reportada em $30 \%$ dos adultos com início na infância de EL (Saxton-Daniels; Jacobe, 2010) e em 20\% dos pacientes com EL de início após os 20 anos (Peterson et al., 1997).

Baseado na utilização na ES, outros imunossupressores são utilizados na morfeia, como a D-penicilamina, que é pouco recomendada por seu pobre perfil de segurança. A ciclosporina e a fotoférese extracorpórea possui relatos isolados (Crespo et al., 2009; Neustadter et al., 2009; Schlaak et al., 2008). Também tem sido descrito em casos de morfeia generalizada melhora significativa com infliximab (antiTNF) (Diab et al., 2010) e imatinib (inibidor da atividade da tirosina cinase) (Moinzadeh et al., 2010).

Outra opção terapêutica é a utilização de técnicas de cirurgia plástica e fisiatria. A fisioterapia nos pacientes com sequela de morfeia, apresentando limitações de mobilidade das extremidades e contraturas articulares, não existindo estudos que demonstrem sua utilidade real. De qualquer forma, parece não 
exacerbar a enfermidade, portanto, podendo ser utilizada em casos indicados (Fett; Werth part II, 2011).

Entretanto, o manejo da atrofia facial é desafiador. A reconstrução cirúrgica paliativa é potencialmente benéfica nos casos de atrofia facial desfigurante. $O$ emprego da imagem tridimensional pode ser útil para o pré-operatório da cirurgia de reconstrução cirúrgica óssea (Inigo et al., 2000).

A radiação ultravioleta constitui uma opção que pode ser considerada para o tratamento da morfeia. Como opção temos a luz ultravioleta A (UVA) de banda larga associado ou não a psoralênico, UVA1 e UVB de banda estreita. O mecanismo que poderia trazer um benefício na morfeia é desconhecido. A maior parte dos estudos referem se ao UVA1. O UVA1 é capaz de ocasionar apoptose das células de Langerhans e linfócitos T, diminuindo a síntese de colágeno, aumenta a produção de colagenase e altera a concentração local de citocinas como a IL-6, o fator transformador de crescimento beta (TGF $\beta$ ) e interferon gama, influenciando na produção de colágeno e glicosaminoglicanos, crescimento de fibroblastos e quantidade de metaloproteinases na matriz (Morita et al., 2000; El-Mofty et al., 2004).

Foi descrita uma eficácia de $90 \%$ com uso de UVA1, principalmente para fase mais fibrótica, ou seja, a fase tardia da morfeia. Sendo pouco útil nos pacientes com doença agressiva, rápida em sua evolução, que afeta o subcutâneo e músculo (Kreuter et al., 2007; Kreuter et al., 2005; Kreuter et al., 2008). As principais dificuldades no seu uso são: pouca disponibilidade para uso por seu aparato especial necessário para sua administração, tempo prolongado de exposição (entre 30 a 60 minutos, 3 vezes por semana) e ação menos eficaz em fototipos mais altos (Wang et al., 2008). 
A experiência com UVA de banda larga, associado ou não com psoralênicos é muito menor. É descrita melhora clínica de $80 \%$ dos pacientes tratados (Kerscher et al., 1996; El-Mofty et al., 2004; Usmani et al., 2008). Alguns autores sugerem que o tratamento com PUVA (psoralênico tópico e UVA), pode ser útil na fase inflamatória inicial da morfeia (Kreuter et al., 2007). Experiência é menor com UVB de banda estreita, cuja eficácia é referida na maioria das vezes em casos isolados, existindo poucos estudos controlados (Kreuter et al., 2006).

A morfeia pode apresentar tendência a progredir e recorrer, em especial quando inicia na infância (Saxton-Daniels; Jacobe, 2010). No entanto, a EL classicamente apresenta um curso autolimitado com tendência à regressão espontânea após 3 a 5 anos (Christianson et al., 1956). A variante em placas raramente progride para formas generalizadas ou mesmo debilitantes. Porém, a incerteza quanto ao grau de progressão do acometimento de lesões de esclerodermia na face demandam pronta intervenção terapêutica quando na presença de lesões nesta topografia, a fim de evitar lesão de órgãos ou estruturas internas e grave comprometimento estético. Da mesma forma, as variantes ELGS e SPR devem sempre ser tratadas de forma precoce e intensiva, procurando minimizar sequelas futuras. Não é incomum em um mesmo paciente a administração de diversas terapêuticas ao longo de sua vida (Marsol, 2012).

Nos relatos de tratamentos a associação de MTX ou MMF e esteroides parece ter um impacto no controle do tratamento de convulsões refratárias e estabilização do dano no SNC (Kister et al., 2008; David et al., 1991; Paprocka et al., 2006; Fain et al., 2011; Satori et al., 2009). 
Tabela 6. Algoritmo terapêutico da EL (Kreuter et al., 2007; Fett; Werth, 2011)

Morfeia em placas

(tratamento tópico)

Corticosteroides

tópicos (fase

inflamatória inicial)

Sem resposta em

4-8 semanas

Tacrolimus tópico

Sem resposta em

4-8 semanas

Calcipotriol + betametasona ou imiquimod

ou PUVA (creme)/ UVA1

(40 sessões, 3-5 $\mathrm{x} /$ semana)
Morfeia generalizada

(sem contraturas articulares)

Fototerapia PUVA (creme)/

UVA1 (40 sessões, 3-5 x/semana)

UVB banda estreita

Sem resposta em

4-8 semanas

MTX: 15-25mg/semana + Metilprednisolona (30mg/K x

3 dias mensal, 6 bolus)/

Prednisona $0,5-1 \mathrm{mg} / \mathrm{kg} / \mathrm{dia}$

Sem resposta

Micofenolato mofetil
Morfeia linear

(face e extremidades com possibilidade de contraturas)

MTX: 15-25 mg/semana + Prednisona 0,5-1 mg/kg/dia Metilprednisolona (30mg/K x 3 dias mensal, 6 bolus)

Sem resposta

Micofenolato mofetil

Sem resposta

Fototerapia PUVA (creme)/ UVA1

(40 sessões, 3-5 x/semana)

UVB banda estreita

\subsection{0 estudo}

Com base nestas observações, realizamos um estudo em pacientes com ELF a fim de avaliar os dados demográficos, as manifestações neurológicas e oftalmológicas, sua correlação com a atividade cutânea e o espectro de alterações laboratoriais associadas. Após 3 anos de seguimento, os exames de RM foram repetidos num subgrupo de pacientes disponíveis para seguimento a fim de identificar a evolução dos achados radiológicos. 
1. Determinar os achados neurológicos da RM de crânio, dos pacientes com esclerodermia da face, após 3 anos da realização do primeiro exame radiológico e a sua relação com a atividade cutânea.

2. Avaliar os dados demográficos, a presença de doenças autoimunes e alterações laboratoriais em pacientes com ELGS, SPR e esclerodermia em placas da face.

3. Avaliar a presença de alterações neurológicas, oftalmológicas e achados de RM de crânio, em pacientes com esclerodermia da face.

4. Determinar a associação dos achados de RM de crânio nos pacientes portadores de esclerodermia da face com suas manifestações clínicas neurológicas. 
4 Métodos 


\subsection{Seleção de Pacientes}

O estudo foi aprovado pelo Comitê de Ética do HCFMUSP (CAPPesq Comissão de ética para análise de projetos de pesquisa- protocolo 0059/09).

No período compreendido entre agosto de 2009 e agosto de 2012, foram selecionados 34 pacientes provenientes do Ambulatório de Colagenoses do Departamento de Dermatologia do Hospital das Clínicas da Faculdade de Medicina da Universidade de São Paulo. Todos os pacientes assinaram e concordaram com o termo de consentimento livre e informado.

Os pacientes deveriam apresentar EL com acometimento da face, como critério de inclusão. Foram incluídos no levantamento todos os pacientes com diagnóstico de ELGS, HFP, esclerodermia em placa, bolhosa, generalizada e profunda acometendo qualquer região facial, com ou sem extensão das lesões para a região cervical ou do couro cabeludo, denominando-os como portadores de esclerodermia localizada na face (ELF). Todos pacientes foram diagnosticados clinicamente e biópsia cutânea foi realizada nos casos de dúvida diagnóstica. O diagnóstico foi baseado na presença de lesão bem delimitada esclerótica ou atrófica, única ou múltipla, acometendo a face. Os casos podiam apresentar ou não lesões de esclerodermia em outros segmentos corporais.

Em todos os casos foi realizada revisão dos prontuários e todos os pacientes foram submetidos a exame de ressonância magnética (RM) de crânio, avaliação clínica neurológica e oftalmológica, além da coleta de exames de sangue laboratoriais e seguimento clínico através de avaliações ambulatoriais periódicas.

Os critérios de exclusão previamente estabelecidos no estudo foram:

$>$ Casos de ES ou síndrome overlap; 
> Pacientes com contraindicação ao exame de RM como clips de aneurismas, marca-passos ou próteses otológicas ;

> História de alergia ao gadolínio;

- História de claustrofobia;

> Gravidez;

$>$ Lactação e

> Falta de compreensão ou adesão dos pacientes ao protocolo utilizado.

\subsection{Protocolo de Investigação}

Em 2009 realizamos estudo piloto, projeto $n^{\circ}$ 0059/09, aprovado pela CAPPesq no qual foram incluídos 19 pacientes com diagnóstico de esclerodermia da face, em seguimento no Ambulatório de Colagenoses do Departamento de Dermatologia do Hospital das Clínicas da FMUSP. Todos os 19 pacientes foram clinicamente examinados e seus prontuários revisados. Os pacientes foram convocados para realização de exame de RM de crânio e exame oftalmológico completo.

O afilamento do tecido subcutâneo estava presente em $42 \%$ pacientes e depressão da calota estava presente em 15,8\% destes casos. Neste estudo, identificamos a presença de hipossinal e/ou hipersinal em T1, T2 e FLAIR como alteração de SNC mais frequente, encontrada em $42 \%$ dos pacientes avaliados. Os achados incluíram dilatação ventricular, gliose, calcificações, microangiopatia do SNC, amígdala cerebelar baixa e anormalidade vascular insular. $\mathrm{O}$ antecedente de convulsão e outros sintomas neurológicos foram ausentes em todos os pacientes. As alterações cerebrais na RM foram ipsilaterais à lesão cutânea da esclerodermia em $64 \%$ dos pacientes e não houve relação com o local da lesão cutânea em 36\%. Em 42\% dos 
pacientes foi evidenciada alteração ocular. Em 36,8\% dos doentes foram encontradas diferentes anormalidades de glândulas anexiais, incluindo blefarite e olho seco. O achado de ceratite punctata foi encontrado em $31,6 \%$ dos pacientes.

Devido à significância dos achados encontrados, propusemos aumento da casuística, com minuciosa avaliação neurológica e oftalmológica dos pacientes e seu seguimento, para melhor compreendermos a complexidade desta doença, suas manifestações extracutâneas e sua evolução após 3 anos.

Para identificação dos pacientes acometidos pela doença em acompanhamento no Ambulatório de Colagenoses do Departamento de Dermatologia do HCFMUSP, inicialmente levantamos os prontuários de todos os doentes designados com o diagnóstico de EL. Trinta e quatro pacientes apresentavam diagnóstico de esclerodermia com acometimento da face. Foram levantados dados demográficos como sexo, idade, início do quadro, atividade da doença, manifestações extracutâneas, clínicas e laboratoriais, bem como tipo e duração do tratamento instituído.

Os pacientes foram submetidos à avaliação do subtipo clínico pelos Critérios da Classificação da Clínica Mayo, denominando os como morfeia em placa, generalizada, bolhosa, esclerodermia linear (Golpe de Sabre ou síndrome de Parry Romberg) e morfeia profunda.

A atividade da doença foi avaliada considerando a progressão da extensão e/ou atrofia/esclerose das lesões, presença de anel lilás nos casos de esclerodermia em placas e surgimento de novas lesões de esclerodermia em qualquer segmento corpóreo. 


\subsection{Avaliação por Imagem}

O exame de RM de crânio foi realizado em aparelhos de 1,5 ou 3,0 Teslas. Conforme protocolo: imagens axiais pesadas em difusão, imagens axiais pesadas em T2, imagens axiais gradiente eco $\left(\mathrm{T}^{*}\right)$, imagens coronais pesadas em $\mathrm{T} 2$, imagens axiais pesadas em FLAIR (Fluid attenuated inversion recovery), imagens volumétricas pós-contraste (após a injeção de gadolíneo na dosagem de $0,1 \mathrm{mMOL} / \mathrm{Kg})$.

O exame de RM de crânio foi realizado inicialmente e após três anos, para acompanhar a evolução e permanência ou não das alterações encontradas, devido à existência de relatos na literatura de que anormalidades dos exames de RM geralmente estão correlacionadas com a progressão clinica da esclerodermia da face (Ramboer et al., 1997). Como a fase de atividade da doença geralmente dura cerca de 2 a 5 anos (Chazen et al., 1962), considerando esse período, optamos pela repetição da RM do crânio com intervalo de 3 anos.

Todas as imagens foram avaliadas e interpretadas pela mesma médica neurorradiologista (CCL) com 20 anos de experiência.

\subsection{Avaliação Clínico Neurológica}

Os pacientes foram convocados para avaliação clínica neurológica completa, durante o seguimento, após a realização da RM do crânio, executada pelo mesmo examinador, médico neurologista do Ambulatório de Neurologia do Instituto da Criança do HCFMUSP. 
Foi realizada anamnese e "Exame Neurológico do Adulto", padronizado pelo Departamento de Neurologia do Hospital das Clínicas da Faculdade de Medicina da Universidade de São Paulo (Julião, 1969).

Foi ainda utilizado para os pacientes maiores de 16 anos:

1. O Mini Exame do Estado Mental (validado para a população brasileira) (Folstein et al., 1975), que avalia a orientação, memória, atenção, memória operacional, evocação verbal, compreensão, praxia e nominação. A pontuação pode variar de 0 a 30 . O ponto de corte médio é 26 , sendo que para analfabetos este ponto é 13-20, para pessoas com o ensino fundamental apenas é de 18. Notas menores que 10 representam comprometimento grave, entre 10 e 15 comprometimento moderado e entre 15 e 26 comprometimento leve (Brucki SM et al., 2003).

2. Teste com Desenho de Relógio (Sunderland et al., 1989), avalia aspectos verbais e não verbais, compreensão verbal, planejamento, memória visual, habilidade visuo-espacial, programação e execução motoras, conhecimento de numerais e pensamento abstrato. A sua pontuação varia entre 1 e 10 , indicando normalidade entre 9 e 10, comprometimento leve entre 5 e 8 , moderado entre 3 e 4 e grave entre 1 e 2 .

3. Teste de Fluência Verbal Semântica, com contagem de animais nomeados no período de um minuto, sendo o valor de corte $<13$ para maiores de 8 anos de escolaridade e 9 para os indivíduos com até 8 anos de escolaridade (Brucki et al., 2003).

4. Teste de Memorização de Figuras, com a memorização de dez figuras identificadas, avaliação da percepção visual e memória incidental, memória imediata, memória pós-latência de cinco, quinze e trinta minutos e o reconhecimento 
e memória para fatos remotos. A pontuação de corte em alfabetizados ou analfabetos para a percepção visual é 9, para a memória incidental é cinco, para a evocação tardia de 5 minutos é seis, para a evocação tardia de quinze minutos é 5 e para o reconhecimento é 9 (Nitrini et al., 1994).

5. Teste de Repetição de Dígitos na Ordem Direta e Indireta (Digit Spam Test) avalia a atenção, memória imediata, memória verbal e operacional, utilizando sete séries diretas e cinco indiretas. A nota de corte direta é 5 e a indireta é 3 (Conn, 1977).

Nos pacientes que eram crianças (menores que 16 anos), estes testes acima não são válidos e, portanto não foram aplicados a esta faixa etária.

\subsection{Avaliação Oftalmológica}

Todos os pacientes foram convocados para avaliação com o mesmo examinador, médico oftalmologista do Ambulatório de Oftalmologia do HCFMUSP.

Os pacientes foram submetidos à avaliação oftalmológica completa, incluindo:

$>$ Exame de fundo de olho,

> Medida da pressão intraocular,

$>$ Tonometria,

$>$ Teste de Shirmer e rosa bengala,

$>$ Reflexo pupilar,

$>$ Motilidade ocular,

$>$ Biomicroscopia,

$>$ Paquimetria corneana. 
Todos os pacientes foram avaliados após a realização da RM de crânio.

\subsection{Avaliação Laboratorial}

Todos os pacientes foram convocados para realização de dosagem sérica de fator anti núcleo (FAN), fator reumatoide e Scl-70 durante o seguimento, com o objetivo de pesquisar a presença atividade inflamatória (Garcia et al., 1995). A prevalência de FAN e FR foi demonstrada significantemente maior nos pacientes com EL e envolvimento extracutâneo do que naqueles com somente envolvimento cutâneo, em detrimento dos demais anticorpos (Zulian et al., 2005), por esse motivo, optamos por realizar em nossos pacientes a dosagem sérica de FAN e FR com objetivo de documentar esses achados. E dosamos também Scl-70, que é um marcador para ES, para auxiliar na exclusão desta hipótese em nossos pacientes.

O exame de FAN Hep2, foi dosado no sangue pela técnica de imunofluorescência indireta, considerado positivo quando título de 1:160 ou maior.

A dosagem sérica do FR, pela técnica de nefelometria, foi considerada negativa quando menor que $20 \mathrm{Ul} / \mathrm{ml}$.

O exame do anticorpo anti-Scl 70 (anti-topoisomerase I), foi dosado no sangue pela técnica de Elisa, considerado como reagente ou não reagente. 


\subsection{Outros achados}

Foi realizado extenso levantamento dos prontuários na busca de identificação de doenças associadas, comorbidades e outras alterações laboratoriais presentes, além de pesquisa ativa durante o seguimento ambulatorial dos pacientes.

\subsection{Análise Estatística}

A estatística descritiva foi usada para reportar dados demográficos, clínicos laboratoriais.

O teste estatístico utilizado foi o teste exato de Fisher para verificar a associação entre as medidas qualitativas. Este teste é adequado quando as variáveis analisadas são qualitativas e obtidas do mesmo individuo. A forma adequada de apresentar as informações é através de tabelas de contingência. Este teste é indicado quando o tamanho da amostra é pequeno e desse modo os valores observados em cada célula da tabela são pequenos (Pagano; Gauvreau, 2011). 
5 Resultados 


\subsection{Pacientes}

Os achados demográficos e clínicos: de agosto de 2009 a agosto de 2012, foram estudados 34 pacientes provenientes do Ambulatório de Colagenoses do Departamento de Dermatologia do Hospital das Clínicas da Faculdade de Medicina da Universidade de São Paulo. Do total, 12 pacientes (35,3\%) apresentavam apenas envolvimento cutâneo, e 22 pacientes $(64,7 \%)$ apresentavam uma ou mais manifestações extracutâneas. Dezoito pacientes (52,9\%) apresentavam mais de uma manifestação extracutânea e 4 pacientes $(11,8 \%)$ apresentavam apenas um acometimento.

As características clínicas dos dois grupos estão sumarizadas na Tabela 7.

Do total dos 34 pacientes, 21 pertenciam ao sexo feminino $(61,8 \%)$ e 13 ao sexo masculino $(38,2 \%)$. As idades variaram entre 03 a 55 anos, com média de 24,5 anos.

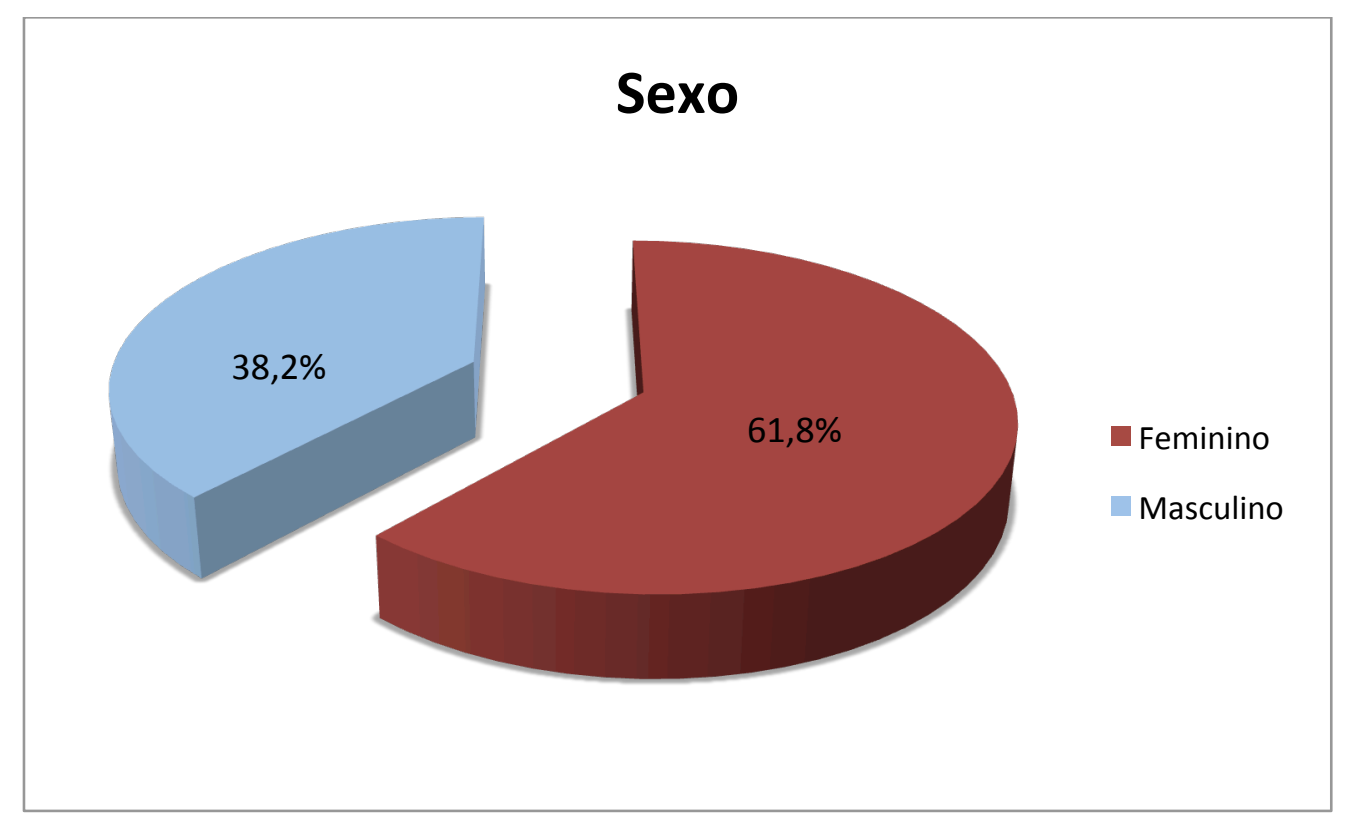

Figura 7. Gráfico da distribuição por sexo (percentual) 
A idade de início da doença variou de 2 a 51 anos, com idade média de 16,5 anos.

A duração da doença previamente ao primeiro exame de RM realizado variou de 1 a 26 anos, com média de 9 anos.

A duração do seguimento dos pacientes variou de 1 a 22 anos, com média de 6,7 anos.

Do total de pacientes, 29 apresentavam lesões localizadas na fronte. Dos 29 pacientes, 25 foram classificados como ELGS e 4 como SPR. Os 5 pacientes restantes apresentavam lesão em placa na região mandibular, mentoniana ou malar, sem caracterizar SPR ou ELGS. Foram incluídos outros pacientes com lesões na face, como na região mandibular, malar, mento e mandibular associada ao mento.

Não houve diferença em relação ao lado de acometimento da fronte, pois os pacientes apresentavam lesão cutânea localizadas na fronte direita $(n=13)$, esquerda $(n=13)$ e medial $(n=10)$. Alguns pacientes apresentavam lesões mediais, que estendiam para fronte direita ou esquerda, tendo sido também considerados como lesões mediais. Um paciente seguido por nós foi classificado como portador de lesões bilineares e 04 foram classificados com lesões trilineares. Foram considerados pacientes como bilinear, quando estes apresentavam 2 bandas escleróticas distintas acometendo a fronte e trilinear quando esse número correspondia a 3 lesões.

Vinte e nove $(85,3 \%)$ dos pacientes apresentavam lesões em outras áreas que não na região frontal. Foram encontradas as seguintes regiões acometidas (exceto fronte): couro cabeludo, mandibular, mento, mão, pé, membro inferior e superior, gengiva, língua, tronco, região cervical, região nasal e nádega. Quatro pacientes apresentavam lesões intraorais, sendo 3 com acometimento da gengiva e 
um da língua. $27(79,4 \%)$ pacientes apresentavam apenas esclerodermia acometendo a região da face.

Todos pacientes possuíam o diagnóstico de esclerodermia localizada na face (ELF), ou seja, lesões de esclerodermia acometendo a face. Pela Classificação de Peterson da Clínica Mayo (Peterson et al., 1995) utilizada: 25 (73,5\%) pacientes se enquadravam no diagnóstico de ELGS, 4 casos foram classificados como HFP $(11,8 \%)$ e 5 pacientes com morfeia em placas da face $(14,7 \%)$. Cinco pacientes apresentavam lesões extrafaciais, caracterizadas como morfeia em placas. Dois desses pacientes também apresentavam o diagnóstico de morfeia profunda, com acometimento do membro inferior (MMII). Nenhum caso de morfeia bolhosa ou generalizada foi identificado.

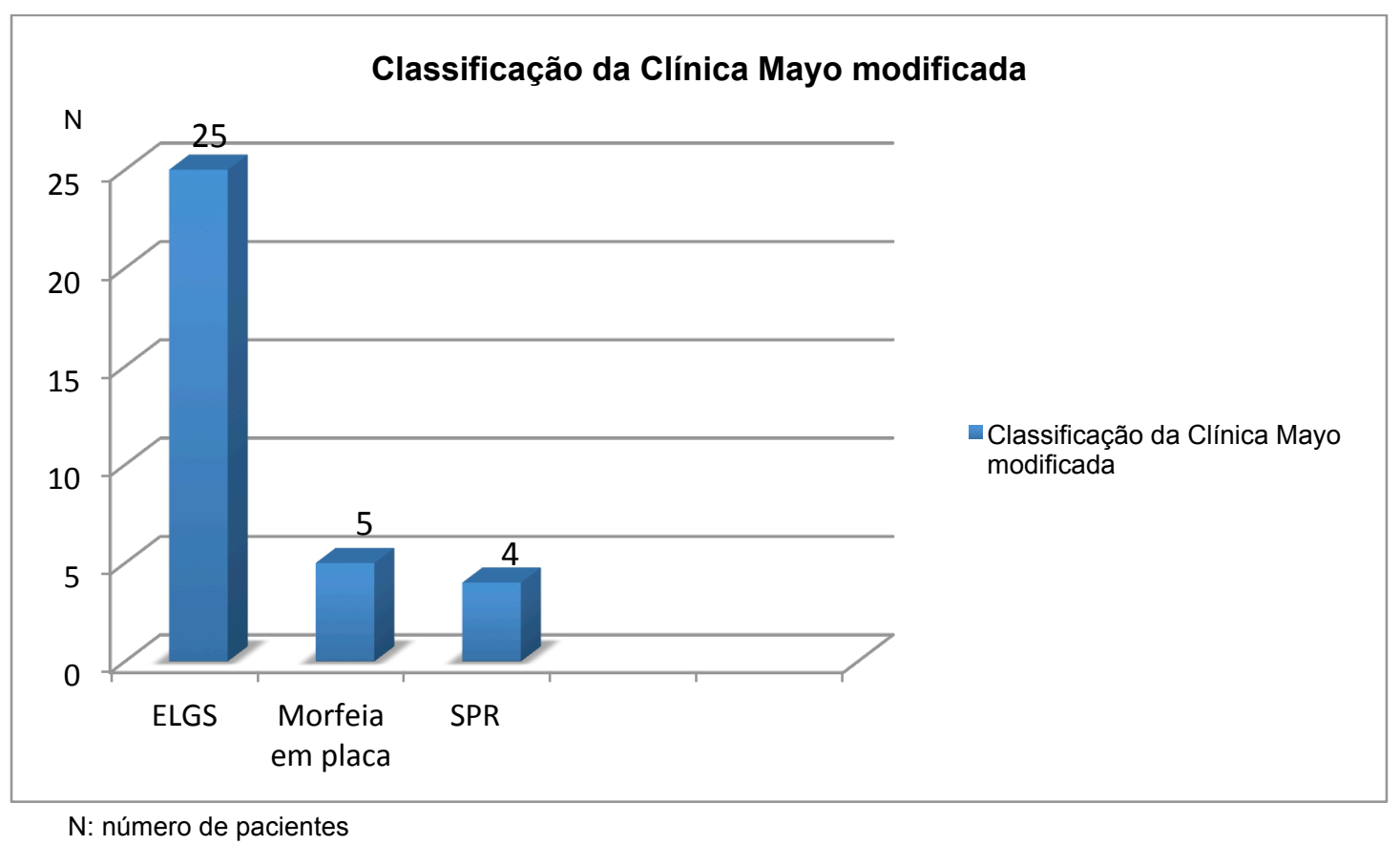

Figura 8. Gráfico da Classificação Clínica dos pacientes com ELF segundo a Clínica Mayo modificada

Doze pacientes (35,3\%) apresentaram atividade da doença durante o período de seguimento ambulatorial, com indicação de tratamento com imunossupressores. 
A duração destes tratamentos foi entre 1 e 2 anos, com duração média de 1,2 anos. As medidas terapêuticas incluíram metotrexato (MTX), prednisona e D penicilamina. O MTX foi indicado em $10(29,4 \%)$ pacientes. Dois $(5,9 \%)$ pacientes receberam prednisona via oral e dois $(5,9 \%) \mathrm{D}$ penicilamina.

Cerca de $11(32,3 \%)$ pacientes foram submetidos à correção cirúrgica da lesão. Sendo $7(63,6 \%)$ deles antes da realização da RM, $3(27,3 \%)$ após e $1(9 \%)$ antes e após a realização da RM do crânio. Os pacientes foram submetidos à correção pela técnica de fuso $(n=2)$, na qual é realizada a exérese da área acometida ou parte dela de uma forma fusiforme, sendo as pontas agudas, permitindo diminuição percentual da área da lesão. Outra abordagem foi a lipoenxertia $(n=6)$, na qual gordura autóloga é retirada de uma área doadora (abdome ou flanco) e colocada na área deprimida, com o objetivo de diminuir a profundidade da lesão. Três casos realizaram a lipoenxertia e exérese em fuso da mesma lesão cutânea. 
Tabela 7. Cálculo das estatísticas para as variáveis quantitativas separadamente dos resultados da evolução clínica

\begin{tabular}{|c|c|c|c|c|c|}
\hline & \multirow[b]{2}{*}{ Atividade } & \multirow[b]{2}{*}{$\mathrm{N}^{\circ}$ Pacientes } & \multirow[b]{2}{*}{ Média (DP) } & \multicolumn{2}{|c|}{$\begin{array}{c}\text { Intervalo de confiança para } \\
\text { média }\end{array}$} \\
\hline & & & & Limite inferior & $\begin{array}{l}\text { Limite } \\
\text { superior }\end{array}$ \\
\hline Duração & Presente & 29 & $9,38(6,45)$ & 6,93 & 11,83 \\
\hline da & Ausente & 5 & $6,6(6,465)$ & $-1,43$ & 14,63 \\
\hline doença & Total & 34 & $8,97(6,431)$ & 6,73 & 11,21 \\
\hline Duração & Presente & 29 & $0,31(0,541)$ & 0,10 & 0,52 \\
\hline do & Ausente & 5 & $1,00(0,707)$ & 0,12 & 1,88 \\
\hline tratamento & Total & 34 & $0,41(0,609)$ & 0,20 & 0,62 \\
\hline Duração & Presente & 29 & $7,10(4,776)$ & 5,29 & 8,92 \\
\hline do & Ausente & 5 & $4,60(1,342)$ & 2,93 & 6,27 \\
\hline seguimento & Total & 34 & $6,74(4,515)$ & 5,16 & 8,31 \\
\hline
\end{tabular}

$\mathrm{N}^{\circ}$ : número de pacientes, DP: desvio padrão

\subsection{Avaliação por imagem}

Em apenas 3 casos $(8,8 \%)$ na RM de crânio não foi encontrada nenhuma alteração. O achado mais frequente foi a presença de lesão cutânea identificada na RM, em 27 (79,4\%) dos exames (Figura 9). 


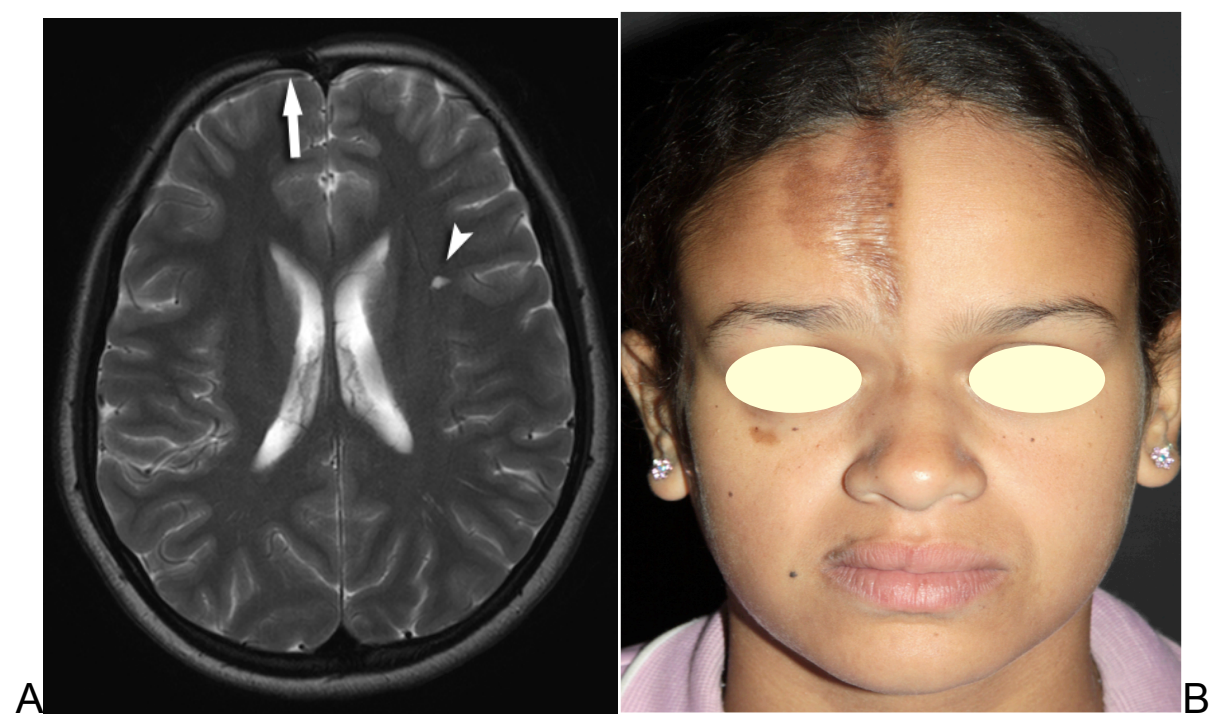

Figura 9. A) Imagem axial pesada em T2 demonstra afilamento ósseo e do tecido celular subcutâneo na região frontal paramediano à direita (SETA). Note ainda foco de hipersinal à esquerda (cabeça de seta); B) Foto clínica da paciente com lesão escleroatrófica, pigmentada, deprimida paramediana à direita (PACIENTE 6).

O segundo achado mais frequente foram lesões parenquimatosas com alteração de sinal na RM, em 17 pacientes (50\%). Focos com hipersinal em T2 na substância branca estavam presentes em 12 (70,6\%) dos pacientes com lesão intraparenquimatosa (Figura 10), 5 apresentavam lesões com hipossinal em T2 (Figura 11) e 2 pacientes apresentavam tanto lesões com hipersinal como lesões com hipossinal, sendo que lesões com hipersinal em 1 paciente correspondia a focos na substância branca e em 1 paciente à cistos parenquimatosos. Um dos pacientes tinha lesões com hipersinal em T2 córtico-subcorticais correspondendo a um aspecto sequelar de origem vascular (Figura 12). Apenas um paciente apresentava lesões com hipersinal em T1. Lesões sugestivas de calcificação intracerebral ou conteúdo de produtos de degradação da hemoglobinahemossiderina (hipossinal em T2*) foram encontrados em 5 pacientes $(29,4 \%)$. Portanto, o encontro de lesões na substância branca com hipersinal em T2 foi o achado intraparenquimatoso mais frequente. 

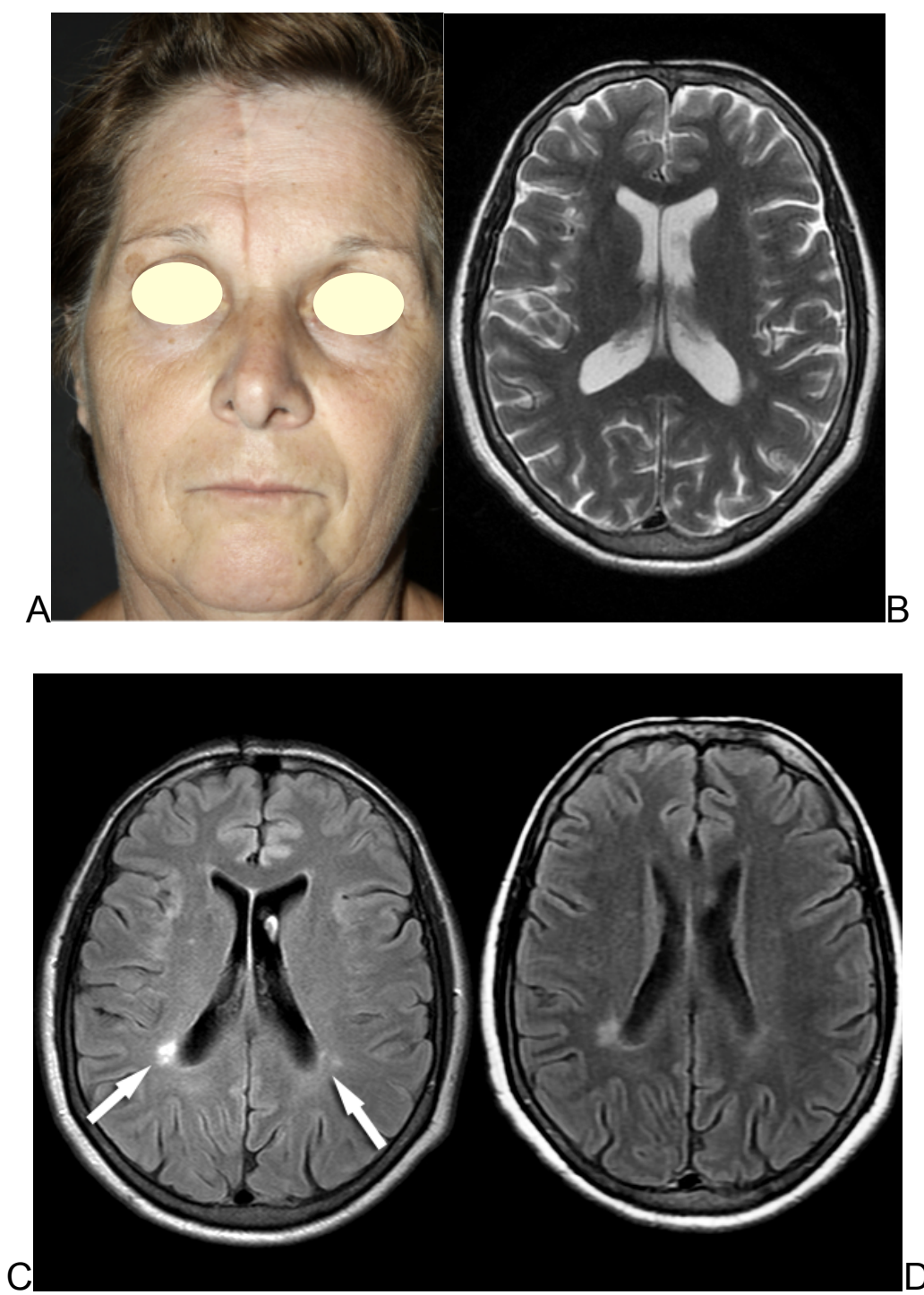

Figura 10. A) - Foto clínica da paciente com lesão escleroatrófica, linear, levemente deprimida na fronte paramediana direita (PACIENTE 30); B) Imagem axial pesada em T2 em corte inferior à D demonstra a assimetria dos ventrículos laterais, sendo ligeiramente maior o esquerdo; C) Imagem axial pesada em FLAIR demonstra lesões periventriculares com hipersinal (SETAS); D) Imagem axial FLAIR realizada 3 anos após não demonstra alterações significativas. 


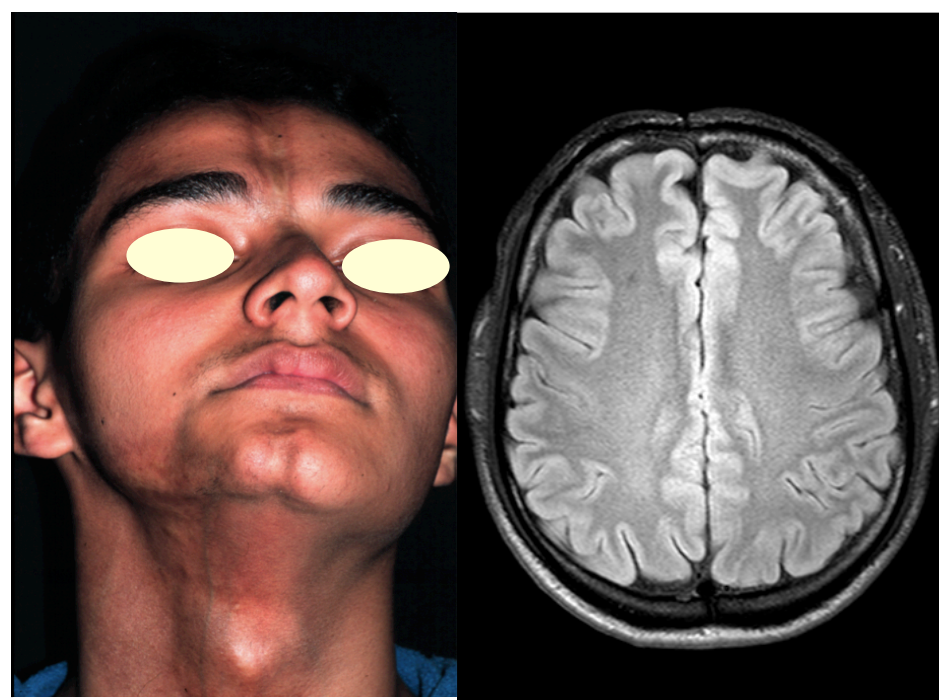

A

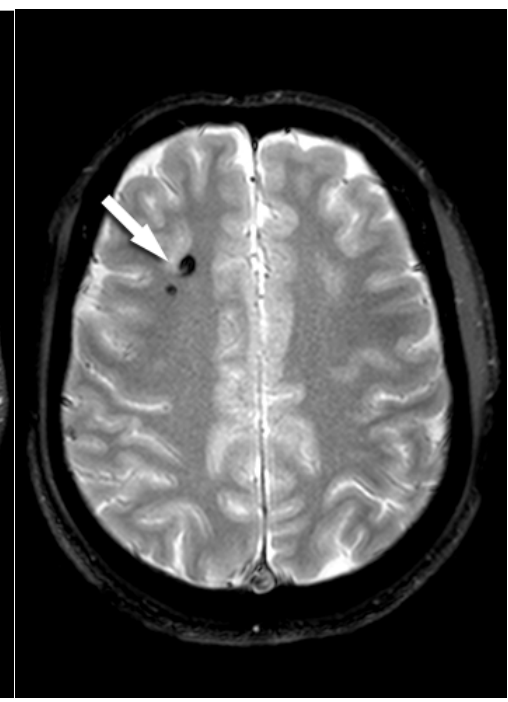

C

Figura. 11 A) Foto clínica do paciente com lesão escleróatrófica, pigmentada, deprimida na fronte paramediana direita, mento e submandibular (PACIENTE 24); B) e C) Imagem axial pesada em FLAIR (B) e imagem axial pesada em T2 (C) demonstram duas lesões focais com marcado hipossinal (SETA), que podem corresponder a calcificação ou hemossiderina e são melhor identificadas em T2.

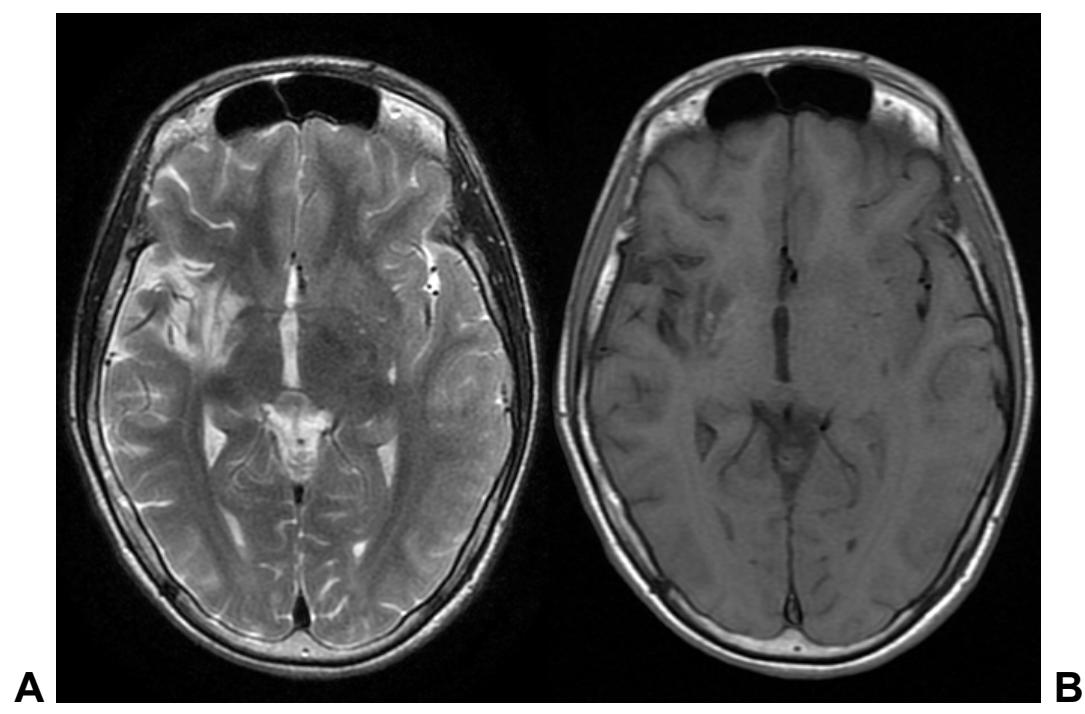

Figura. 12 A) e B) - Imagens axiais pesadas em T2 (A) e T1 (B) mostram lesão em ínsula e núcleo lentiforme direito associada a alargamento da fissura Sylviana adjacente, com aspecto sequelar de provável origem isquêmica (PACIENTE 15).

Nos pacientes que apresentavam alteração intracerebral $(n=17 ; 50 \%)$, a lesão cutânea era homolateral em cerca de 7 (41,2\%) casos, não apresentavam correlação entre a lesão cutânea e cerebral em $6(35,3 \%)$ pacientes e 4 (23,5\%) tinham lesões contralaterais a lesão da pele. Dos 17 pacientes com lesão 
intraparenquimatosa na RM, 4 pacientes $(23,5 \%)$ estavam em atividade clínica. Dos 27 pacientes que apresentavam lesão cutânea identificada na RM, apenas 3 $(11,1 \%)$ estavam em atividade clínica.

Outro achado intraparenquimatoso foi o encontro de assimetria do sistema ventricular (Figura 9), sendo encontrado em 2 pacientes o ventrículo esquerdo maior que o direito e 1 com o ventrículo direito maior que o esquerdo. Dos pacientes com ventrículo esquerdo maior, a lesão cutânea era contralateral, um paciente com lesão mandibular direita e outro frontal direita. O terceiro paciente que apresentava o ventrículo direito maior, apresentava lesão cutânea ipsilateral malar direita. Todos esses pacientes com alteração do ventrículo lateral apresentavam alteração de sinal associada. Em um deles a alteração de sinal era ipsilateral ao ventrículo aumentado e nos outros dois pacientes a alteração de sinal era bilateral.

Nos quatro pacientes com HFP foi encontrado em $75 \%$ hipersinal na RM em T2 e também 75\% com alteração do subcutâneo na RM de crânio.

Dos 5 pacientes que apresentaram atividade clínica, durante o seguimento nesses 3 anos, $3(60 \%)$ apresentavam lesões parenquimatosas com hipersinal, 1 (20\%) apresentava RM normal e 1 (20\%) com lesões parenquimatosas com hipossinal na RM do crânio.

Em resumo, foram encontrados: 27 exames de RM (79,4\%) com identificação de lesão cutânea, 17 RM (50\%) com alteração do parênquima, 12 com lesões em substância branca com hipersinal em T2 (inespecíficos), 5 pacientes com lesões sugestivas de calcificação, 3 pacientes com hipossinal, 2 pacientes com assimetria do ventrículo lateral e 3 pacientes com lesões tanto com hipo como lesões com hipersinal em T2, ainda foi observado um paciente com lesão sequelar. 


\subsection{Avaliação clínico neurológica}

Do total de 34 pacientes, 14 pacientes $(41,2 \%)$ eram assintomáticos do ponto de vista de queixas neurológicas no momento da avaliação. Porém dentre esses pacientes, no exame neurológico, foi encontrado déficit cognitivo e atraso escolar em um deles, antecedente de convulsão na infância em outro e desvio de rima previamente em um terceiro paciente, sem sequelas no presente momento.

Vinte e três $(67,6 \%)$ pacientes estavam disponíveis e foram avaliados clinicamente pelo neurologista.

Do total de pacientes, a queixa mais frequente foi a de cefaleia, encontrada em $21(61,8 \%)$ pacientes.

Dos pacientes que apresentaram alteração neurológica, 13 referiam início após o surgimento da lesão de pele. Os achados encontrados foram: cefaleia incaracterística (12 casos), enxaqueca (6 casos), epilepsia (4 casos), atraso escolar (4 casos), neuropatia periférica (2 casos), distúrbio cognitivo (2 casos), antecedente de paralisia facial periférica ( 2 casos), quadro extrapiramidal ( 1 caso) e mielite autoimune (1 caso). Dos pacientes com alteração neurológica, apenas um apresentou alteração no exame neurológico que podia ser imputada a esclerodermia (paciente 15), caracterizado pela presença de quadro extrapiramidal.

Dois pacientes apresentavam diagnóstico de depressão e síndrome do pânico. A posição baixa da amígdala cerebelar foi identificada na RM de um paciente, tendo sido considerada como constitucional pelo neurologista. Dos 9 pacientes com avaliação neurológica alterada, 3 (33,3\%) apenas apresentavam atividade clínica da esclerodermia. 
Nos pacientes com queixa de dor de cabeça, 6 apresentavam critérios para enxaqueca (pacientes 1, 3, 6, 10, 29 e 34), sendo que três dos pacientes (casos 1,3 e 34) tiveram o início da enxaqueca após manifestação do quadro dermatológico. Cefaleia incaracterística ou hiperalgesia sobre o local da lesão esteve presente em 15 pacientes (pacientes 4, 5, 9, 11, 12, 13, 15, 17, 21, 22, 23, 24, 27, 30, 32).

A epilepsia esteve presente em 4 pacientes. Sendo 3 do tipo parcial complexa (pacientes 15, 20, 26) e em um caso (paciente 30) com epilepsia na infância. Entre esses três pacientes que apresentavam convulsões, um iniciou o quadro de epilepsia um ano antes do início da lesão de pele. Dois pacientes (pacientes 13 e 33) apresentavam antecedente de paralisia facial periférica, sendo que ambos foram acometidos anteriormente ao início da esclerodermia e, em um deles a paralisia foi ipsilateral a lesão cutânea (paciente com HFP), o outro paciente teve o diagnóstico antes do seu seguimento em nosso serviço, não sendo possível correlacionar com o lado da lesão facial. Os dois casos não apresentaram sequelas. Um caso apresentava clinicamente quadro extrapiramidal (paciente 15). Atraso escolar foi identificado na avaliação de dois casos (paciente 14 e 15).

Em relação aos testes, a maioria dos pacientes apresentaram o exame Minimental adequado, exceto um caso (paciente 10). Na extensão de dígitos direto todos estavam normais. Na extensão de dígitos indireta, como nota de corte 3, apenas um caso estava abaixo (paciente 1). Notas entre 5 e 3 ficam na variável, onde estariam três casos (pacientes 3, 13 e 33). No teste do relógio, foi encontrado um caso (paciente 8) na faixa 5 e 8, que não é alterada, mas é considerado leve. Na fluência verbal todos estavam adequados. Na avaliação da memória, todos estavam normais quanto à percepção, memória imediata e incidental, aprendizado, memória com 5 minutos e reconhecimento. 
Nos pacientes menores que 16 anos (pacientes 14, 15, 26), essas avaliações acima (teste mini-mental, dígitos, memória, desenho do relógio e fluência verbal) não são válidas para esta faixa etária.

Nos pacientes com HFP um possuía histórico de desvio de rima.

Dos pacientes que apresentavam alteração neurológica, $80 \%$ também apresentavam alteração na RM. Um paciente com diagnóstico de déficit cognitivo e atraso escolar possuía exame de RM normal. Um dos pacientes com neuropatia periférica do membro superior ipsilateral a lesão cutânea, também possuía RM normal.

Em $30,4 \%$ dos pacientes com exame neurológico considerado como normal foi encontrado alteração da RM. Do total dos 34 pacientes, em $8,82 \%$ dos pacientes assintomáticos foi encontrado alteração da RM.

\subsection{Avaliação oftalmológica}

Vinte e oito $(82,3 \%)$ pacientes, que estavam disponíveis, foram submetidos à avaliação oftalmológica, 19 (67,8\%) deles apresentavam avaliação normal.

O achado mais frequente foi o acometimento por lesões cutâneas de esclerodermia na região da sobrancelha em 7 pacientes $(20,6 \%)$.

O segundo achado mais frequente foi a observação que alguns pacientes (4 casos) apresentam sinais oculares de olho seco, mas nem sempre com sintomas referidos. Esse achado foi encontrado na forma de diminuição do filme lacrimal e ceratite punctata, sendo o quadro de olho seco descrito frequentemente nesta doença. 
Alguns achados encontrados já reportados na literatura como relacionados a esclerodermia foram: estrabismo divergente (1), lesão do nervo óptico (1), lagoftalmo (1) ipsilateral a lesão cutânea e diminuição do reflexo pupilar (1). Outros achados encontrados provavelmente não relacionados à esclerodermia foram: miopia (2) e hiperpigmentação peripapilar temporal (1). As lesões dermatológicas da esclerodermia, quando acometem a região palpebral, podem causar exposição do globo ocular com o aparecimento do olho seco evaporativo, cicatrizes e úlceras de córnea.

Nos quatro pacientes com HFP uma paciente apresentava olho seco, um enoftalmo e o outro com diminuição do reflexo pupilar.

Dos $9(32,1 \%)$ pacientes com alteração oftalmológica, 5 (55,5\%) apresentavam RM normal e $4(44,4 \%)$ com lesões parenquimatosas de hipersinal na RM do crânio.

Dos 17 pacientes submetidos ao exame oftalmológico com avaliação normal, $64,7 \%$ apresentavam alteração da RM. 
Tabela 8. Correlação entre os achados neurológicos, oftalmológicos e da RM

\begin{tabular}{|c|c|c|c|c|}
\hline Pacientes & Avaliação oftalmológica & Avaliação neurológica & RM & Sinal em T2 \\
\hline 1 & $\begin{array}{l}\text { hiperpigmentação } \\
\text { peripapilar }\end{array}$ & normal & normal & \\
\hline 2 & -- & -- & $\begin{array}{l}\text { focos na substância } \\
\text { branca }\end{array}$ & hipersinal \\
\hline 3 & -- & normal & Normal & \\
\hline 4 & - & -- & normal & \\
\hline 5 & normal & normal & lesão focal & hipossinal \\
\hline 6 & olho seco & $\begin{array}{l}\text { lentificação psíquica, } \\
\text { enxaqueca }\end{array}$ & $\begin{array}{l}\text { focos na substância } \\
\text { branca }\end{array}$ & hipersinal \\
\hline 7 & normal & normal & normal & \\
\hline 8 & lagoftlamo ipsilateral & normal & normal & \\
\hline 9 & normal & normal & Normal & \\
\hline 10 & ceratite & $\begin{array}{l}\text { enxaqueca, dificuldade } \\
\text { de cálculo }\end{array}$ & $\begin{array}{l}\text { focos na substância } \\
\text { branca e assimetria } \\
\text { dos ventrículos } \\
\text { laterais }\end{array}$ & hipersinal \\
\hline 11 & & & normal & \\
\hline 12 & normal & enxaqueca & $\begin{array}{l}\text { focos na substância } \\
\text { branca }\end{array}$ & hipersinal \\
\hline 13 & normal & $\begin{array}{l}\text { déficit de atenção, } \\
\text { distúrbio cognitivo }\end{array}$ & $\begin{array}{l}\text { focos na substância } \\
\text { branca }\end{array}$ & hipersinal \\
\hline 14 & miopia & $\begin{array}{l}\text { distúrbio cognitivo, } \\
\text { atraso escolar }\end{array}$ & normal & \\
\hline 15 & normal & $\begin{array}{l}\text { epilepsia, quadro } \\
\text { extrapiramidal }\end{array}$ & $\begin{array}{l}\text { lesão sequelar e } \\
\text { assimetria dos } \\
\text { ventrículos laterais }\end{array}$ & hipersinal \\
\hline 16 & normal & $\begin{array}{l}\text { alteração da amígdala } \\
\text { constitucional }\end{array}$ & $\begin{array}{l}\text { focos na substância } \\
\text { branca }\end{array}$ & hipersinal \\
\hline 17 & normal & normal & normal & \\
\hline 18 & estrabismo divergente & -- & normal & \\
\hline 19 & normal & -- & normal & \\
\hline 20 & normal & epilepsia & $\begin{array}{l}\text { focos na substância } \\
\text { branca e lesões } \\
\text { focais com } \\
\text { hipossinal }\end{array}$ & $\begin{array}{l}\text { hipersinal e } \\
\text { hipossinal }\end{array}$ \\
\hline 21 & $\begin{array}{l}\text { diminuição do reflexo } \\
\text { pupilar ipsilateral }\end{array}$ & - & normal & \\
\hline 22 & $\begin{array}{l}\text { miopia e lesão do nervo } \\
\text { óptico }\end{array}$ & -- & normal & \\
\hline 23 & -- & -- & normal & \\
\hline 24 & normal & normal & lesões focais & hipossinal \\
\hline 25 & normal & normal & lesões focais & hipossinal \\
\hline 26 & normal & epilepsia prévia & $\begin{array}{l}\text { lesões focais e } \\
\text { cistos }\end{array}$ & $\begin{array}{l}\text { hipossinal e } \\
\text { hipersinal }\end{array}$ \\
\hline 27 & normal & normal & $\begin{array}{l}\text { focos na substância } \\
\text { branca }\end{array}$ & hipersinal \\
\hline 28 & normal & -- & normal & \\
\hline 29 & olho seco & normal & $\begin{array}{l}\text { focos na substância } \\
\text { branca }\end{array}$ & hipersinal \\
\hline 30 & normal & normal & $\begin{array}{l}\text { focos na substância } \\
\text { branca e assimetria } \\
\text { dos ventrículos } \\
\text { laterais }\end{array}$ & hipersinal \\
\hline 31 & -- & $\begin{array}{l}\text { neuropatia periférica do } \\
\text { MSE }\end{array}$ & normal & \\
\hline 32 & normal & -- & normal & \\
\hline 33 & olho seco & -- & $\begin{array}{l}\text { focos na substância } \\
\text { branca }\end{array}$ & hipersinal \\
\hline 34 & normal & normal & $\begin{array}{l}\text { focos na substância } \\
\text { branca }\end{array}$ & hipersinal \\
\hline
\end{tabular}




\subsection{Avaliação laboratorial}

Do total, foi dosado FAN em 31 (91,2\%) pacientes, 4 (12,9\%) apresentavam exame positivo. Um dos pacientes com FAN positivo apresentou quadro de mielite autoimune, um segundo também apresentava ANCA positivo, o terceiro relatava quadro prévio de neuropatia do membro superior e o quarto paciente com diagnóstico prévio de LES, apresentando também anti Ro e La positivos. Dos 4 pacientes com FAN positivo, apenas $1(25 \%)$ apresentava atividade clínica.

FR foi dosado em 29 (85,3\%) pacientes com 4 (13,8\%) apresentando exame positivo. Uma das pacientes com FR positivo apresentava encurtamento do membro inferior, com envolvimento articular associado, sendo que a mesma paciente que desenvolveu quadro de mielite autoimune (caso 5). A segunda paciente com FR positivo também apresentava FAN e ANCA positivo (caso 25). A terceira paciente com FR positivo apresentava associadamente calcinose, fenômeno de Raynaud, vasculite, PFP normal, EED normal, anti DNA fracamente reagente (52) e anti Ro positivo (51) (caso 29). A quarta paciente com FR positivo apresentava diagnóstico de LES e artrite (paciente 34). Dos quatro pacientes com FR positivo, apenas 1 (25\%) apresentava atividade clínica durante a evolução (caso 5).

O Scl-70 foi dosado em 26 (76,5\%) pacientes, todos com exame negativo.

Os exames foram dosados nos pacientes disponíveis e em alguns períodos faltaram insumos, em nosso serviço, para realização dos exames listados acima. 


\subsection{Outros Achados}

Durante a revisão dos prontuários em onze $(32,3 \%)$ pacientes foi identificado algum sinal de autoimunidade. Dentre eles, destacamos o hipotireoidismo com anticorpos positivos (3 casos), vitiligo (2 casos). Outros anticorpos positivos encontrados, além do FAN (4 casos) e FR (4 casos), foram anti DNA (1 caso), ANCA (1 caso) e anti músculo liso (1 caso).

Identificamos ainda uma paciente com quadro de mielite autoimune, um caso de artrite idiopática juvenil, um caso com vasculite cutânea de pequenos vasos, e um caso de LES e outro de LESA. Esses achados foram encontrados associados em alguns pacientes. Uma paciente com FR positivo apresentava associadamente calcinose, fenômeno de Raynaud, vasculite, anti DNA fracamente reagente e anti Ro positivo (caso 29). Outra paciente também com FR positivo apresentava diagnóstico de LES e artrite (caso 34). A paciente que apresentava LESA, também tinha o diagnóstico de RGE (caso 30).

\subsection{Seguimento radiológico}

Doze pacientes estavam disponíveis e foram submetidos à RM após 3 anos da realização da primeira avaliação por RM. Em todos os pacientes os achados de imagem estavam inalterados (figura 9 e 13). 

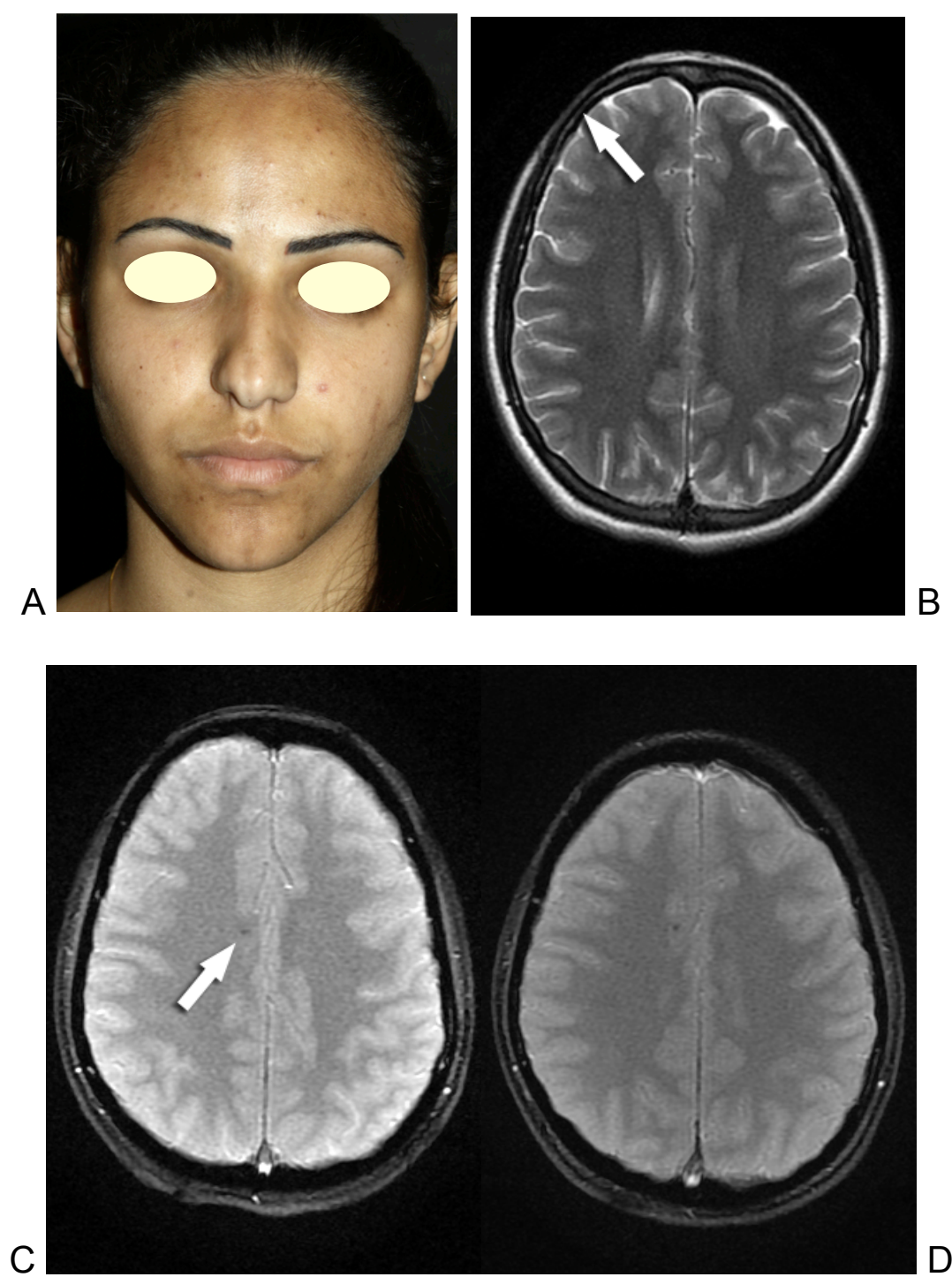

Figura 13 A) Foto clínica da paciente com discreta lesão atrófica, levemente pigmentada, mediana na fronte (PACIENTE 25); B) Na imagem axial pesada em T2 note o afilamento do tecido subcutâneo frontal direito (SETA); C) e D) Imagens axiais pesadas em gradiente eco $\left(T 2^{*}\right)$ com intervalo de 3 anos (C e D) demonstram persistência da pequena lesão frontal direita (SETA) que apresenta hipossinal.

Durante esse intervalo de 3 anos, 3 (25\%) pacientes apresentaram sinais de atividade clínica, sendo em 2 deles introduzido MTX associado à prednisona e no outro apenas MTX isoladamente. Uma das pacientes apresentou quadro de mielite autoimune durante a evolução, sendo feito a hipótese de síndrome overlap.

Em resumo, dos 12 pacientes que repetiram a RM em 3 anos, 3 estavam em uso de medicação sistêmica e apresentavam atividade clínica. Desta forma existe 
uma associação significativa entre medicação sistêmica e atividade clínica, com p = 0,042 (pelo teste exato de Fisher).

Do total dos pacientes seguidos, 5 pacientes $(14,7 \%)$ apresentaram atividade clínica cutânea e necessitaram de tratamento. Porém 2 deles não puderem repetir a RM no intervalo de três anos.

Um dos pacientes que apresentou atividade clínica foi uma paciente do sexo feminino, de 20 anos de idade, apresentou quadro de mielite autoimune após a realização do segundo exame de RM. Esta paciente usou MTX por 1 ano no início do diagnóstico, antes da realização da primeira RM. E pulsoterapia com metilprednisolona, seguido de azatioprina após a segunda RM, devido ao quadro de mielite. As alterações das RM estavam mantidas (paciente 5 - Tabela 7).

A segunda paciente considerada como em atividade da doença, apresentou novas lesões cutâneas após a realização da primeira RM, sendo introduzido MTX e prednisona sistêmica. Porém essa paciente não repetiu a RM (paciente 6 - Tabela 7).

O terceiro paciente em atividade iniciou MTX e prednisona no início da doença. Realizou a primeira RM na vigência de MTX, o qual usou por 2 anos. Quando realizou a segunda RM estava sem uso de MTX há 2 anos. As alterações das RM estavam mantidas (paciente 10 - Tabela 7).

O quarto paciente foi introduzido MTX e prednisona sistêmica após a realização da primeira RM, por atividade clínica das lesões. Usou as medicações por 1 ano. Sendo repetida a segunda RM 1 ano após a interrupção da medicação. As alterações das RM estavam mantidas (paciente 13 - Tabela 7). 
A quinta paciente realizou a primeira RM, com resultado normal, em uso de MTX por critério de lesões de pele em atividade. A paciente não repetiu a RM (paciente 19 - Tabela 7).

Tabela 9. Dados demográficos dos pacientes com seguimento de RM após 3 anos

\begin{tabular}{l|l|l|l|l} 
& Sexo & Idade & $\begin{array}{l}\text { Duração da } \\
\text { doença (anos) }\end{array}$ & Terapêutica \\
\hline 1 & F & 29 & 11 & \\
\hline 5 & F & 20 & 18 & vitamina E, lactato amônio, MTX (1 ano) \\
\hline 10 & M & 26 & 5 & MTX, prednisona (1 ano) \\
\hline 13 & M & 36 & 4 & MTX / prednisona (1 ano) \\
\hline 14 & F & 9 & 4 & -- \\
\hline 16 & M & 6 & 4 & vitamina E, lactato amônio, MTX \\
\hline 17 & M & 15 & 7 & Lactato amônio, vitamina E \\
\hline 26 & M & 23 & 6 & vitamina E, MTX \\
\hline 27 & M & 18 & 5 & vitamina E, lactato Amônio \\
\hline 31 & F & 17 & 15 & vitamina E, lactato Amônio \\
\hline & M & 11 & 8 & -- \\
\hline
\end{tabular}

F: feminino; $\quad$ M: masculino 
Tabela 10. Achados neurológicos dos pacientes com seguimento de RM após 3 anos

\begin{tabular}{|c|c|c|c|c|}
\hline & RM do encéfalo & RM- Descrição & $\begin{array}{l}\text { Avaliação } \\
\text { Neurológica }\end{array}$ & $\begin{array}{l}\text { Atividade } \\
\text { da } \\
\text { doença }\end{array}$ \\
\hline 1 & Normal & Lesão SC frontal esquerda & Normal & - \\
\hline 5 & $\begin{array}{l}\text { Lesão com } \\
\text { hipossinal em T2 } \\
\text { (contralateral) }\end{array}$ & $\begin{array}{l}\text { Foco de marcado hipossinal em T2* } \\
\text { occipital esq. T2 (provável calcificação), } \\
\text { lesão no SC occipito cervical à direita }\end{array}$ & Normal & + \\
\hline 10 & $\begin{array}{l}\text { Focos na SB } \\
\text { com hipersinal } \\
\text { T2 e assimetria } \\
\text { do ventrículo } \\
\text { lateral }\end{array}$ & $\begin{array}{l}\text { Raros focos de hipersinal em T2 e FLAIR } \\
\text { no centro semioval }\end{array}$ & $\begin{array}{l}\text { Enxaqueca, } \\
\text { dificuldade de } \\
\text { cálculo }\end{array}$ & + \\
\hline 13 & $\begin{array}{l}\text { Focos na SB } \\
\text { com hipersinal } \\
\text { T2 (homolateral) }\end{array}$ & $\begin{array}{l}\text { Focos confluentes de hipersinal em T2 e } \\
\text { FLAIR na SB peritrigonal e isolados frontais, } \\
\text { lacuna periventricular no corno anterior } \\
\text { esquerdo/ lesão SC paramediano à frontal } \\
\text { direita }\end{array}$ & $\begin{array}{l}\text { Déficit de } \\
\text { atenção, } \\
\text { distúrbio } \\
\text { cognitivo }\end{array}$ & + \\
\hline 14 & Normal & Alteração tênue no SC frontal direito & $\begin{array}{l}\text { Déficit cognitivo, } \\
\text { atraso escolar }\end{array}$ & - \\
\hline 16 & $\begin{array}{l}\text { Foco na SB com } \\
\text { hipersinal T2 } \\
\text { contralateral }\end{array}$ & $\begin{array}{l}\text { Foco isolado de hipersinal em T2 e FLAIR } \\
\text { frontal esquerdo. Alteração no SC frontal } \\
\text { direito }\end{array}$ & $\begin{array}{l}\text { Alteração das } \\
\text { amígdalas } \\
\text { constitucional }\end{array}$ & - \\
\hline 17 & Normal & Alteração no SC frontal à direita & Normal & - \\
\hline 24 & $\begin{array}{l}\text { Focos com } \\
\text { hipersinal e } \\
\text { outros com } \\
\text { hipossinal em T2 }\end{array}$ & $\begin{array}{l}\text { Focos de marcado hipossinal em T2* } \\
\text { frontal, parietal, temporal, insula e occipital, } \\
\text { focos de hipersinal parieto occipital à direita }\end{array}$ & Normal & - \\
\hline 25 & $\begin{array}{l}\text { Focos com } \\
\text { hipossinal em T2 } \\
\text { (contralateral) }\end{array}$ & $\begin{array}{l}\text { Focos de marcado hipossinal em T2*. } \\
\text { Alteração no SC frontal à direita }\end{array}$ & Normal & - \\
\hline 26 & $\begin{array}{l}\text { Focos de } \\
\text { hipossinal em T2 } \\
\text { e cistos } \\
\text { (contralateral) }\end{array}$ & $\begin{array}{l}\text { Cistos córtico-subcorticais frontal, temporal, } \\
\text { no cíngulo à direita e corpo caloso. Focos } \\
\text { de marcado hipossinal em T2* difusos } \\
\text { frontal à direita, ectasias vasculares, } \\
\text { apagamento dos sulcos à direita. Alteração } \\
\text { no SC frontal à esquerda }\end{array}$ & Convulsão prévia & - \\
\hline 30 & $\begin{array}{l}\text { Focos na SB } \\
\text { com hipersinal } \\
\text { em T2, } \\
\text { assimetria do } \\
\text { ventrículo lateral } \\
\text { (ipsilateral) }\end{array}$ & $\begin{array}{l}\text { Focos de hipersinal em T2 e FLAIR na } \\
\text { substância branca, assimetria dos } \\
\text { ventrículos laterais, alteração no SC na } \\
\text { região mediana frontal }\end{array}$ & Normal & - \\
\hline
\end{tabular}


A EL ou morfeia manifesta-se através de um amplo espectro de lesões clínicas incluindo as formas linear, em placas, bolhosa, profunda e generalizada; associadas ou não à alterações extracutâneas. A regressão ou atenuação das lesões costumam ocorrer com frequência, porém sequelas são frequentes e reativação pode ocorrer (Eubanks et al., 1996). Nos casos com acometimento do segmento cefálico, especificamente, o envolvimento neurológico e/ou oftalmológico pode estar associado, caracterizando casos mais graves e de pior prognóstico.

De forma geral, os casos descritos na literatura são habitualmente variantes graves e não usuais que provavelmente não refletem a real prevalência das várias manifestações neurológicas associadas à EL.

Nesta perspectiva, avaliamos pacientes com ELF com ou sem sintomatologia sistêmica a fim de determinar a prevalência de alterações associadas, a sua correlação com a atividade clínica e a associação com outras doenças. No subgrupo de pacientes disponíveis para seguimento, o exame radiológico do crânio foi repetido após um período de 3 anos.

Do ponto de vista epidemiológico, nossos achados estão de acordo com os das séries de casos publicados quanto à idade de início da lesão cutânea (idade média de 11 anos), nossa casuística foi de 16,5 anos; índice femino:masculino (23:1), nosso índice foi 1,6:1 (Marzano et al., 2003; Tollefson; Witman, 2007; Zannin et al., 2007; Bonilla et al., 1995).

O espectro de doenças associadas e alterações laboratoriais relatadas em pacientes com EL é extremamente variável. No estudo de Li S et al., os autores descreveram a associação com artrite, outras limitações articulares, envolvimento ocular, neurológico, alopecia no sítio específico acometido, RGE, fenômeno de 
Raynaud, vasculite (Li et al., 2012) e vitiligo, achado já previamente relatado (Zulian et al., 2006).

Em nosso estudo, observamos $29,4 \%$ dos doentes com doenças autoimunes associadas, entre elas hipotireoidismo, vitiligo, mielite autoimune, artrite idiopática juvenil, vasculite cutânea, LES e LESA. Autoanticorpos (FAN, FR e Scl-70) foram detectados em $14,7 \%$ dos casos.

Dois casos, estudados por nós, apresentavam diagnóstico de morfeia profunda, com diferença de comprimento entres os membros, contraturas articulares e dificuldade para deambulação. Wu et al. descreveram em 38\% dos pacientes com EL atrofia muscular, encurtamento do membro, hemiatrofia facial e/ou contraturas articulares, e $25 \%$ com limitação da capacidade funcional (Wu et al., 2011). Portanto, em nosso estudo a prevalência foi de $6 \%$.

Em um estudo de Marzano et al. de 113 pacientes adultos com EL, fenômeno de Raynaud foi encontrado em $7 \%$, sendo que $87,5 \%$ apresentavam fator antinúcleo (FAN) positivo e 50\% anticorpo anticentrômero (ACA). Nas 126 crianças estudadas a prevalência foi de $2 \%$ (Marzano et al., 2003). No presente estudo foi encontrado apenas um paciente com fenômeno de Raynaud (3\%), com anti DNA fracamente positivo e FR positivo.

Outras condições autoimunes como: vitiligo, diabetes mellitus (DM) insulino dependente, tireoidite de Hashimoto, doença de Graves, LES e colite ulcerativa, também foram reportados em outros relatos (Zulian et al., 2006; Zulian et al.,2005; Lee et al., 2002; Dervis et al., 2004; Finkelstein et al., 1995; Stone, 2003) .

Em muitos pacientes descritos na literatura a EL precede os sintomas neurológicos por muitos anos (surgimento das lesões cutâneas com 9,5 anos +/- 7,9, início dos sintomas neurológicos 13,8 anos $+/-10,0$ ), sendo que em $29 \%$ os 
sintomas dermatológicos e neurológicos são separados por menos de 1 ano. Em $16 \%$ dos casos o acometimento neurológico precede a manifestação dermatológica, isso porque algumas lesões cutâneas inicialmente são indetectáveis. Esses pacientes apresentam achados de neuroimagem típicos de esclerodermia linear (atrofia focal, calcificações, lesões com hipersinal em T2), desenvolvendo anos após lesões cutâneas de esclerodermia (Chbicheb et al., 2005). Essa observação que o cérebro pode ser acometido previamente as lesões cutâneas, sugere o que processo não necessariamente inicia-se na pele. Em nossos pacientes, um apresentou diagnóstico de epilepsia e um ano após foi identificado lesão cutânea de esclerodermia. Outro apresentou quadro de epilepsia somente na infância.

As lesões cerebrais da EL parecem ser mais epileptogênicas que as das outras doenças autoimunes do SNC, como esclerose múltipla, na qual epilepsia é encontrada em porcentagem menor (2\%) de pacientes (Poser; Brinar, 2003).

Foi revisto retrospectivamente que estudos demonstram manifestações neurológicas em 19 a 39\% das crianças com ELGS e HFP (Christen-Zaech et al., 2008; Zulian et al., 2006; Zulian et al., 2005). Sendo o sintoma mais frequente a convulsão (Christen-Zaech et al., 2008; Zulian et al., 2006; Chiu et al., 2012).

Em nosso estudo $39 \%$ dos pacientes avaliados apresentavam alguma alteração neurológica, sendo cefaleia a queixa mais comum. Além disso, observamos casos de enxaqueca, epilepsia, neuropatia periférica, distúrbio cognitivo, paralisia facial periférica, quadro extrapiramidal, mielite autoimune, déficit de atenção e atraso escolar.

Nesta perspectiva estudamos muitos casos assintomáticos, do ponto de vista neurológico, com ELF realizando exame de RM do crânio para avaliar o real acometimento cerebral desses doentes. 
Existem alguns relatos de ELGS com associação de lesões cerebrais ipsilaterais à lesão cutânea em pacientes assintomáticos do ponto de vista neurológico (Unterberger et al., 2003; Appenzeller et al., 2004; Holland et al., 2006; Holl-Wieden et al., 2006; Blaszczyk et al., 2003). As lesões cerebrais são ipsilaterais à lesão cutânea em $78 \%$ a $100 \%$ dos casos (Kister et al., 2008; Moko et al., 2003; Terstegge et al., 1994). Em nosso estudo encontramos $41,2 \%$ dos pacientes com alteração intracerebral ipsilateral à lesão cutânea.

Fry et al. documentaram as anormalidades do SNC na RM de crânio de 5 crianças com SPR, sendo que um dos pacientes era assintomático do ponto de vista neurológico, apresentando lesões na RM, sugerindo que o acometimento do SNC pode ser mais comum do que era acreditado (Fry et al., 1992).

Em um estudo recente, Chiu et al. avaliaram 32 crianças, entre 1 a 15 anos, 21 foram submetidas a exame de imagem, sendo 12 assintomáticas. Foram realizadas RM do crânio em 19 pacientes. Em 62\% dos exames haviam evidências de alteração da calota craniana, 19\% apresentavam anormalidade do parênquima ipsilateral à lesão cutânea, sendo que todos apresentavam hipersinal em T2, um tinha produtos hemáticos crônicos ou calcificação e, um paciente com efeito de massa leve com apagamento do sulco cortical na RM. Foi encontrado $10 \%$ dos pacientes com anormalidades neurorradiológicas sem manifestações neurológicas (Chiu et al., 2012). Nove de 32 pacientes apresentavam sintomas neurológicos, sendo o mais frequente convulsões $(13 \%)$, cefaléia $(9 \%)$, anormalidade de nervo craniano e defeito motor e sensitivo nas extremidades foi reportado em $6 \%$. Outras queixas foram problemas cognitivos, distúrbios do comportamento, dismetria e fala arrastada, todos casos isolados. Nos pacientes sintomáticos (9) apenas $22 \%$ apresentavam anormalidade intracraniana na RM. Não houve diferença significativa 
de achados de neuroimagem entre os pacientes sintomáticos (22\%) e assintomáticos (17\%). O início das manifestações neurológicas foi simultâneo ou ocorreu em até um ano após o início da doença cutânea em 6 crianças. E em 2 crianças as manifestaçoes neurológicas iniciaram 4 e 11 anos após o início da doença cutânea, porém em ambas a doença cutânea ainda estava ativa. Os autores concluíram que a gravidade do acometimento cutâneo, os achados de neuroimagem e as manifestações neurológicas não pareceram estar correlacionados. As 4 crianças com achados de neuroimagem e oito de 9 com manifestações neurológicas apresentavam ELGS e nenhum caso de SPR associada (Chiu et al., 2012).

$\mathrm{Na}$ nossa casuística, 14 pacientes $(41,2 \%)$ foram considerados assintomáticos do ponto de vista neurológico. O nosso achado mais frequente na RM está de acordo com esse estudo, que foi a presença de lesão cutânea identificada na RM, em 27 (79,4\%) dos exames (Figura 9). Assim como os achados parenquimatosos, sendo a alteração de sinal na RM encontrada em 17 pacientes (50\%). Focos com hipersinal em T2 na substância branca estavam presentes em 12 (70,6\%) dos pacientes com lesão intraparenquimatosa (Figura 10), 5 apresentavam lesões com hipossinal em T2 (Figura 11) e 2 pacientes apresentavam tanto lesões com hipersinal como lesões com hipossinal, sendo que as lesões com hipersinal em 1 paciente correspondia a focos na substância branca e em 1 caso à cistos parenquimatosos. Lesões sugestivas de calcificação intracerebral ou conteúdo de produtos de degradação da hemoglobina-hemossiderina (hipossinal em T2*) foram encontrados em 5 pacientes $(29,4 \%)$.

Em nossos pacientes, a queixa mais frequente foi cefaleia $(61,8 \%)$. Na população geral $50 \%$ refere cefaleia durante um determinado ano e $90 \%$ refere história de cefaleia durante a vida (Abu-Arafeh et al., 2010). A epilepsia foi 
encontrada em $11,8 \%$ dos pacientes estudados. A epilepsia afeta aproximadamente 1\% da população mundial (Ren, 2009). Outros achados encontrados foram: atraso escolar (4 casos), neuropatia periférica (2 casos), distúrbio cognitivo (2 casos), antecedente de paralisia facial periférica ( 2 casos), quadro extrapiramidal (1 caso) e mielite autoimune (1 caso). Dos pacientes que apresentavam alteração neurológica (12 pacientes), 80\% também apresentavam alteração na RM. Dos pacientes com RM normal, um paciente apresentou diagnóstico de déficit cognitivo e atraso escolar e o outro neuropatia periférica do membro superior ipsilateral a lesão cutânea.

Em $30,4 \%$ dos pacientes com exame neurológico considerado normal foi encontrado alteração da RM. Do total dos 34 pacientes, em 8,8\% dos pacientes assintomáticos foi encontrado alteração de RM. Nos pacientes sintomáticos (20 casos), $60 \%$ apresentava alteração de RM. Dos pacientes que apresentaram alteração neurológicas, 13 tinham aparente relação ou início após a lesão de pele. O nosso estudo não envolveu apenas crianças, mas os achados foram bastante semelhantes aos encontrados por Chiu et al. (Chiu et al., 2012), apesar dos pacientes estudados por eles apresentarem uma prevalência maior de manifestações neurológicas, sendo a principal a convulsão.

O envolvimento cerebrovascular geralmente é quiescente na $E S$, mas pode contribuir para o desencadeamento de desordens do SNC durante estados de baixo fluxo cerebral ou vasoespasmos (Héron et al., 1998; Blanche et al., 1996). Isto explicaria a ocorrência de acidente isquêmico transitório com déficit neurológico focal ou amnésia global transitória relatado na literatura (Héron et al., 1998; Averbuch-Heller et al., 1992; Hietaharju et al., 1993; Nishida et al., 1990). O acometimento psicológico tem sido reportado e pode ser devido ao envolvimento orgânico cerebral, inclusive em pacientes com calcificação do gânglio basal 
(Hietaharju et al., 1993; Roca et al., 1996; Straszecka et al., 1997; Lopez-Villegas et al., 1996). Desta forma, os pacientes com ES que apresentam desordens neuropsicológicas devem ter o SNC avaliado de forma sistemática (Héron et al., 1999). Assim como nos pacientes com EL, que podem apresentar como substrato das alterações cerebrais desordens vasculares.

Dois dos nossos pacientes apresentavam alteração neuropsicológica, classificadas como síndrome do pânico e depressão. Porém o exame de RM realizado estava normal.

O achado intraparenquimatoso mais frequente relatado é calcificação cerebral. Existe uma grande variedade de causas de calcificação cerebrovasculares mais intensas ou exuberantes, sendo a maioria localizada no gânglio basal. Entre as causas estão: o hipoparatiroidismo ou pseudohipoparatiroidismo (excepcionalmente hiperparatiroidismo), ferrocalcinose cerebrovascular idiopática (doença de Fahr), doença hereditária como osteodistrofia de Albright's, síndrome de Cockayne's, síndrome de Down, citopatia mitocondrial (doença oculocrâniossomática), miopatia mitocondrial, anóxia do parto, envenenamento por monóxido de carbono, intoxicação por chumbo, infecção do SNC (como por doença de inclusão por citomegalovírus, toxoplasmose, cisticercose, herpes ou encefalite por sarampo, meningite por tuberculose) ou hemorragia, leucemia aguda, irradiação do crânio por radioterapia e tratamento com MTX (Esiri, 1996; Fénelon et al., 1993). A calcificação do gânglio basal também foi descrita em pacientes com AIDS (Fénelon et al., 1993). Esta é a alteração da TC do crânio mais frequente nos pacientes com lúpus, nos quais pode corresponder a cicatriz de vasculite (Raymond et al., 1996).

A calcificação do gânglio basal é, portanto, um achado sensível e não específico para alterações cerebrovasculares. A prevalência de detecção acidental 
de calcificação do gânglio basal nas TC de crânio é de $0,2 \%$ à $2 \%$ (Fénelon et al., 1993).

Entretanto, o nosso achado intraparenquimatoso mais frequente foi o de lesões com alteração de sinal na RM, em 17 pacientes (50\%). Lesões com hipersinal em T2 estavam presentes em 12 (70,6\%) dos pacientes com lesão intraparenquimatosa. Achado que pode corresponder à calcificação intracerebral ou conteúdo hemático crônico foi encontrado em 5 pacientes $(29,4 \%)$. Um paciente apresentava uma lesão sequelar cujo aspecto sugere origem isquêmica. Portanto, o encontro de lesões focais com hipersinal em T2 foi o achado intraparenquimatoso mais frequente, que é tipicamente encontrado na EL.

Devido à existência de poucos estudos sobre a prevalência das alterações de imagem cerebral nos pacientes com ELF e o que de fato estas alterações podem significar quando encontradas, levantamos os achados na literatura de RM do cérebro da população normal. Alterações com importância clínica são reportadas numa frequência em torno de 2 a $8 \%$ das imagens alteradas (Katzman et al., 1999; Kim et al., 2002; Illes et al., 2004; Mamourian, 2004; Weber; Knopf, 2006; Hentschel; Klix, 2006; Vernooij et al., 2007). A incidência pode aumentar nos pacientes acima de 65 anos, entretanto, a importância clínica não é a mesma nesse grupo do que aquela encontrada no caso de achados inesperados em jovens (Illes et al., 2004). Os achados incidentais são complicados de serem determinados, devido à complexidade e variabilidade do desenvolvimento cerebral. Em um estudo com 1618 RM de crânio de crianças os achados incidentais (171) foram divididos em variação da normalidade (113) e anormais (58), não sendo reportada diferença entre sexo, idade ou diagnóstico clínico (Gupta; Belay B, 2008).

Vernooij et al. estudaram 2000 imagens de RM do crânio realizadas na 
população em geral. Foram considerados achados incidentais com potencial relevância clínica, requerendo referência imediata ou urgente: tumor cerebral, aneurisma, coleção de fluido subdural e cisto aracnóideo. Achados cerebrais que não foram considerados relevantes e, portanto, não reportados como achados incidentais: doença dos seios da face, variantes do normal como cisto pineal, assimetria ventricular e alargamento dos espaços de Virchow-Robin. Foi encontrado infarto assintomático em 145 pessoas $(7,2 \%)$, aneurisma cerebral foi encontrado em $1.8 \%$ da população e tumor primário benigno em $1,6 \%$, sendo o tumor benigno mais frequente o meningioma. A prevalência de infartos cerebrais assintomáticos e meningiomas aumentam com a idade, assim como o volume das lesões da substância branca, entretanto, aneurismas não demonstram relação com o aumento da idade (Vernooij et al., 2007).

A incidência de anormalidades na RM de crânio é maior nos pacientes com demência, esclerose múltipla, trauma cerebral, câncer e doença mental, ou seja, com doenças do SNC. Porém não é pequeno o achado de anormalidades em grupo controle tido como normal. Assim sugerem-se os cortes em T2 e FLAIR sejam realizados, além de $T 1$, pois certas alterações como os aneurismas são melhores vistos em T2 e FLAIR (Mamourian, 2004; Weber; Knopf, 2006).

Em resumo, os achados incidentais cerebrais na RM de crânio, incluindo alterações vasculares patológicas subclínicas, não são raros na população geral. O mais frequente achado é o infarto cerebral, seguido por aneurisma cerebral e tumores benignos primários. Os tumores benignos, geralmente são meningeomas, que possuem crescimento lento e permanecem assintomáticos durante toda a vida (Staneczek; Janish, 1992).

As informações do curso natural das lesões são necessárias para o manejo 
clínico e prognóstico dos pacientes. Sugere-se para maior acurácia que as imagens sejam sempre avaliadas por um neurorradiologista. O conhecimento do status neurológico destes pacientes é fundamental para interpretação destes achados.

A morfeia parece ser autolimitada, com atividade e progressão da doença por 3 a 5 anos (Christianson et al., 1956), entretanto, a reativação pode ocorrer especialmente na ELGS.

Alguns relatos descrevem a manifestação primariamente da doença cutânea e posteriormente, cerca de 2 anos ou mais, manifestação da doença neurológica (Grosso et al., 2003; Menni et al., 1997; Appenzeller et al., 2004). Considerando que o prejuízo da função neurológica, frequentemente, não ocorre em paralelo com a doença cutânea, minucioso seguimento é obrigatório.

Desta forma, optamos pela repetição da RM de crânio nos pacientes após 3 anos da realização da primeira. Objetivando avaliar se as alterações radiológicas encontradas eram mantidas ou se modificavam, comparando a evolução clínica da lesão cutânea e neurológica.

Existem apenas poucos relatos de seguimento dos achados neurorradiológicos na ELF. Cory et al. monitorou uma criança por 2 anos e demonstrou que as calcificações no lobo frontal não mudaram, mas as lesões na substância branca subjacente progrediram com a progressão da atrofia facial (Cory et al., 1997).

Outro relato, no quais os autores seguiram uma criança de 7 anos com lesão esclerótica frontal direita, que com 9 anos iniciou quadro de fraqueza muscular do lado esquerdo do corpo, apresentava FAN 1:160 padrão homogêneo, com outros anticorpos normais. A eletroneuromiografia, EEG e TC do crânio eram normais. Apresentava RM de crânio com hipersinal em T2 na substância branca do 
hemisfério direito, sugerindo infarto lacunar. Após 1 ano a RM foi repetida, com achados mantidos. A manifestação neurológica resolveu espontaneamente em 2 anos (Menni et al., 1997).

Raros relatos de casos reportaram a evolução radiológica dos pacientes com ELF. Sakai et al. descreveram um caso de uma mulher com 47 anos, com diagnóstico de ELGS, assintomática do ponto de vista neurológico, apresentado hipersinal ipsilateral à lesão cutânea na RM de crânio. Foi repetida a RM pós 3 meses, sem alterações dos achados neurológicos. O encontro de edema intersticial foi atribuído à vasculopatia cerebral em pacientes com ELGS, considerado como curso neurológico benigno. Sendo importante levar em consideração essa evidência na indicação de uso de corticosteroides ou biópsia para prevenção de intervenções prematuras ou inoportunas (Sakai et al., 2008).

Appenzeller et al. estudaram 9 pacientes com ELGS. A TC do crânio mostrou deformidade óssea, com espessamento da calota abaixo das lesões cutâneas em 6 deles. A RM demonstrou atrofia focal e borramento na interface entre a substância branca e a cinzenta, correspondendo à lesão cutânea, em todos pacientes. Em 3 deles, a RM apresentava hipersinal em T2 e FLAIR associados. A RM foi repetida 1 ano após, mostrando extensão das lesões cerebrais em apenas 1 paciente, nos demais não houve progressão. Quatro dos 9 pacientes apresentavam epilepsia parcial. Um deles foi submetido à cirurgia devido às convulsões refratárias, sendo que os achados patológicos indicaram processo inflamatório focal. Os autores atribuíram a doença a uma etiologia inflamatória, geralmente focal, mas que pode ser progressiva (Appenzeller et al., 2004).

Kister et al. levantaram os 29 pacientes seguidos com RM na literatura, demonstrando 15 deles com novas lesões (52\%) sendo a resolução das lesões 
ocasionalmente foi observada. Sugerindo que doença subclínica progride em muitos pacientes (Kister et al., 2008). Porém, esses exames foram realizados em um intervalo de tempo variável e muitos dos pacientes estavam com doença neurológica em atividade, por isso foram submetidos à nova RM.

Em nosso estudo, doze pacientes foram novamente submetidos à RM de crânio após 3 anos da realização da primeira avaliação. Em todos os pacientes os achados de imagem permaneceram inalterados. Durante esse intervalo de 3 anos, $3(25 \%)$ pacientes apresentaram sinais de atividade clínica, sendo em 2 deles introduzido MTX associado à prednisona e no outro apenas MTX. Uma das pacientes apresentou quadro de mielite autoimune após a realização da segunda RM.

Acredita-se que a resolução e recorrência das lesões radiológicas podem estar correlacionadas com a atividade da doença neurológica (Stone et al., 2001; Unterberger et al., 2003). Assim como a imagem pode ser anormal em um paciente sem sintomas neurológicos, a imagem pode ser normal a despeito do achado de doença neurológica (Gambichler et al., 2001; Holland et al., 2006).

A ausência de especificidade e/ou sensibilidade dos achados de neuroimagem em poder correlacionar com o achado de doença neurológica, contribui com a dificuldade em predizer o prognóstico desses pacientes. Certamente o encontro de achados neurorradiológicos indica um seguimento cauteloso.

Recentemente SPECT do cérebro detectou anormalidades em 7 pacientes com ELGS assintomáticos e com RM normais (Blaszczyk et al., 2003). Esse envolvimento subclínico do SNC parece estar presente em muitos dos pacientes com esclerodermia craniofacial, dependendo da sensibilidade do exame de imagem. Desta forma, o envolvimento neurológico parece não ser tão infrequente quanto se 
supunha no passado (Pansler et al., 1990). As manifestações clínicas são reportadas em metade dos pacientes com esclerodermia craniofacial (Marzano et al., 2003; Stone, 2003).

Em um estudo de Marzano et al. de 126 crianças com EL, 117 delas estavam em remissão. $\mathrm{O}$ acometimento da face foi encontrado em 17 crianças, incluindo o diagnóstico de SPR, ELGS e formas "mistas" (ELF associado à morfeia em placa ou esclerodermia linear em outras áreas). Destas 17 crianças com ELF, 8 delas, ou seja, 47\% apresentavam alterações neurológicas. A alteração da RM em 6 pacientes, 3 deles com manifestações neurológicas, incluindo convulsões, hemiparesia e episódios de fraqueza muscular. Duas crianças apresentavam enxaqueca e neuralgia do trigêmeo, respectivamente. O acometimento oftalmológico apenas ocorreu nos pacientes com ELF, incluindo 2 casos de exoftlamo, 2 ptoses, 3 com reabsorção óssea da órbita ocasionando deslocamento do canto externo do olho e 1 com uveíte (Marzano et al., 2003).

Sommer et al. descreveram 12 pacientes com HFP, tendo encontrado elevação de FAN em 33\%; 25\% com lesões associadas de EL no tronco; $58 \%$ com acometimento do SNC, sendo que a metade deles apresentavam convulsões e a maioria iniciou após o surgimento das lesões cutâneas de HFP. Um terço destes apresentava enxaqueca. Menos de 10\% com acometimento de nervo periférico. $42 \%$ apresentavam acometimento ocular, mais de $50 \%$ destes envolvia a pálpebra e $20 \%$ não conseguia fechar o olho. Foi achado pupila fixa homolateral e enoftalmo por atrofia da gordura retroocular. Do total de pacientes, $70 \%$ não tinham alterações na RM ou TC. Nos $30 \%$ que apresentavam alterações, foi encontrada dilatação ventricular, calcificação subcortical, hipersinal frontoparietal subcortical com ou sem incremento de contraste. Esses achados foram interpretados como benignos, de 
encefalite. Um caso teve o liquor cefalorraquidiano (LCR) puncionado demonstrando lgG, o que sugere uma natureza inflamatória da lesão (Sommer et al., 2006).

No total dos pacientes seguidos em nosso estudo, quatro pacientes apresentavam o diagnóstico de HFP, sendo que nenhum caso possuía FAN elevado, lesões cutâneas no tronco, enxaqueca ou convulsões. Um paciente possuía histórico de desvio de rima. Dos achados oftalmológicos, um paciente apresentava olho seco, um paciente com enoftalmo e o outro diminuição do reflexo pupilar. Em $75 \%$ dos pacientes foi encontrado hipersinal na RM em T2 e identificado alteração do subcutâneo na RM de crânio.

Nos casos de EL como um todo, o achado oftalmológico mais frequente foi o acometimento por lesões cutâneas de esclerodermia na região da sobrancelha $(20,6 \%)$, seguido de sinais oculares de olho seco. Estas alterações condizem com as relatadas por Sommer et al. (Somme et al., 2006). Na população em geral a prevalência da síndrome do olho seco varia de 8 a 20\% (McKinney P e Byun M, 1999).

Não existe estudo prospectivo dos efeitos do tratamento no envolvimento neurológico. Alguns relatos de caso sugerem que o tratamento melhora os sintomas neurológicos e as alterações de neuroimagem (Holl-Wieden et al., 2006; Fain et al., 2011; Goldberg-Stern et al., 1997; Menascu et al., 2009). Quando os sintomas neurológicos são refratários ao tratamento, pode evoluir com sequela de fibrose e calcificação, semelhante à lesão cutânea cicatricial na doença superficial, na qual a terapêutica sistêmica é incapaz de alterar o curso.

Os nossos achados condizem com os encontrados na literatura, sendo o achado mais frequente na RM de crânio a alteração cutânea ou de calota craniana. O achado intracerebral mais frequente encontrado foi a presença de lesões com 
hipersinal em T2 na RM, também frequente na literatura. Talvez a calcificação intracraniana não tenha sido o achado mais encontrado, porque o exame mais sensível para identificar essa alteração é a TC do crânio.

A manifestação neurológica mais encontrada em nossos pacientes foi a cefaleia $(61,8 \%)$. Seguida por epilepsia em $11.8 \%$ dos casos, sendo que um dos pacientes teve apenas na infância, antes do início da doença na idade adulta. Dois pacientes iniciaram as crises convulsivas após o início da doença cutânea. E o quarto paciente iniciou o quadro com epilepsia e um ano após foi identificado a lesão cutânea. Nesses três últimos casos as crises convulsivas foram classificadas como do tipo parcial complexa. Na literatura o achado mais frequente é a convulsão. Talvez haja essa diferença porque partimos de pacientes, em sua maioria, sem queixas neurológicas presentes, acompanhados no ambulatório de Dermatologia do nosso hospital. A queixa neurológica mais frequente encontrada foi de cefaleia, que é manifestação clinica frequente de outras doenças não neurológicas.

Alguns estudos vêm descrevendo que os sintomas neurológicos não necessariamente predizem anormalidades de neuroimagem, vice-versa. Os autores acreditam que a não identificação de achados na neuroimagem em pacientes sintomáticos se deva a baixa sensibilidade na RM com 1,5-Tesla, sugerindo estudos com 3-Tesla, que são mais sensíveis (Chiu et al., 2012).

Desta forma os estudos para determinar a significância do achado de anormalidades na RM na ausência de manifestações clínicas são extremamente importantes para desvendar o real comprometimento da EL e o quanto o tratamento altera o curso da doença neurológica.

Baseado nos dados coletados neste estudo, sugerimos que todos pacientes com ELF devam ser examinados cuidadosamente pela evidência de acometimento 
de órgãos internos, particularmente SNC e olhos. Nós também recomendamos monitoramento de autoanticorpos como FAN, FR e Scl-70.

Como o envolvimento de outros órgãos internos na EL é considerado extremamente incomum por muitos autores (Vierra et al., 199; Krafchik, 1992; Birdi et al., 1993; Dehen et al., 1994; Tuffanelli, 1998; Jablonska et al., 1992; Blaszczyk et al., 1996) nós consideramos que os estudos sistêmicos para os demais órgãos estão indicados apenas em pacientes sintomáticos e/ou na presença de marcadores imunes para ES ou outras doenças do tecido conectivo.

Os achados neurorradiológicos sugestivos de alteração pela EL são: borramento da junção entre substância branca e cinzenta, atrofia focal, lesões em T2 e calcificações (Kister et al., 2008). Existe pouca correlação entre a gravidade do acometimento cutâneo e os achados de neuroimagem.

De acordo com nossos achados e de outros investigadores, a RM de crânio deve ser incluída na avaliação diagnóstica de pacientes com ELF para detecção subclínica do acometimento do SNC (Sommer et al., 2006; Blaszczyk et al., 2003). O uso da neuroimagem não é preconizado e varia entre diversas instituições, entretanto, o reconhecimento do envolvimento neurológico precoce é importante para a decisão da terapêutica adequada. A terapia imunossupressora sistêmica deve ser indicada para os pacientes com acometimento intracraniano associado e manifestação neurológica correspondente.

As anormalidades oculares não são frequentes nos pacientes com EL, porém não são raras nos casos com acometimento facial. Tais alterações são frequentemente associadas com o acometimento do SNC (Zannin et al., 2007, Blaszczyk et al., 2003). Assim, um monitoramento oftalmológico cuidadoso deve ser 
realizado no paciente com EL, sendo mandatório no paciente com lesão da face ou acometimento concomitante do SNC.

Estes pacientes devem passar por consulta oftalmológica de rotina para diagnóstico, pois nem sempre desenvolvem sintomas, mas o olho, comprovadamente, está afetado. Como a doença progride rapidamente nos primeiros 2-3 anos, sugerimos avaliação oftalmológica periódica nos primeiros 3 anos do diagnóstico da doença, após esse período apenas no caso de progressão ou reativação.

O seguimento desses pacientes deve ser realizado, baseado na evidência que as alterações neurológicas e oftalmológicas podem se desenvolver durante qualquer período do curso da doença.

Pacientes com ELF devem ser identificados precocemente, avaliados periodicamente, tratados agressivamente e monitorados cuidadosamente. Seguimento criterioso deve ser realizado baseado na evidência de que as alterações sistêmicas, tanto neurológicas quanto oftlamológicas, podem se desenvolver durante qualquer período do curso da doença. 
1. Independentemente da atividade cutânea dos casos de esclerodermia localizada da face, não houve alteração de imagem neurológica após 3 anos.

2. Os dados demográficos avaliados, os achados laboratoriais e a presença de doenças autoimunes na população estudada são comparáveis aos da literatura.

3. Alterações no exame neurológico foram observadas em $39 \%$ dos casos avaliados, alterações no exame oftalmológico em 32,1\% dos casos e alterações radiológicas cerebrais em $50 \%$ dos pacientes.

4. Na grande maioria dos casos avaliados, não houve correlação direta entre as alterações de imagem à RM e as manifestações clínicas neurológicas dos pacientes examinados. 
Anexo 


\section{Anexo}

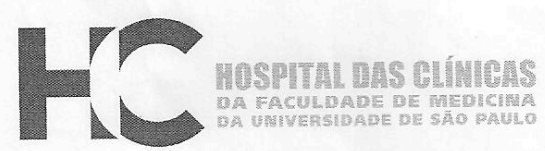

\section{APROVAÇÃO}

A Comissão de Ética para Análise de Projetos de Pesquisa CAPPesa da Diretoria Clínica do Hospital das Clínicas e da Faculdade de Medicina da Universidade de São Paulo, em sessão de 19/08/2009, APROVOU O Protocolo de Pesquisa $n^{\circ}$ 0059/09, intitulado: "ESTUDO PROSPECTIVO, PARA AVALIAR A CORRELAÇĀO CLÍNICA RADIOLÓGICA DOS PACIENTES PORTADORES DE ESCLERODERMIA EM GOLPE DE SABRE EM ACOMPANHAMENTO NO AMBULATÓRIO DE COLAGENOSES DA DIVISĀO DE DERMATOLOGIA DO HCFMUSP." apresentado pelo Departamento de DERMATOLOGIA, inclusive o Termo de Consentimento Livre e Esclarecido.

Cabe ao pesquisador elaborar e apresentar à CAPPesq, os relatórios parciais e final sobre a pesquisa (Resolução do Conselho Nacional de Saúde no 196, de 10/10/1996, inciso IX.2, letra "c").

Pesquisador (es) Responsáve(eis): Dr. Ricardo Romiti; Dra Claudia da Costa Leite Pesquisador (a) Executante: Mariana Figueiroa Careta

CAPPesq, 19 de Agosto de 2009

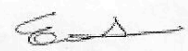

Prof. Dr. Eduardo Massad Presidente da Comissāo de Ética para Análise de Projetos de Pesquisa 
Referências 
Abu-Arafeh I, Razak S, Sivaraman B, Graham C. Prevalence of headache and migraine in children and adolescenets: a systematic reviem of population-based studies. Dev Med Child neurol 2010;52:1088-97.

Addison $\mathrm{CH}$. Medico-chirurgical transactions of 1854 quoted by Fox TC: note on the history of scleroderma in England. Br J Dermatol. 1892;4:101.

Ahn SK, Won JH, oi EH, Kim SC, Lee SH. Perforating plate-like osteoma cútis in a man with solitary morphea profunda. Br J Dermatol. 1996;134:949-52.

Aktekin B, Oguz Y, Aydin H, Senol U. Cortical silent period in a patient with focal epilepsy and Parry Romberg syndrome. Epilepsy Behav. 2005;6:270-3.

Appenzeller S, Montenegro MA, Dertkigil SJ, Sampaio-Barros PD, Marques-Neto JF, Samara AM, Anderman F, Cendes F. Neuroimaging findings in scleroderma en coup de sabre. Neurology. 2004;62:1585-9.

Arkachaisri T, Pino S. Localized scleroderma severity index and global assessments: a pilot study of outcome instruments. J Rheumatol. 2008;35:650-7.

Arnett FC, Cho M, Chatterjee S, Aguilar MB, Reveille JD, Mayes MD. Familial occurrence frequencies and relative risks for systemics sclerosis (Scleroderma) in three United States cohorts. Arthiritis and Rheumatism. 2001;44: 1359-62.

Asher SW, Berg B. Progressive hemifacial atrophy. Report of three cases, including one observed over 43 years and computed tomographic findings. Arch Neurol. 1982;39:44-6.

Averbuch-Heller L, Steiner I, Abramsky O. Neurologic manifestations of progressive systemic sclerosis. Arch Neurol. 1992;49:1292-5.

Aynaci FM, Sen Y, Erdol H, Ahmetoglu A, Elmas R. Parry-Romberg syndrome associated with Adie's pupil and radiologic findings. Pediatric Neurol. 2001;25:416-8.

Azad J, Dawn G, Shaffrali FCG, Holmes SC, Barnetson RJ, Forsyth A. Does solitary morphea profunda progress? Clin Exp Dermatol. 2004;29:25-7.

Bielsa I, Cid M, Herrero C, Cardellach F. Generalized morphea: systemic aspects of a cutaneous disease. Description of 12 cases and review of the literature. Med Clin (Brac). 1985;85:171-4.

Birdi N, Laxer RM, Thorner P, Fritzler MJ, Silverman ED. Localized scleroderma progressing to systemic disease: case report and review of the literature. Arthritis Rheum 1993:36:410-5.

Blanche $\mathrm{P}$, lamy C, Zuber M, Sicard D, Mas JL. Cerebral arteriopathy in scleroderma. Clin Exp Rheumatol. 1996;14:700-1.

Blanco P, Viallard JF, Ellie E, Faure I, Mercie P, Pellegrin JL, Leng B. Extensive brain calcifications in systemic sclerosis: two cases. J Neurol Neurosurg Psychiatry.1999;67(5):697-8.

Blann AD, Illingorth K, Layson MIV. Mechanisms of endotelial damage in systemic sclerosis and Raynaud's phenomenon. J Rheumatol. 1993;20:1325-30.

Blaszczyk M, Jablonska S. Linear scleroderma en coup de sabre. Relationship with progressive facial hemiatrophy (PFH). Adv Exp Med Biol. 1999;455:101-4. 
Blaszczyk M, Janniger C, Jablonska S. Childhood scleroderma and its peculiarites. Cutis. 1996;58:141-4,148-52.

Blaszczyk M, Krolicki L, Krasu M, Glinska O, Jablonska S. Progressive facial hemiatrophy: central nervous system involvement and relationship with scleroderma en coup de sabre. J Rheumatol. 2003;30:1997-2004.

Blaszczyk M, Krysicka Janniger C, Jablonska S. Primary atrophic profound linear scleroderma. Dermatology. 2000; 200:63-6.

Bonilla G, Guerrerosantos J, Fritzler MJ. Autoantibodies in Parry-Romberg syndrome: a serological study of 14 patients. J Rheumatol 1995;22:73-7.

Brucki SM, Nitrini R, Caramelli P, Bertolucci PR, Okamoto IH. Suggestions for utilization of the mini-mental state examination in Brazil. Arq. Neuropsiquiatria. 2003; 61(3B) 777-81.

Campbell PM, Le Roy EC. Pathogenesis of sytemic sclerosis: a vascular hypothesis. Semin Arthur Rheum. 1975;4:351-368.

Campello I, Velilla J, Almarcegui C, and Perez Lopez-Fraile I. Trigeminal neuropathy in progressive systemic sclerosis. Rev. Neurol. 1997;25,137.

Campione E, Paternò EJ, Diluvio L, Orlandi A, Bianchi L, Chimenti S. Localized morphea treated with imiquimod $5 \%$ and dermoscopic assessment of effectiveness. J Dermatolog Treat. 2009;20:10-3.

Carreno M, Donaire A, Barcelò MI, Rumià J, Falip M, Agudo R, Bargalló N, Setoain X, Boget T, Raspall A, Pintor L, Ribalta T. Parry Romberg syndrome and linear scleroderma in coup de sabre mimicking Rasmussen encephalitis. Neurology. 2007;68:1308-10.

Cassidy JT, Petty RE. The systemic scleroderma and related disorders. In: Cassidy JT, Petty RE, editors. Textbook of pediatric rheumatology. Philadelphia: W. B. Saunders; 2001. p. 50534.

Castanet J, Lacour Jph Perrin C, Tailan B, Dubois D, Ortonne JP. Association of eosinophilic fasciitis, multiple morphea and antiphospholipid antibody. Dermatology. 1994;189:304-7.

Catala M. Progressive intracranial aneurysmal disease in a child with progressive hemifacial atrophy (Parry-Romberg disease): Case report. Neurosurgery. 1998;42:1195.

Chang GY, Park SH, Youn YC, Kwon OS. Neuroimaging findings in scleroderma en coup de sabre. Neurology. 2004;63:2197-8.

Chapman MS, Peraza JE, Spencer SK. Parry Romberg syndrome with contralateral and ipsilateral extremity involvement. J Cutan Med Surg. 1999;3:260-2.

Chazen EM, Cook CD, Cohen J. Focal scleroderma. J Pediatr, 1962;60:385-93.

Chbicheb M, Gelot A, Rivier F, Roubertie A, Humbertclaude V, Coubes P, Echenne B. ParryRomberg's syndrome and epilepsy. Rev Neurol. 2005;161:92-7.

Chiang KL, Chang KP, Wong TT, Hsu TR. Linear scleroderma "en coup de sabre": initial presentation as intractable partial seizures in a child. Pediatrics and Neonatology. 2009;50:294-8.

Chiu YE, Vora S, Kwon EKM, Maheshwari M. A Significant proportion of children with morphea en coup de sabre and Parry-Romberg syndrome have neuroimaging findings. Pediatric Dermatology. 2012;29:738-48. 
Christen-Zaech S, Hakim M, Afsar F, Paller A. Pediatric morphea (localized scleroderma): review of 136 patients. J Am Acad Dermatol. 2008;59:385-96.

Christianson HB, Dorsey CS, O'Leary PA, Kierland RR. Localized scleroderma: a clinical study of two hundred thirty-five cases. Arch Dermatol. 1956;74:629-39.

Chung L, Lin J, Furst D, Fiorentino D. Systemic and localized scleroderma. Clin Dermatol. 2006;24:374-92.

Chung MH, Sum J, Morrell MJ, Horoupian DS. Intracerebral involvement in scleroderma en coup de sabre: report of case with neuropathologic findings. Ann Neurol. 1995; 37: 679-81.

Clements P, Lachenbruch P, Siebold J, White B, Weiner S, Martin R, et al. Inter and intraobserver variability of total skin thickness score (modified Rodnan TSS) in systemic sclerosis. J Rheumatol. 1995;22:121-5.

Cohen MM. Asymmetry: molecular, biologic, embryopathic, and clinical perspectives. Am J Med Genet. 2001;101:292-314.

Conn HO. Trailmaking and number-connection tests in the assessment of mental state in portal systemic encephalopathy. Am J Dig Dis 1977, 22(6):541-50.

Connolly MK. Systemic sclerosis (scleroderma) and related disorders. En: Bolognia JL, Jorizzo JL, Rapini RP, editores. Dermatology. Madrid: Elsevier; 2008. P.585-96.

Cory RC, Clayman DA, Faillace WJ, McKee SW, Gama CH. Clinical and radiologic findings in progressive facial hemiatrophy (Parry-Romberg syndrome). Am $\mathrm{J}$ Neuroradiol. 1997;18:751-7.

Cox D, O'Regan G, Collins S, Byrne A, Irvine A, Watson R. Juvenile localized scleroderma: a retrospective review of response to systemic treatment. Ir J Med Sci. 2008;177:343-6.

Crespo MP, Mas IB, Díaz JM, Costa AL, Nortes IB. Rapid response to cyclosporine and maintenance with methotrexate in linear scleroderma in a young girl. Pediatr Dermatol. 2009;26:118-20.

Cunningham BB, Bandells ID, Langman C, Sailer DE, Paller AS. Topical calcipotriene for morphea/linear scleroderma. J Am Acad Dermatol. 1998;39:211-5.

Cutolo M, Nobili F, Sulli A, Pizzorni C, Briata M, Faelli F, Vitali P, Mariani G, Coplello F, Seriolo B, Barone C, Rodriguez G. Evidence of cerebral hypoperfusion in scleroderma patients. Rheumatology (Oxford). 2000;39:1366-73.

Cutolo M, Sulli A, Pizzorni C, Accardo S. Nailfold videocapillaroscopy assment of microvascular damage in systemic sclerosis. J Rheumatol. 2000;27:155-60.

Daoud MS, Su WP, Leifrman KM, Perniciaro C. Bullous morphea: clinical pathologic and immunopathologic evaluation of 13 cases. J Am Acad Dermatol. 1994;30:937-43.

David J, Wilson J, Woo P. Scleroderma 'en coup de sabre”. Ann Rheum Dis. 1991; 50:260-2.

De P, Lloyd HJ, Rashid AM, Anstey AV. Morphea presenting shortly after the onset of Schmidt's syndrome. Clin Exp Dermatol. 2000;25:168-9.

DeFelipe J, Segura T, Arellano JI, Merchán A, DeFelipe-Oroquieta J, Martin P, Maestú F, Ramón y Cajal S, Sánchez A, Sola RG. Neuropathological findings in a patient with epilepsy and the Parry-Romberg syndrome. Epilepsia. 2001; 42:1198-1203. 
Dehen L, Roujeau JC, Cosnes A, Revuz J. Internal involvement in localized scleroderma. Medicine (Baltimore). 1994;73:241-5.

Derex $\mathrm{L}$, Isnard $\mathrm{H}$, Revol M. Progressive facial hemiatrophy with multiple benign tumors and hamartomas. Neuropediatrics. 1995;26:306-9.

Dervis E, Acbay O, Barut G, Karaoglu A, Ersoy L. Association of vitiligo, morphea and Hashimoto's thyroiditis. Int J Dermatol. 2004;43:236-7.

Diab M, Coloe JR, Magro C, Bechtel MA. Treatment of recalcitrant generalized morphea with infliximab. Arch Dermatol. 2010;146:601-4.

Dupont S, Catala M, Hasboun D, Semah F, Baulac M. Progressive facial hemiatrophy and epilepsy. Neurology. 1997, 48: 1013-1018.

Duyff RF, Vos J. A "scar" and epilepsy: coup de sabre. J Neurol Neurossurg Psychiatry. 1998;65:568.

Dytoc MT, Kossintseva I, Ting PT. First case series on the use of calcipotriol-betamethasone dipropionate for morphea. Br J Dermatol. 2007;157:615-8.

Dytoc MT, Ting PT, Man J, Sawyer D, Fiorillo L. First case series on the use of imiquimod for morphea. Br J Dermatol. 2005;153:815-20.

El-Mofty M, Mostafa W, El-Darouty M, Bousseila M, Nada H, Youssef R, et al. Different low doses of broad-band UVA in the treatment of morphea and systemic sclerosis. Photodermatol Photoimmunol Photomed. 2004;20:148-56.

El-Mofty M, Mostafa W, Esmat S, Youssef R, Bousseila M, Nada H, Yousef R, Esmat S, ElLawindy M, Assaf M, El-Enani G. Suggested mechanisms of action of UVA phototherapy in morphea: a molecular study. Photodermatol Photoimmunol Photomed. 2004;20:93-100.

Elst EF, Van Suijlekom-Smit LW, Oranje AP. Treatment of linear scleroderma with oral 1,25ddihydroxyvitamin D3 (calcitriol) in seven children. Pediatr Dermatol. 1999;16:53-8.

Emery H. Pediatric scleroderma. Semin Cutan Med Surg. 1998;17:41-7.

Esgleyes-Ribot T, Garcia de la Torre I, Gonzalez-Mendonza A, Guerresantos J, Barcelo R. Progressive facial hemiatrophy (Parry-Romberg syndrome) and antibodies to Borrelia. J Am Acad Dermatol. 1991;25:578-9.

Esiri MM. Metabolic diseases of the nervous system. In: Esiri MM, ed. Oppenheimer's Diagnostic Neuropathology. 2nd ed. Oxford, UK: Blackwell Scientific Publications Inc; 1996:346-347.

Eubanks LE, McBurney El, Galen W, Reed R. Linear scleroderma in children. Int J Dermatol. 1996;35:330-6.

Fain ET, Mannion M, Pope E, Young DW, Laxer RM, Cron RQ. Brain cavernomas associated with en coup de sabre linear scleroderma: two case reports. Pediatr Rheumatol Online J. 2011;9:18.

Falanga V, Medsger Jr TA, Reichlin M. Antinuclear and anti-single-stranded DNA antibodies in morphea and generalized morphea. Arch Dermatol. 1987;123:350-3.

Farrel AM, Marren PM, Wojnarowska F. Genital lichen sclerosus associated with morphea or systemic sclerosis: clinical and HLA characteristics. Br J Dermatol. 2000;143:598-603. 
Feghali-Bostwick C, Medsger Jr. TA, Wright TM. Analysis of systemic sclerosis in twins reveals low concordance for the presence of antinuclear antibodies. Arthritis and Rheumatism. 2003;48:1956-63.

Fénelon G, Gray F, Thiebierge M, Mahieux F, Guillard A. A propective study of patients with pallidal calcifications. J Neurol Neurosurg Psychiatry. 1993;56:622-5.

Fett N, Werth VP. Update on morphea: part I. Epidemiology, clinical presentation, and pathogenesis. J Am Acad Dermatol. 2011;64:217-28.

Fett N, Werth VP. Update on morphea: part II. Outcome measures and treatment. J Am Acad Dermatol. 2011;64:231-42.

Fieschi C, Rasura M, Anzini A, Beccia M. Central nervous system vasculitis. J Neurol Sci. 1998;153:159-171.

Finkelstein E, Amichai B, Metzker A. Coexistence of vitiligo and morphea: a case report and review of the literature. J Dermatol. 1995;22:351-3.

Fitch PG, Rettig P, Burnham JM, Finkel TH, Yan AC, Akin E, Cron RQ. Treatment of pediatric localized scleroderma with methotrexate. J Rheumatol. 2006;33:609-14.

Fitzpatrick TB, Eisen AZ, Wolff K, Freedberg IM, Austen KE, eds. Dermatology in General Medicine; 1987. p.1841-52.

Flores-Alvarado DE, Esquivel-Valerio JA, Garza-Elizondo M, Espinoza LR. Linear scleroderma en coup de sabre and brain calcification: is there a pathogenic relationship? $\mathrm{J}$ Rheumatol. 2003;30(1):193-5.

Folstein MF, Folstein SE, McHugh PR. Psychiatr Res. 1975; 12:189-98.

Fry JA, Alvarellos A, Fink CW, Blaw ME, Roach ES. Intracranial findings in progressive facial atrophy. J Rheumatol. 1992, 19(6):956-958.

Gambichler T, Kreuter A, Hoffmann K, Bechara FG, Altmeyer P, Jansen T. Billateral linear scleroderma "en coup de sabre" associated with facial atrophy and neurological complications. BMC Dermatol. 2001;1:9-13.

Garcia de la Torre I, Castello-Sendra J, Esgleyes-Ribot T, Martinez-Bonilla G, Guerrerosantos J, Fritzler MJ. Autoantibodies in Parry-Romberg syndrome: a serological study of 14 patients. J Rheumatol. 1995;22:73-7.

Gass JDM, Harbin TS, Del Piero EJ. Exudative stellate neuroretinopathy and Coat's syndrome in patients with progressive hemiafacial atrophy. Eur J Ophthalmol. 1991;1:2-10.

Goldberg-Stern H, deGrauw T, Passo M, Ball WS Jr. Parry Romberg syndrome: Follow up imaging during supressive therapy. Neuroradiology. 1997;39:873-6.

Goldenstein Schaiberg C, Pereira RMR, Gusukuma MC, Messina WC, Cossermelli W. Childhood linear scleroderma "en coup de sabre" with uveitis. Clin Labor Obeserv. 1990;117:581-4.

Gordon KS, David DS, William GB (eds). Infection and inflamation, in Magnetic Resonance Imaging. $3^{\text {rd }}$ ed, Mosby, St Louis, 1999, p 1361.

Govori V, Gjikolli B, Ajvazi H, Morina N. Management of patient with Sturge-Weber syndrome: a case report. Cases J. 2009;2:9394. 
Grosso S, Fioravanti A, Biasi G, Conversano E, Marcolongo R, Morgese G, Balestri P. Linear scleroderma associated with progressive brain atrophy. Brain Dev. 2003; 25:57-61.

Gupta SN, Belay B. Intracranial incidental findings on brain MR images in a pediatric neurology practice: a retrospective study. J Neurol Sci. 200815;264(1-2):34-7.

Hatzis JA, Stratigos AJ, Dimopoulos JC, Tzermias CK, Orfanidou A, Bassioukas KC. Linear scleroderma with severe leg deformity. Aust J Dermatol. 1992;33:155-7.

Hawk A, English JC 3rd. Localized and systemic scleroderma. Semin Cutan Med Surg. 2001;20:27-37.

Heidary N, Cheung W, wang N, Kamino H, Franks Jr AG. Eosinophilic fasciitis/generalized morphea overlap. Dermatology Online Journal. 2009;15:2-6.

Hentschel F, Klix WE. Magement of incidental findings in neuroimaging in diagnosing and pathophysiological research. Fortschr Neurol Psychiatr. 2006;74:651-5.

Héron E, Fornes $\mathrm{P}$, Rance A, Emmerich J, Bayle O, Fiessinger JN. Brain involvement in scleroderma: two autopsy cases. Stroke. 1998;29:719-21.

Héron E, Hernigou A, Chatellier G, Fornes P, Emmerich J, Fiessinger JN. Intracerebral Calcification in Systemic Sclerosis. Stroke. 1999; 30: 2183-5.

Hietaharju A, Jaaskelainen S, Hietarinta M, Frey H. Central nervous system involvement and psychiatric manifestations in systemic sclerosis (scleroderma): clinical and neurophysiological evaluation. Acta Neurol Scand. 1993;87:382-7.

Hietaharju A, Jaaskelainen S, Kalimo $\mathrm{H}$, and Hietarinta $\mathrm{M}$. Peripheral neuromuscular manifestations in systemic sclerosis (scleroderma), Muscle Nerve. 1993;16, No. 11, 12041212.

Higashi Y, Kanekura T, Fukumaru K, Kanzaki T. Scleroderma en Coup de Sabre with Central Nervous System Involvement. The Journal of Dermatology. 2000; 27: 486-8.

Holland KE, Steffes B, Nocton JJ, Schwabe MJ, Jacobson RD, Drolet BA. Linear cleroderma en coup de sabre with associated neurologic abnormalities. Pediatrics. 2006;117(1):e132-6.

Holl-Wieden A, Klink Th, Klink J, Warmuth-Metz M, Girschick HJ. Linear scleroderma "en coup de sabre" associated with cerebral and ocular vasculitis. Scand J Rheumatol. 2006;35(5):402-4.

Hulshof MM, Bouwes Bavinck JN, Bergaman W, Masclee AA, Heickendorff L, Breedveld FC, Dijkmans BA. Double-blind, placebo-controlled study of oral calcitriol for treatment of localized and systemic scleroderma. J Am Acad Dermatol. 2000;43:1017-23.

Hunzelmann N, Scarffetter Kochanek K, Hager K, Krieg T. Management of localized scleoderma. Semin Cutan Med Surg. 1998, 17:34-40.

Illes J, Rosen AC, Huang L, Goldstein RA, Raffin TA, Swan G, Atlas SW. Ethical consideration of incidental findings on adult brain $\mathrm{MRI}$ in research. Neurology. 2004;62(6):888-90.

Inigo F, Jimenez-Murat $\mathrm{Y}$, Arroyo O, Fernandez M, Yusanza A. Restoration of facial contour in Romberg's disease and hemifacial microssomia: experience with 118 cases. Microssurgery. 2000; 20:167-72. 
Itin $\mathrm{PH}$, Schiller P. Double-lined frontparietal scleroderma en coup de sabre. Dermatology. 1999; 199: 185-6.

Jablonska S, Blaszczyk M, Chorzelski TP, Jarzabek-Chorzelska M, Kumar V, Beutner EH. Clinical relevance of immunologic findings in scleroderma. Clin Dermatol. 1992;10(4):407-21.

Jablonska S, Blaszczyk M, Rosinska D. Progressive facial hemiatrophy and scleroderma en coup de sabre: clinical presentation and course as related to the onset in early childhood and young adults. Arch Argent Dermatol. 1998;48:125-8.

Jablonska S, Blaszczyk M. Is superficial morphea synonymous with atrophoderma PasiniPierini? J Am Acad Dermatol. 2004;50:979-80.

Jablonska S, Blaszczyk M. Scleroderma like disorders. Semin Cutan Med Surg. 1998;17:6576.

Jablonska S, Blaszyk M. Long-lasting follow-up favours a close relationship between progressive facial hemiatrophy and scleroderma en coup de sabre. JEADV. 2005; 19:403-4.

Jappe U, Holzle E, Ring J. Parry Romberg syndrome. Review and new observations based on a case with unusual features. Hautarzt. 1996;47:599-603.

Joly $\mathrm{P}$, Bamberger N, Crickx B, Belaich S. Treatment of severe forms of localized scleroderma with oral corticosteroids: folow-up study on 17 patients. Arch Dermatol. 1994;130:663-4.

Julian CG, Bowera PW. Osteoma cútis in a lesion of solitary morphea profunda. Clin Exp Dermatol. 2003;28:673-4.

Kanzato N, Matsuzaki T, Komine Y, Saito A, Yoshio T, Suehara M. Localized scleroderma associated with progressing ischemic stroke. J Neurol Sci. 1999; 164:86-9.

Kasapcopur O, Ozkan HC, Tuysuz B. Linear scleroderma en coup de sabre and brain calcification: is there a pathogenic relationship? J Rheumatol. 2003;30:2724-5.

Katsumoto TR, Whitfield ML, Connolly MK. The patogenesis of systemic sclerosis. Annual Review of Pathology. 2011;6: 509-37.

Katzman GL, Dagher AP, Patronas NJ. Incidental findings on brain magnetic resonance imaging from 1000 asymptomatic volunteers. JAMA. 1999;281:36-9.

Kencka D, Blaszczyk M, Jablonska S. Atrophoderma Pasini-Pierini is a primary atrophic abortive morphea. Dermatology. 1995;190:203-6.

Kerscher M, Meurer M, Sander C, Volkenandt M, Lehmann P, Plewig G, Rocken M. PUVA bath photochemotherapy for localized scleroderma. Evaluation of 17 consecutive patients. Arch Dermatol. 1996;132(11):1280-2.

Kikuchi K, Sato S, Kadono T, Ihn H, Takehara K. Serum concentration of procollagen type I carboxyterminal propetide in localized scleroderma. Arch Dermatol. 1994;130:1269-72.

Kim BS, Illes J, Kaplan RT, Reiss A, Atlas SW. Incidental findings on pediatric MR images of the brain. Am J Neuroradiol. 2002;23:1674-7.

Kirkali PA, Kansu T, Sanac AS. Unilateral enophthalmos in systemic scleroderma. J Clin Neuro-Ophthalmol. 1991;11:43-4. 
Kirsner RS, Pardes JB, Falanga V. Solitary fibrosing paraspinal plaque: solitary morphea profunda. Br J Dermatol. 1993;128:99-101.

Kister I, Inglese M, Laxer R, Herbert J. Neurologic manifestations of localized scleroderma. A case report and literature review. Neurology. 2008;71: 1538-1545.

Kobayashi KA, Lui H, Prendiville JS. Solitary morphea profunda in a 5-year-old girl: case report and review of the literature. Pediatr Dermatol. 1991;8:292-5.

Koch G. The phakomatoses. Handbook of clinical neurology. New York, 1972:512.

Komocsi A, Tavari E, Kovacs J, Czirják L. Physical injury as a provoking fator in three patients with scleroderma. Clin Exp Rheumatol. 2000;18(5):622-4.

Korkmaz C, Adapinar B, Uysal S. Beneficial effect of immunosupressive drugs on ParryRomberg syndrome: a case report and review of the literature. South Med J. 2005;98:940-2.

Krafchik BR. Localized cutaneous scleroderma. Semin Dermatol. 1992; 11:65-72.

Kreuter A, Altmeyer P, Gambichler T. Treatment of localized scleroderma depends on the clinical subtype. Br J Dermatol. 2007;156:1363-5.

Kreuter A, Gambichler T, Avermaete A, Jansen T, Hoffmann M, Hoffmann K, Altmeyer P, von Kobyletzki G, Bacharach-Buhles M. Combined treatment with calcipotriol ointment and low-dose ultravioleta A I phototherapy in childhood morphea. Pediatr Dermatol. 2001, 18(3):241-5.

Kreuter A, Gambichler T, Breuckmann F, Rotterdam S, Freitag M, Stuecker M, Hoffman K, Altmeyer P. Pulsed high-dose corticosteroids combined with low-dose methotrexate in severe localized scleroderma. Arch Dermatol. 2005;141(7):847-52.

Kreuter A, Gambichler T. UV-A1 phototherapy for sclerotic skin diseases: implications for optimizing patient selection and mangeent. Arch Dermatol. 2008;144:912-6.

Kreuter A, Hyun J, Stücker M, Sommer A, Altmeyer $\mathrm{P}$, Gambichler T. A randomized controlled study of low-dose UVA1, UVA1 medium-dose, and narrowband UVB phototherapy in the treatment of localized scleroderma. J Am Acad Dermatol. 2006;54:440-7.

Kroft EB, Creemers MC, van den Hoogen FH, Boezeman JB, de Jon EM. Effectiveness, side-effects and period of remission after treatment with methotrexate in localized scleroderma and related sclerotic skin diseases: an inception cohort study. $\mathrm{Br} \mathrm{J}$ Dermatol. 2009;160:1075-82.

Kroft EB, Groeneveld TJ, Seyger MM, de Jong EM. Efficacy of topical tacrolimus $0,1 \%$ in active plaque morphea: randomized, double-blind, emoliente-controlled pilot study. Am J Clin Dermatol. 2009;10:181-7.

Laxer RM, Feldman BM. General and local scleroderma in children and dermatomyositis and associated syndromes. Curr Opin Rheumatol. 1997;9:458-64.

Laxer R, Zulian F. Localized scleroderma. Curr Opin Rheumatol. 2006;26:90-5.

Ledeman RJ. Progressive facial and cerebral hemiatrophy. Cleve Clin Q. 1984 Fall;51:545-8.

Lee HJ, Kim MY, Ha SJ, Kim JW. Two cases of morphea associated with Hashimoto's thyroiditis. Acta Derma Venereol. 2002;82:58-9. 
Lehmann TJA. The Parry- Romberg syndrome of progressive facial hemiatrophy and linear scleroderma en coup de sabre. Mistaken diagnosis or overlaping conditions? J Rheumatol. 1992;19:844-5.

Leitenberger JJ, Cayce RL, Haley RW, Adams-Huet B, Bergstresser PR, Jacobe HT. Distinct autoimune syndromes in morphea: a review of 245 adult and pediatric cases. Arch Dermatol. 2009;145:545-50.

Li S, Feldman B, Higgins G, Haines K, Punaro M, ONeil K. Treatment of pediatric localized scleroderma: results of a survey of North American pediatric rheumatologists. J Rheumatol. 2010:37:175-81.

Li S, Torok K, Pope E, Dedeoglu F, Hong S, Jacobe H, Rabinovich E, Laxer R, Higgins G, Ferguson P, Lasky A, Baszis K, Becker M, Campillo S, Cartwright V, Cidon M, Inman C, Jerath R, O'Neil KM, Vora S, Zeft A, Wallace CA, llowite NT, Fuhlbrigge RC. Development of Consensus Treatment Plans for Juvenile Localized Scleroderma: A Roadmap Toward Comparative Effectiveness Studies in Juvenile Localized Scleroderma. Arthritis Care \& Research. 2012, 64:1175-85.

Littman B. Linear scleroderma: a response to neurological injury? Report and literature review. J Rheumatol. 1989;16:1135-40.

Liu P, Uziel Y, Chuang S, Silverman E, Krafchik B, Laxer R. Localized scleroderma: Imaging fetures. Pediatr Radiol. 1994;24:207-9.

Lopez-Villegas D, Kulisevsky J, Deus J, Junque C, Pujol J, Guardia E, Grau JM. Neuropsychological alterations in patients with computed tomography-detected basal ganglia calcification. Arch Neurol. 1996;53:251-6.

Lu Her W, Jockel D, Henze T, Schipper HI. Progressive inflammatory lesions of the brain parenchyma in localized scleroderma of the head. J Neurol. 1990;237:379-381.

Malandrini A, Dotti MT, Frederico A. Selective ipsilateral neuromuscular involvement in a case of facial and somatic hemiatrophy. Muscle Nerve. 1997; 20:890-2.

Mamourian A. Incidental findings on research functional MR images: Should we look? Am J Neuroradiol. 2004;25:520-2.

Maragh SH, Davis MD, Bruce AJ, Nelson AM. Disabling pansclerotic morphea: clinical presentation in two adults. J Am Acad Dermatol. 2005;53:S115-9.

Marsol B. Actualización en la classificación y el tratamento de la esclerodermia localizada. Actas Dermosifiliogr. 2012. htp://dx.doi.org/12012.10.003.

Martini G, Ramanan A, Falcini F, Girschick H, Goldsmith D, Zulian F. Sucessful treatment of severe or methotrexate resistant juvenile localized scleroderma with mycophenolate mofetil. Rheumatology (Oxford). 2000;48:1410-3.

Marzano AV, Menni S, Parodi A, Borghi A, Fuligni A, Fabbri P, Caputo R. Localized scleroderma in adults and children. Clinical and laboratory investigations on 239 cases. European Journal of Dermatology. 2003;13:171-6.

Matsuura K, Umebayashi Y, Otsuka E. Computed tomography reveals thickened subcutaneous tissue in scleroderma. Br J Dermatol. 1997;137:1011-31.

Maurer J, Knollmann FD, Schlecht I, Terstegge K, Felix R. High-resollution magnetic resonance imaging in patients with facial hemiatrophy. Acta Derm Venereol. 1999; 79:373-5. 
Mayorquin FJ, McCurley TL, Levernier JE, Myers LK, Becker JA, Graham TP, Pincus T. Progression of childhood linear scleroderma to fatal systemic sclerosis. J Rheumatol. 1994;21(10):1955-7.

McKinney $\mathrm{P}$, Byun $\mathrm{M}$. The value of tear film breakup and Schirmer's test in preoperative blepharoplasty evaluation. Plast Reconstr Surg. 1999; 104(2):566-9.

Menascu S, Padeh S, Hoffman C, Ben-Zeev B. Parry-Romberg syndrome presenting as status migrainosus. Pediatr Neurol. 2009;40(4):321-3.

Menni S, Marzano AV, Passoni E. Neurologic abnormalities in two patients with facial hemiatrophy and sclerosis coexisting with morphea. Pediatric Dermatol. 1997;14:113-6.

Miedziak Al, Stefanyszyn M, Flanagan J, Eagle RC Jr. Parry-Romberg syndrome associated with intracranial vascular malformations. Arch Ophthalmol. 1998;116(9):1235-7.

Miller JJ. The fasciitis-morphea complex in children. AJDC. 1992;146:733-6.

Mirsky L, Chakkittakandiyil A, Laxer RM, O'Brien C, Pope E. Relapse after systemic treatment in pediatric morphea. Br J Dermatol. 2012;166:443-5.

Moinzadeh P, Krieg T, Hunzelmann N. Imatinib treatment of generalized localized scleroderma (morphea). J Am Acad Dermatol. 2010;63:102-4.

Moko SB, Mistry Y, Blandin De Chalain TM. Parry Romberg syndrome: intracranial MRI apearances. J Craniomaxillofac Surg 2003;31:321-4.

Morita A, Kobayashi K, Isomura I, Tsuji T, Krutmann J. Ultraviolet A1 (340-400nm) phototherapy for scleroderma in systemic sclerosis. J Am Acad Dermatol. 2000;43:670-4.

Morrel A, Betlloch I. Morphea-like reaction from vitamin K1. Int J Dermatol. 1995;34:201-2.

Moseley BD, Burrus TM, Mason TG, Shin C. Contralateral cutaneous and MRI findings in a patient with Parry-Romberg syndrome. J Neurol Neurosurg Psychiatry. 2010;81(12):1400-1.

Nadeau SE. Neurologic manifestations of connective tissue disease. Neurol Clin. 2002;20:151-78.

Nelson A. Localized scleroderma including morphea, linear scleroderma, and eosinophilic fasciitis. Curr Probl Pediatr. 1996:26:318-24.

Nelson A. Localized slerodermas. In: Cassidy JT, Petty, RE, editors. Textbook of pediatric rheumatology. Philadelphia: W. B. Saunders; 2001. p. 535-44.

Neustadter JH, Samarin F, Carlson KR, Girardi M. Extracorporeal photochemotherapy for generalized deep morphea. Arch Dermatol. 2009;145:127-30.

Ng SH, Tang LM, Lui TN, Ko SF, Wong HF, Wai YY, Wan YL. Tuberculoma en plaque: CT. Neurorradiology. 1996;38(5):453-5.

Nishida A, Kaiya H, Uematsu M, Maeda M, Mori S, Wakabayashi S. Transient global amnesia and Raynaud's phenomenon in scleroderma. Acta Neurol Scand. 1990; 81:550-2.

Nitrini R, Lefèvre BH, Mathias SC, Caramelli P, carrilho PE, Sauaia N, Massad E, Takiguti C, Da Silva IO, Porto CS, et al. Neuropsychological tests of simple application for diagnosing dementia. Arq Neuropsiquiatr. 1994, 52(4): 457-65. 
Nobili F, Cutolo M, Sulli A, Castaldi A, Sardanelli F, Accardo S, Rosadini G, Rodriguez G. Impaired quantitative cerebral blood flow in scleroderma patients. J Neurol Sci. 1997;166:255-263.

Nussgens Z, Roggenkamper P. Congenital facial hemiatrophy. Report of two pediatric cases. Klin Monastbl Augenheilkd. 1992; 201:119-21.

Obermoser G, Pfausler BE, Linder DM, Sepp NT. Scleroderma en coup de sabre with central nervous system and ophthalmologic involvement: treatment of ocular symptoms with interferon gamma. J Am Acad Dermatol. 2003;49(3):346-543.

Olney RK. Neuropathies associated with connective tissue disease. Semin. Neurol. 1998;18, No 1, 63-72.

Orozco-Covarrubias L, Guzmán-Meza A, Ridaura-Sanz C, Carrasco Daza D, Sosa-deMartinez C, Ruiz-Maldonado R. Scleroderma "en coup de sabre" and progressive facial hemiatrophy. Is it possible to differentiate them? J Eur Acad Dermatol Venereol. 2002; 16(4):361-6.

Ostertag JU, Hulsmans RF, Neumann HA. Bilateral tempoparietal scleroderma "en coup de sabre". Hautarzt. 1994; 45 (6):398-401.

Oswaldo Freitas Julião. O exame neurológico do adulto cap. 24 pg 337-76 in Propedêutica Neurológica. Temas essenciais. Adherbal P M Tolosa, Horácio M Canelas. Fundo Editorial Procienx. 1969. São Paulo.

Otaduy MC, Toyama C, Arantes PC, Amaro Jr E. Técnicas de obtenção de imagem em neurorradiologia. In: Leite CC, Lucato LT, Amaro Jr. E. Neurorradiologia-Diagnóstico por imagem das alterações encefálicas. $2^{a}$ edição. Ed. Guaranabara-kogan, Rio de Janeiro 2011: 1-49.

Pagano M. e Gauvreau K. Princípios da bioestatística, São Paulo, Cengage Learning, 2011.

Pansler JM, Murphy GF, Mulliken JB. Clinical and ultrastructural studies of Roberg's hemifacial atrophy. Plast Reconstr Surg. 1990;85:669-74.

Paprocka J, Adamek D, Mandera M. Difficulties in differention of Parry-Romberg syndrome, unilateral facial sclerodermia, and Rasmussen syndrome. Childs Nerv Syst. 2006;22: 409415.

Park JH, Lee CW. Concurrent development of dermatomyositis and morphea profunda. Clin Exp Dermatol. 2002;27:324-7.

Parodi Drosera M, Barbieri L, Rebora A. Antihistone antibodies in scleroderma. Dermatology. 1995;191:16-8.

Parodi PC, Riberti C, Draganic Stinco D, Patrone P, Stinco G. Squamous cell carcinoma arising in a patient with long-standing pansclerotic morphea. Br J Dermatol. 2001;144:417-9.

Parry $\mathrm{CH}$. Collections from unpublished papers. London: Underwood, 1825:178.

Pathak R, Gabar AJ. Scleroderma and central nervous system vasculitis. Stroke. 1991;22:410-13.

Pearson JD. The endothelium: in role in scleroderma. Ann Rheum Dis. 1991;50:866-71.

Pensler JM, Murphy GF, Mulliken JB. Clinical and ultrastructural studies of Romberg's hemifacial atrophy. Plast Reconst Surg. 1990;85:669-674. 
Peterson L, Nelson A, Su W, Mason T, O'Fallon W, Gabriel S. The epidemiology of morphea (localized scleroderma) in Olmstead Country 1960-1993. J Rheumatol. 1997;24:73-80.

Peterson LS, Nelson AM, Su D. Classification of Morphea (Localized Scleroderma). Mayo Clin Proc. 1995; 70: 1068-76.

Pichiecchio A, Uggetti C, Grazzia Egitto M, Zappoli F. Parry-Romberg syndrome with migraine and intracranial aneurysm. Neurology. 2002;59(4):606-8.

Piette WW, Dorsey JK, Foucar E. Clinical and serologic expression of localized scleroderma: case report and review of the literature. J Am Acad Dermatol. 1985;13:342-50.

Pizova NV. Vascular Lesions of the Brain in Some Rheumatological Diseases (in Russian). Author's abstract of thesis for doctorate in medical sciences, Moscow, 2004.

Poormoghim H, Lucas M, Fertig N, Medgser TA Jr. Systemic sclerosis sine scleroderma: demographic, clinical, and serelogic features and survival in fortyeight patients. Arthiritis Rheum. 2000;43:444-51.

Poser CM, Brinar VV. Epilepsy and multiple sclerosis. Epilepsy Behav. 2003;4:6-12.

Prescott RJ, Freemont AJ, Jones CJP, Hoyland J, Fielding P. Sequencial dermal microvascular and perivascular changes in the development of scleroderma. J Pathol. 1992; 166:255-63.

Pupillo G, Andermann F, Dubeau F. Linear scleroderma and intractable epilepsy: neuropathologic evidence for a chronic inflamatory process. Ann Neurol. 1996;39:277-8.

Rai R, Handa S, Gupta S, Kumar B. Bilateral En Copu de Sabre - A Rare Entity. Pediatric Dermatology. 2000;17(3): 222-4.

Ramboer K, Dermaerel PH, Baert AL, Casteels I, Dralands G. Linear scleroderma with orbital involvement: follow up and magnetic resonance imaging. $\mathrm{Br}$ Ophthalmol.1997;81:90-1.

Raymond AA, Zariah AA, Samad SA, Chin CN, Kong NC. Brain calcification in patients with cerebral lúpus. Lupus. 1996;5:123-8.

Rencic A, Goyal S, Mofid M, Wigley F, Nousari HC. Bullous Iseions in scleroderma. Int J Dermatol. 2002;41:335-9.

Ren WHP. Anesthetic management of epileptic pediatric patients. Int Anesthesiol Clin. 2009;47:101-16.

Resende LA, Dal Pai V, Alves A. Experimental study of progressive facial hemiatrophy: effects of cervical sympathectomy in animals. Rev Neurol. 1991;147:609-11.

Roca RP,Wigley FM, White B. Depressive symptoms asscoiated with scleroderma. Arthritis Rheum. 1996;39:1035-1040.

Romberg MH. Trophoneurosen. In: Klinische ergebnisse. Berlin: Forstner, 1946:75-81.

Rosenbaum R. Neuromuscular complications of connective tissue diseases. Muscle Nerve. 2001;24, No. 2, 154-69.

Sagild JC, Alving J. Hemiplegic migraine and progressive hemifacial atrophy. Ann Neurol. 1985;17:620. 
Sahin MT, Baris Karaman A. Parry-Romberg syndrome: a possible association with borreliosis. J Eur Acad Dermatol Venereol. 2004;18:204-7.

Sakai M, Aoki S, Inoue Y, Ashida R, Yamada H, Kiryu S, Inano S, Mori H, Masutani Y, Abe $\mathrm{O}$, Ohtomo S, Nakamura $\mathrm{H}$. Silent white matter lesion in linear scleroderma en coup de sabre. J Comput Assist Tomogr. 2008;32:822-4.

Salpietro DC, Merlino MV, Bruglia S, Guarnieri F, Vaccaro M. Linear scleroderma "en coup de sabre"associated with facial atrophy in a patient seropositive for Borrelia burdorferi: a true caso f molecular mimicry? Pediatric Allergy and Immunology. 2004;15(6):570-2.

Sandhu K, Handa S. Subdural hygroma in a patient with Parry-Romberg syndrome. Pediatr Dermatol. 2004;21:48-50.

Sardanelli F, Lozzelli A, Coticelli B, Losacco C, Cutolo M, Sulli A, Nobili F, Rodriguez G. White matter hyperintensities on brain magnetic resonance in systemic sclerosis. Ann Rheum Dis. 2005; 64:777-779.

Sathornsumetee S, Schanberg L, Rabinovich E, Lewis D, Weisleder. Parry-Romberg syndrome with fatal brain stem involvement. J Pediatr. 2005;146:429-31.

Sato S, Fujimoto M, Ihn H, Kikuchi K, Takehara K. Antigen specificity of antihistone antibodies in localized scleroderma. Arch Dermatol. 1994;130:1273-7.

Sato S, Fujimoto M, Ihn H, Kikuchi K, Takehara K. Clinical characteristics associated with antihistone antibodies in patients with localized scleroderma. J Am Acad Dermatol. 1994;31:567-71.

Satori S, Martini G, Calderone M, Patrizi A, Gobbi G, Zulian F. Severe epilepsy preceding by four months the onset of scleroderma en coup de sabre. Clin and Exp Rheumatol. 2009;27:64-7.

Sawamura D, Yaguchi T, Hashimoto I, Nomuka K, Konta R, Umeki K. Coexistence of generalized morphea with histological changes in lichen sclerosus et atrophicus. Int $\mathrm{J}$ Dermatol. 1998;25:409-11.

Saxton-Daniels S, Jacobe HT. An evaluation of long-term outcomes in adults with pediatriconset morphea. Arch Dermatol. 2010;146:1044-5.

Schievink WI, Piepgras DG, Nichols DA. Spontaneous carotid-jugular fistula and carotid dissection in a patient with multiple intracranial arachnoid cysts and hemifacial atrophy: a generalized connective tissue disorder? Case report. J Neurosurg. 1995;83(3):546-9.

Schlaak M, Friedlein H, Kauer F, Renner R, Rogalski C, Simon JC. Sucessful therapy of a patient with therapy recalcitrant generalized bullous scleroderma by extracorporal photopheresis and mycophenolate mofetil. J Eur Acad Dermatol Venereol. 2008;22:631-3.

Scope A, Barzilai A, Trau H, Orestein A, Winkler E, Haik J. Parry-Romberg syndrome and sympathectomy-a conicidence? Cutis. 2004;73:343-4, 346.

Seyger MMB, van den Hoogen FHJ, de Boo T, de Jong EMGJ. Low-dose methotrexate in the treatment of widespread morphea. J Am Acad Dermatol. 1998;39:220-5.

Shah JR, Juhász C, Kupsky WJ, Asano E, Sood S, Fain D, Chugani HT. Rasmussen encephalitis associated with Parry-Romberg syndrome. Neurology. 2003;61:395-7. 
Schievink WI, Mellinger J, Atkinson J. Progressive intracranial aneurysmal disease in a child with progressive hemifacial atrophy (Parry-Romberg Disease): Case report. J Neurosurg. 1996;38(6):1237-41.

Shono S, Imura M, Ota M, Osaku A, Shinomiya S, Toda K. Lichen sclerosus et atrophicus, morphea and coexistence of both diseases: histological studies using lectins. Arch Dermatol. 1991;127:1352-6.

Soma Y, Fujimoto M. Frontoparietal scleroderma "en coup de sabre" following Blaschko's lines. J Am Acad 1998; 38:366-8.

Sommer A, Gambichler T, Bacharach-Buhles M, Rothenburg T, Altemeyer P, Kreuter A. Clinical and serological characteristics of progressive facial hemiatrophy: A case series of 12 patients. J Am Acad Dermatol. 2006;54:227-33.

Spirin NN, Bulanova VA, Pizova NV and Shilkina NP. Peripheral Nervous System Lesions Syndromes and the Mechanisms of Their Formation in Connective Tissue Diseases, Neuroscience and Behavioral Physiology. 2007; 37(1):1-6.

Staneczek W, Janisch W. Epidemiologic data on meningiomas in East Germany 1961-1986: incidence, localization, age and sex distribution. Clin Neuropathol. 1992;11:135-41.

Stone J, Franks AJ, Guthrie JA, Johnson S. Scleroderma "en coup de sabre": pathological evidence of intracerabral inflammation. J Neurol Neurosurg Psychiatry. 2001;70:382-5.

Stone J. Parry-Romberg syndrome: a global survey of 205 patients using the internet. Neurology. 2003;61:674-6.

Straszecka J, Jonderko G, Kucharz EJ, Brzezinska-Wcislo L, Kotulska A, Bogdanowski T. Cognitive function in patients with systemic sclerosis. Pol Arch Med Wewn. 1997;98:213220.

Straub RH, Zeuner M, Lock G, Rath H, Hein R, Scholmerich J, Lang B. Autonomic and sensorimotor neuropathy in patients with systemic lupus erithematosus and systemic sclerosis. J. Rheumatol. 1996;23(1): 87-92.

Su WPD, Person JR. Morphea profunda. A new concept and a histopathological studies. Adv Exp Med Biol. 1999;455:105-9.

Sunderland T, Hill JL, Mellow AM, Lawlor BA, Gundersheimer J, Newhouse Pa, Grafman JH. Clock drawing in Alzheimer's disease. A novel measure of dementia severity. J Am Geriatr Soc. 1989, 37(8):725-9.

Suttorp-Schulten MS, Koorn L. Linear scleroderma associated with ptosis and motility disorders. Br J Ophthalmol. 1990;74:694-5.

Taylor HM, Robinson R, Cox T. Progressive facial hemiatrophy: MRI appearances. Dev Med Child Neurol. 1997;39:484-6.

Terstegge K, Kunath B, Felber S, Speciali JG, Henkes H, Hosten N. MR of brain involvement in progressive facial hemiatrophy (Romberg disease): Reconsideration of a syndrome. Am J Neuroradiol. 1994;15:145-150.

Tollefson MM, Witman PM. En coup de sabre morphea and Parry-Romberg syndrome: a retrospective review of 54 patients. J Am Acad Dermatol. 2007;56:157-63.

Torrelo A, Suárez J, Colmenero I, Azorín D, Perera A, Zambrano A. Deep morphea after vaccination in two young children. Pediatr Dermatol. 2006;23:484-7. 
Trattner A, David M, Sandbank M. Bullous morphea: a distinct entity. Am J Dermatopathol. 1994;16:414-7.

Tuffanelli DL. Localized scleroderma. Semin Cutan Med Surg. 1998;17:27-33.

Unterberger I, Trinka E, Engelhardt K, Muigg A, Eller P, Wagner M, Sepp N, Bauer G. Linear scleroderma "en coup de sabre" coexisting with plaque-morphea: neuroradiological manifestation and response to corticosteroids. J Neurol Neurossurg Psychiatry. 2003;74:661-4.

Usmani N, Murphy A, Veale D, Goulden V, Goodfield M. Photochemotherapy for localized morphea: effect on clinical and molecular markers. Clin Exp Dermatol. 2008;33:698-704.

Uziel Y, Feldman BM, Krafchik BR, Yeung RS, Laxer RM. Methotrexate and corticosteroid therapy for pediatric localized scleroderma. J Pediatr. 2000;136:91-5.

Uziel Y, Miller ML, Laxer RM. Scleroderma in children. Pediatr Clin N Am. 1995;42:1171203.

Verity $\mathrm{C}$, Firth $\mathrm{H}$, French-Constant $\mathrm{C}$. Congenital abnormalities of the central nervous system. J Neurol Neurosurg Psychiatry. 2003;74(suppl 1):3-8.

Vernooij MW, Ikram MA, Tanghe HL, Vincent AJ, Hofman A, Krestin GP, Niessen WJ, Breteler MM, van der Lugt A. Incidental findings on brain MRI in the general population. $N$ Engl J Med. 2007;357(18):1821-8.

Vierra E, Cunningham BB. Morphea and localized scleroderma in children. Semin Cutan Med Surg. 1999;18:210-25.

Vilela FA, Carneiro S, Ramos-e-Silva M. Treatment of morphea or localized scleroderma: review of the literatura. J Drugs Dermatol. 2010;9:1213-9.

Wang F, Garza LA, Cho S, Kafi R, Hammerberg C, Quan T, Hamilton T, Mayes M, Ratnatharathorn V, Voorhees JJ, Fisher GJ, Kang S. Effect of incresead pigmentation on the antifibrotic response of human skin to UV-A1 phototherapy. Arch Dermatol. 2008;144(7):8518.

Wartenberg R. Progressive facial hemiatrophy. Arch Neurol Psychiatry. 1945, 54:75-96.

Weber $\mathrm{F}, \mathrm{Knopf} \mathrm{H}$. Incidental findings in magnetic resonance imaging of the brain of healthy young men. J Neurol Sci. 2006;240:81-4.

Weibel L, Harper JI. Linear morphea follows Blaschko's lines. Br J Dermatol. 2008;159:17581.

Weibel L, Sampaio M, Visentin M, Howell K, Woo P, Harper J. Evaluation of methotrexate and corticosteroids for the treatment of localized scleroderma (morphea) in children. $\mathrm{Br} \mathrm{J}$ Dermatol. 2006;155:1013-20.

Wolf HG, Ehrenclou AH. Trophic disorders of central origin: report of a case of progressive facial hemiatrophy associated with a lipodistrophy and other metabolic derangements. Jam Med Assoc. 1927;58:991.

Wollina U, Buslau M, Weyers W. Squamous cell carcinoma in pansclerotic morphea of childhood. Pediatr dermatol. 2002;19:151-4.

Woolfenden AR, Tong DC, Norbash AM, Albers GW. Progressive facial hemiatrophy: Abnormality of intracranial vasculature. Neurology. 1998;50:1915-7. 
Wu EY, Rabinovich EC, Torok KS, Li SC, Fuhlbrigge RC, CARRANet Investigators. Description of the Localized Scleroderma Subgroup of CARRA net Registry. Arthritis Rheum. 2011;63 Suppl:S787-8.

Yamanaka CT, Gibbs NF. Trauma-induced linear scleroderma. Cutis. 1999;63:29-32.

Yano T, Dawaishi, Toyono M, Takaku I, Takada G. Progressive Facial Hemiatrophy after epileptic seizures. Pediatric Neurology. 2000;23:164-6.

Zannin ME, Martini G, Athreya BH, Russo R, Higgins GC, Vittadello F, Alpigiani MG, Alessio $\mathrm{M}$, Paradisi M, Woo P, Zulian F. Ocular involvement in children with localised scleroderma: a multi-centre study. Br J Ophthalmol. 2007;91:1311-4.

Zulian F, Athreya BH, Laxer R, Nelson AM, Feitosa de Oliveira SK, Punaro MG, Cuttica R, Higgins GC, Van Suijlekom-Smit LW, Moore TL, Lindsley C, Garcia-Consuegra J, Esteves Hilário MO, Lepore L, Silva CA, Machado C, Garay SM, Uziel Y, Martini G, Foeldvari I, Pserico A, Woo P, Harper J; Juvenile Scleroderma Working Group pf the Pediatric Rheumatology European Society (PRES). Juvenile localized scleroderma: clinical and epidemiological features in 750 children. An international study. Rheumatology (Oxford). 2006;45:614-20.

Zulian F, Martini G, Vallongo C, Vitadello F, Falcini F, Patrizi A, Alessio M, La Torre F, Podda RA, Gerloni V, Cutrone M, Belloni-Fortina A, Paradisi M, Martino S, Perilongo G. Methotrexate treatment in juvenile localized scleroderma: a randomized, double-blind, placebo-controlled trial. Arthritis Rheum. 2011;63(7):1998-2006.

Zulian F, Vallongo C, Woo P, Russo R, Ruperto N, Harper J, Espada G, Corona F, Mukamel M, Vesely R, Musiej-Nowakowska E, Chaitow J, Ros J, Apaz MT, Gerloni V, Mazur-Zielinska H, Nielsen S, Ullman S, Horneff G, Wouters C, Martini G, Cimaz R, Laxer R, Athreya BH. Localized Scleroderma in Childhood is not just a skin disease. Arthritis \& Rheumatism. 2005, (52)9:2873-81.

Zwischenberger $B$, Jacobe $\mathrm{H}$. A systematic review of morphea treatments and therapeutic algorithin. J Am Acad Dermatol. 2011;65:925-41. 